Portland State University

PDXScholar

$1-1-2009$

\title{
Peer Network Emergence and Change in the Classroom: A Multiple Systems Perspective
}

Nicole Ann Sage

Portland State University

Follow this and additional works at: https://pdxscholar.library.pdx.edu/open_access_etds Let us know how access to this document benefits you.

\section{Recommended Citation}

Sage, Nicole Ann, "Peer Network Emergence and Change in the Classroom: A Multiple Systems Perspective" (2009). Dissertations and Theses. Paper 303.

https://doi.org/10.15760/etd.303

This Dissertation is brought to you for free and open access. It has been accepted for inclusion in Dissertations and Theses by an authorized administrator of PDXScholar. Please contact us if we can make this document more accessible: pdxscholar@pdx.edu. 
Peer Network Emergence and Change in the Classroom:

A Multiple Systems Perspective

by

Nicole Ann Sage

A dissertation submitted in partial fulfillment of the requirements for the degree of

Doctor of Philosophy
in
Systems Science: Psychology

Dissertation Committee:

Cathleen L. Smith, Chair

Todd E. Bodner

George G. Lendaris

Dalton Miller-Jones

Roderic C. Diman

Portland State University

(C) 2009 


\begin{abstract}
This study examined peer group processes in the classroom that can potentially explain how motivationally "rich" children get "richer" whereas motivationally "poor" children get "poorer." In contrast to research on group processes which focuses on socialization from group to individual, this study focuses on contributions from the individual to his/her group. The viewpoint taken for this study is that children actively choose group members based on their own self-system state, thereby creating their own peer environments in which they develop.
\end{abstract}

Viewed as open complex systems, children's natural peer groups were examined using data collected from students and their teachers at five measurement points across a school year in four grade $4 / 5$ classrooms. Out of 112 students, data were obtained for 94 (51 male, 43 female) children regarding their classroom engagement, peer network affiliations, and associative preferences ("ideal groups" of classmates with whom they would like to hang out). In an effort to overcome some of the challenges that group researchers face, methodologies argued to reliably capture children's networks and to measure the network's psychological characteristics were used. In addition, a hierarchical systems framework was applied whereby the underlying group processes could be examined across time. Two of seven hierarchical perspectives were used to examine influences from the individual to his/her network. Focusing first on the changing nature of a child's network, findings revealed a pattern of robust equilibrium. Networks showed an initial period of rapid change in member turnover (approximately 45\%) during the first few months and then evolved quickly toward a stable (attractor) state of approximately 
Abstract: Peer Network Emergence ii $25 \%$ turnover the remainder of the year. Focusing next on the proximal processes by which the peer network emerges--selection and elimination--children were found to be more similar to those whom they would like to select than those whom they would like to eliminate. Taken together, the findings suggest that the child creates a peer context in the classroom that is stimulating and compatible to his/her own changes in engagement across the school year, thereby providing a possible explanation for how the motivationally "rich" get "richer" and the "poor" get "poorer". 


\section{Dedication}

I would like to dedicate this to my two girls, Hayley and Lana Sage. May both of you know that you can dream big and despite obstacles still accomplish your goals. 
Acknowledgements: Peer Network Emergence iv

\section{Acknowledgements}

I am grateful to many people for their support, encouragement, and insight that have helped me complete this dissertation. First thanks go to my family, especially my mom (Ann Brandt), step-dad (David Brandt), dad (Earl Sage), and sister (Kristen Meyers), who often spent their weekends with my children so I could focus my attention on the dissertation. I am grateful to Hayley, my oldest daughter, who kept her younger sister, Lana, occupied on the many evenings and weekends I worked on my dissertation. Thanks also go to my colleagues at Education Northwest (formally Northwest Regional Educational Laboratory) and Portland State University (PSU) who provided me with the encouragement to continue, with special thanks to Steve Nelson and James Leffler from Education Northwest and Hugo Du Coudrey, Martha Balshem, and Bill Feyerherm from PSU. Finally, the members of my committee -Todd Bodner, Rod Diman, George Lendaris, Dalton Miller-Jones, and Cathleen Smith - also deserve many thanks for their guidance, encouragement, and critique during the process from proposal to defense. 


\section{TABLE OF CONTENTS}

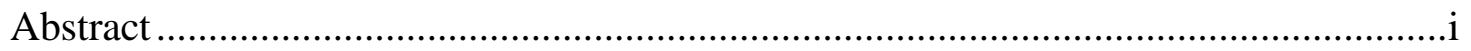

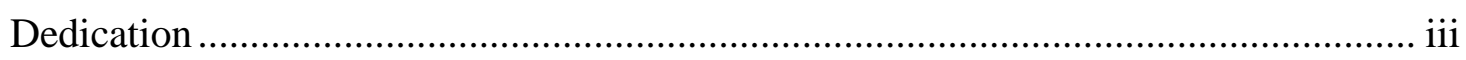

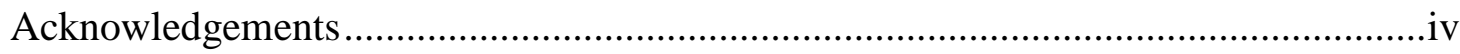

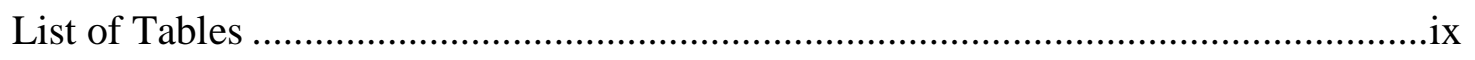

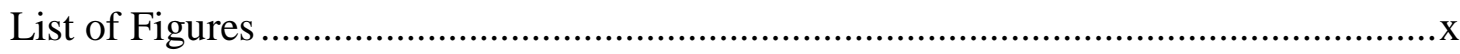

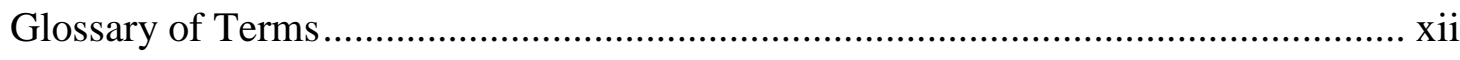

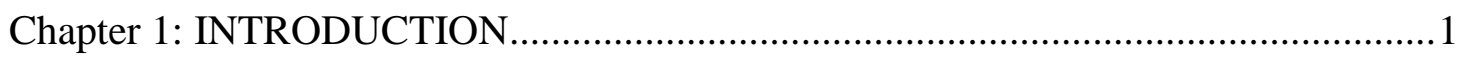

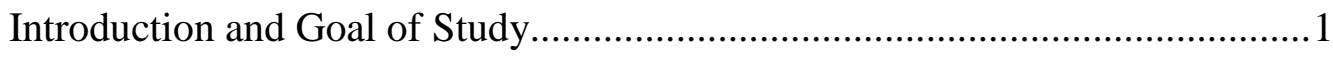

Brief Overview of the Dissertation Chapters ............................................. 9

Chapter 2: REVIEW OF THE LITERATURE .............................................. 12

The Importance of the Peer Group Context ............................................... 12

Methodological Issues in the Study of Peer Groups ................................... 17

Identifying the Peer Group ........................................................... 17

Measuring Peer Group Characteristics ...............................................2 24

Conceptualizing Peer Group Processes ..............................................26

Strategies for Inferring Peer Group Processes With Regard to Academic

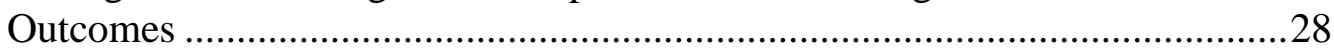

Correlational Studies of Peer Group Processes ................................28

Identifying Potential Mechanisms of Influence ..................................32

Limitations of Research Thus Far ....................................................35

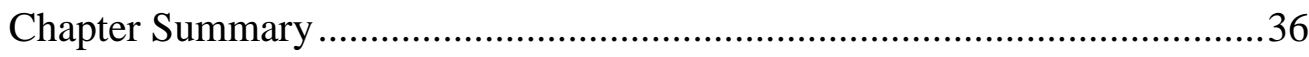

Chapter 3: SYSTEMS THEORY APPLIED TO THE STUDY OF PEER GROUP PROCESSES IN THE CLASSROOM................................................. 38 


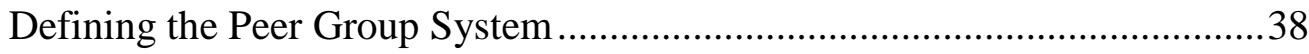

Peer Groups As Complex Open Systems.......................................... 38

Levels of the Peer Group System.....................................................42

The Need for Multiple Perspectives .................................................43

Exploring the Dynamics of the Peer Group System....................................45

Examination of Process.............................................................48

Theoretical Framework for the Current Study ..........................................50

Perceptual Stance \#1 ….................................................................51

Perceptual Stance \#2 …..............................................................54

Perceptual Stance \#3 ...................................................................5 57

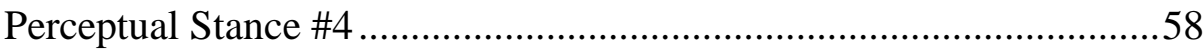

Perceptual Stance \#5 .................................................................... 61

Perceptual Stance \#6 ..................................................................62

Perceptual Stance \#7 ............................................................62

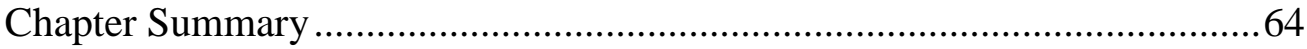

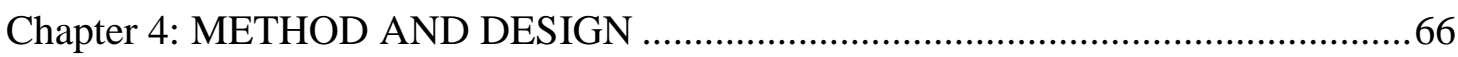

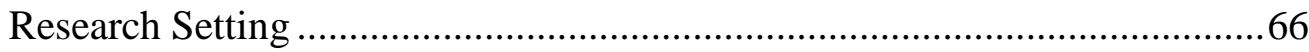

Participants and Informed Consent ......................................................6 67

Recruiting Classroom Participants..............................................6 68

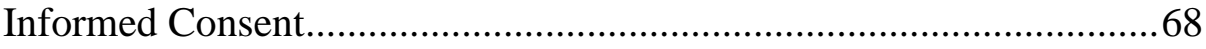

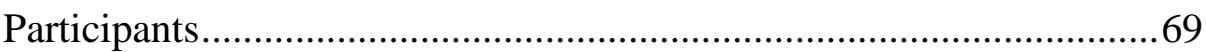

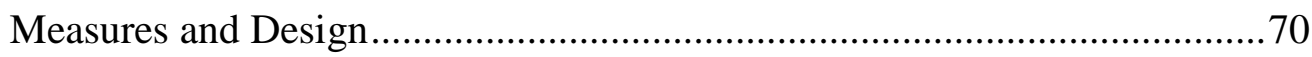

Children's Classroom Engagement................................................73

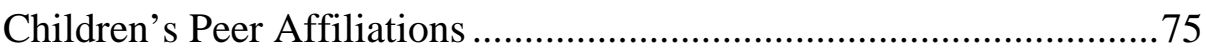

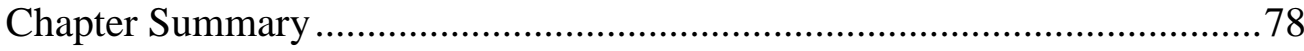

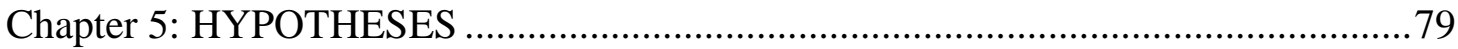


Table of Contents: Peer Network Emergence vii

Change in Children's Peer Group Networks Across Time ..........................81

1. Change in the Structure of the Peer Group ....................................83

2. Change in the Composition of the Peer Group ...............................83

Proximal Processes From Which the Peer Context Emerges .........................84

3. Differences in Structure and Composition Among Network, Ideal Work and Ideal Play Groups ...........................................................8 85

4. Similarity Between Classmates to Be Selected Versus Eliminated..86

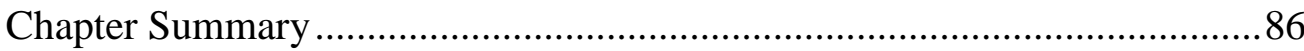

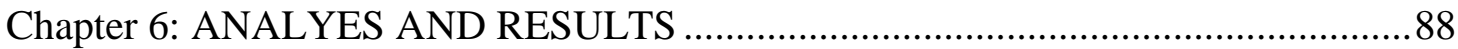

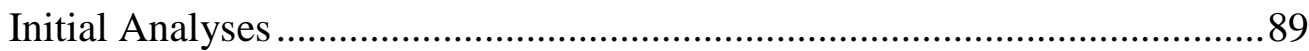

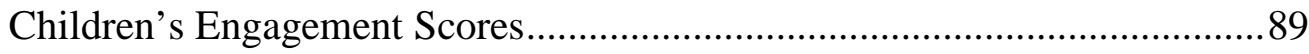

Identifying Children's Peer Network Groups.............................................92

Identifying Children's Associative Preferences (Ideal Groups) ..........96

Identifying Classmates to be Selected Versus Eliminated...................96

Measuring Group Composition...................................................... 97

Change in Peer Group Networks Across Time ............................................99

1. Change in Peer Network Structure ...............................................99

2. Change in Peer Network Composition .......................................108

Proximal Processes From Which the Peer Context Emerges ......................112

3. Differences in Structure and Composition Among Network, Ideal Work, and Ideal Play Groups ......................................................112

4. Differences in Engagement Between Classmates Whom the Child Would like to Potentially "Select" Versus "Eliminate".

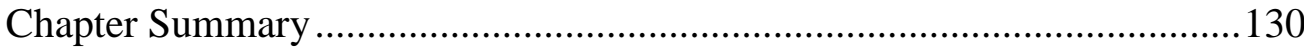

Chapter 7: DISCUSSION OF RESULTS, LIMITATIONS OF STUDY AND

SUGGESTIONS FOR FUTURE RESEARCH

Summary of dissertation's focus, methods, and analytic approach. 
Table of Contents: Peer Network Emergence viii

Implication of the Results............................................................. 135

Individual Engagement in the Classroom ........................................ 135

Change in Peer Networks Across Time ............................................. 136

Proximal Processes By Which the Peer Group Emerges ................... 140

Attention to "Relevant" Environment............................................. 142

Significance of the Study................................................................ 144

Limitations and Suggestions for Future Research.................................. 145

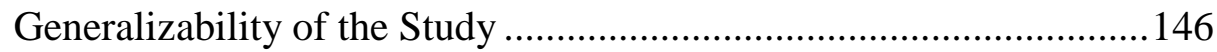

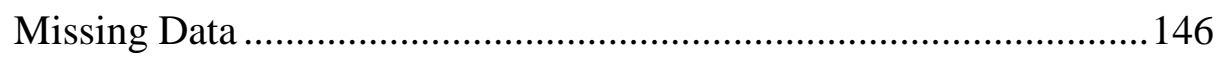

Teacher Versus Self Report of Engagement ................................... 147

Interview versus Questionnaire Administration ...............................149

Permeability of the Group........................................................ 150

Patterns of Group Composition Change Across the School Year ...... 151

Examination of Selection and Elimination Processes........................155

Do Associative Preferences Affect Intra-Individual Engagement In the Classroom? ................................................................ 157

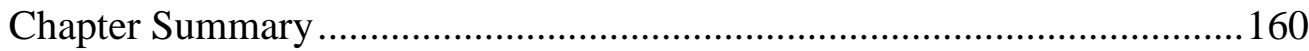

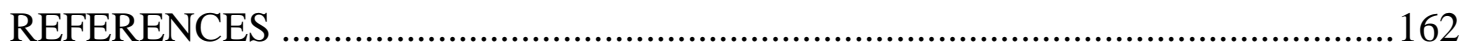

APPENDIX A: Self and Teacher Reports of Student Engagement.........................186

APPENDIX B: Peer Affiliations Measures ....................................................... 193

APPENDIX C: Methods for Computing Member Turnover ....................................209

APPENDIX D: Post Hoc Analyses - Overlap Between Ideal

Work and Play Groups ............................................................................ 212

APPENDIX E: Post Hoc Analyses - Socialization Effects ...................................2215 
Table of Contents: Peer Network Emergence ix

\section{LIST OF TABLES}

Table 4.1: Measures for the 2000-2001 Project..................................................... 71

Table 6.1: Individual Engagement Levels Across the School Year ...........................91

Table 6.2: November Co-Nomination Matrix for 12 Students in Sample...................94

Table 6.3: Peer Network Size Across the School Year ...........................................101

Table 6.4: Peer Network Composition Across the School Year...............................109

Table 6.5: Homogeneity Among Individuals and Network Members......................111

Table 6.6: Average Size of Children's Peer Networks, Ideal Work Groups, and Ideal Play Groups.............................................................................. 114

Table 6.7: Peer Network, Ideal Work, and Ideal Play Group Composition ...............118

Table 6.8: Homogeneity Among Individuals and Groups ..................................121

Table 6.9: Size of Peer Networks and Composed Ideal Groups...............................124

Table 6.10: Peer Network and Composed Ideal Group Composition .......................126

Table 6.11: Peer Network Versus Composed Ideal Group Homogeneity ..................128

Table 6.12: Homogeneity Among Individuals and Groups of Potentially "Selected"

Versus "Eliminated" Classmates ................................................................... 129 


\section{LIST OF FIGURES}

Figure 2.1: Peer Networks In One $5^{\text {th }}$ Grade Classroom - Fall 1996 ..........................21

Figure 3.1: Example of Layers of Embedded Contexts ..........................................41

Figure 3.2: Levels and Multiple Perspectives: The Case of Children's Peer Groups...45

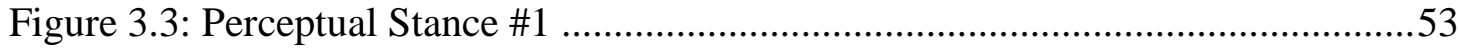

Figure 3.4: Perceptual Stance \#2a..................................................................55

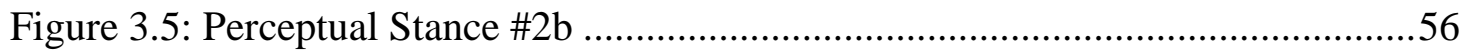

Figure 3.6: Perceptual Stance \#3a-c..............................................................57

Figure 3.7: Perceptual Stance \#4a.................................................................59

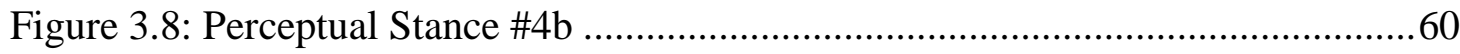

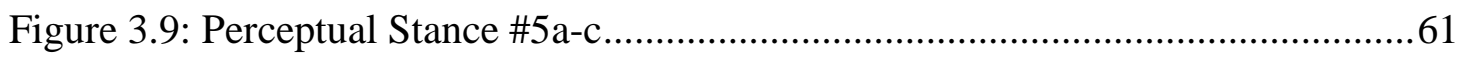

Figure 3.10: Perceptual Stance \#6 and \#7 .......................................................63

Figure 5.1: Example of Potential "Selection" and "Elimination" Processes ...............83

Figure 6.1: Average Individual Engagement Across the School Year .......................90

Figure 6.2: Children's Peer Network Groups at $\mathrm{T}_{1}$-Nov …..................................95

Figure 6.3: Example of Anni's Peer Network Composition....................................97

Figure 6.4: Average Number of Children in a Peer Network (Network Size) ...........100

Figure 6.5: Average Number of Children in a Peer Network by Gender ................... 101

Figure 6.6: Comparisons of DONA's networks from $\mathrm{T}_{1}$-Nov to $\mathrm{T}_{2}-\mathrm{Dec} \ldots \ldots \ldots \ldots \ldots \ldots . . . . . .104$

Figure 6.7: Percentage of Stable Members, Members Lost, and Members Gained ...106

Figure 6.8: Average Member Turnover ....................................................... 106

Figure 6.9: Average Member Turnover by Gender ...........................................107 
Table of Contents: Peer Network Emergence $\quad$ xi

Figure 6.10: Average Peer Network Composition..................................................... 109

Figure 6.11: Average Number of Children in Networks, Ideal Work Groups, and Ideal

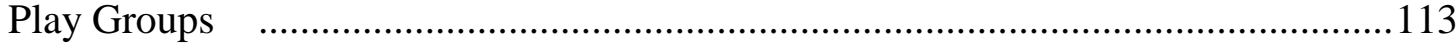

Figure 6.12: Average Peer Network, Ideal Work Group, and Ideal Play Group Composition

Figure 6.13: Average Size of Peer Networks and Composed Ideal Groups ................124

Figure 6.14: Average Composition of Peer Networks and Composed Ideal Groups .126

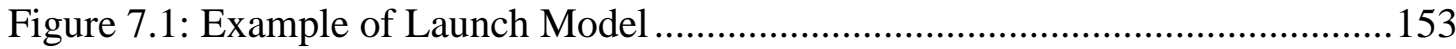

Figure 7.2: Example of Change-to-Change Model .................................................154

Figure 7.3: Example of Cusp Catastrophe Model of Student Engagement ................158 
Glossary of Terms: Peer Network Emergence xii

\section{GLOSSARY OF TERMS}

Associative Preferences - Children's self-reported preferences (ideal groups) of who they would like to affiliate with (may or may not be whom they are actually affiliated with).

Attractors - "system states that can be conceptualized as locations or regions in a phase space (the space defined by possible values of global variables) toward which the system tends to evolve under a given set of contextual conditions" (Arrow, McGrath, and Berdahl, 2000, p. 148).

Complex System - ..."a system composed of interconnected parts that as a whole exhibit one or more properties (behavior among the possible properties) not obvious from the properties of the individual parts" ("Complex System", 2009, para. 1).

Elimination - the processes by which group members leave voluntarily or are rejected by the group (Kindermann, 1996).

Emergence -- ..."the way complex system and patterns arise out of a multiplicity of relatively simple interactions" ("Emergence", 2009, para. 1).

Friendships - intimate bonds between two or more individuals; "The essentials of friendship include reciprocity and commitment between individuals who see themselves as more or less equals (Hartup, 1992, p. 1).

Group Structure - who comprises the group (Kindermann, 1996). For this dissertation, the number of members was used to describe the structure (or size) of a group.

Group Composition - psychological characteristics of a group (Kindermann, 1996). In this dissertation, classroom engagement was the characteristic of interest.

Homophily - see homogeneity.

Homogeneity - a social dynamic where people tend to affiliate with others who are similar to themselves (Lazarsfeld \& Merton, 1954).

Composed Ideal Group - Children's self-selected groups of peers whom they would like to hang out with (ideal play group) and/or whom they would like to do a school project with (ideal work group).

Ideal Play Group - Children's self-selected group of peers whom they would like to hang out with (e.g., at recess, during lunch). 
Ideal Work Group - Children's self-selected group of peers whom they would like to do a school project with.

Instability (of friendship group) - A term used in Chan and Poulin's (2007) study as the converse of stability of the friendship group, where instable friends are defined as those friends nominated at $T_{n}$ but not at $T_{n+1}$ [see also stability of friendship group)].

Microtime interactions -- the continuity and discontinuity within ongoing interactions Bronfenbrenner \& Morris, 1998).

Members Gained - Members of a child's network at time $\mathrm{T}_{\mathrm{n}}$ who were not members of the child's network at $T_{n-1}$.

Members Lost - Members of a child's network at $T_{n}$ but not at $T_{n+1}$.

Members Maintained (Stable Members) - Members of a child's peer network at $\mathrm{T}_{\mathrm{n}}$ and $\mathrm{T}_{\mathrm{n}+1}$ (Kindermann, 1993, Neckerman, 1996).

Member Turnover - The sum of the members lost and members gained from $T_{n}$ and $T_{n+1}$ in a child's peer network (Kindermann, 1993).

Natural Peer Groups - Also referred to as peer networks, naturally existing peer groups are "the multiple and potentially overlapping networks of age-mates with whom the child spends time and shares activities" (Kindermann, 1996, p 2).

Open System - ..."a state of a system, in which a system continuously interacts with its environment.” (Open System (Systems Theory), 2009, para. 1).

Peer group context - the group of peers with whom a child affiliates. Can be identified via a different methods; most common include sociometry, self-nominated friendship groups, or social cognitive mapping.

Peer Networks - see natural peer groups.

Permeable - see permeability of boundaries.

Permeability of boundaries - (with regard to the peer group system) the ease with which members move in and out of the group (Arrow, McGrath, and Berdahl, 2000).

Potential "Elimination" - a method used in this dissertation where children's composed ideal groups were compared to their peer networks. If at time $\mathrm{T}_{\mathrm{i}}$ a child does not nominate a peer as part of his/her composed ideal group but this peer is a part of 
this child's network at time $\mathrm{T}_{\mathrm{i}}$, this could indicate that the child may want to potentially "eliminate" this peer from his/her group.

Potential "Selection" - a method used in this dissertation where children's composed ideal groups were compared to their peer networks. If a child nominates a peer at time $\mathrm{T}_{\mathrm{i}}$ for his/her composed ideal group but this peer was not observed as being part of his/her peer network at time $\mathrm{T}_{\mathrm{i}}$, this could indicate that the child may want to potentially "select" this peer as part of his/her group.

Proximal Processes (PPs) -- reciprocal interactions between the individual and his/her environment (Bronfenbrenner \& Morris, 1998).

Relevant Environment - the relavent components extracted from the various layers of the environment in which the system being studied is situated (c.f., Lendaris, 1986).

Robust Equilibrium - where the system moves quickly toward a stable state and then maintains itself in that state (Arrow, McGrath, and Berdahl, 2000, p. 150).

Selection - the processes by which children choose the peers with whom they affiliate and how (once they belong to a group) they maintain existing members or recruit additional ones (Kindermann, 1996).

Social Networks Research Group (SONET). - a team of undergraduate and graduate level students from the Department of Psychology at Portland State University that studied children's social networks.

Social Isolate - a child who had no network members at $\mathrm{T}_{\mathrm{n}}$.

Socialization - the processes by which group members influence other group members toward conformity and/or similarity (Kindermann, 1996).

Sociometry -- a quantitative method for measuring social relationships (c.f., Moreno, 1934). 
Socio-Cognitive Mapping (SCM) Procedure - method for identifying peer networks (Cairns, Perrin, \& Cairns, 1985). The focus is on a general consensus among reporters based on who is known to naturally affiliate with one another. Following methods from observational research, SCM employs children as expert observers. Multiple children in the classroom are asked to report about those classmates who they know hang out together. These reports are then aggregated and composite maps (similar to Moreno's sociograms) are created that depict the groups on which the reporters agree.

Stability (of friendship group) - A term used in Chan and Poulin's (2007) study to define friendship groups that had a large number of stable friends, where stable friends are those peers nominated at $T_{n}$ and also at $T_{n+1}$.

State Space -- the space of possible system states; referred to as phase space in the definition of attractor.

System - "a) a unit with certain attributes perceived relative to its external environment, and b) a unit that has the quality that it contains subunits that operate to manifest the perceived attributes of the unit" (Lendaris, 1986, p. 604).

System State - an instantaneous description of the system at time t which is sufficient to predict the future states of the system (given all future inputs) without recourse to states prior to $\mathrm{t}$

Time Series - "plots the value, X, of a single global variable on one axis and increments of time on the other" (Arrow, McGrath, and Berdahl, 2000, p. 148). 


\section{CHAPTER 1}

\section{INTRODUCTION}

\section{Introduction and Goal of Study}

Studies on achievement motivation show much divergence in the engagement levels of children in the classroom. While some children approach academic challenges with enthusiasm, others devalue and disengage from such activities. As children progress along their academic career, the gap between those who do well in school and those who do not seems to widen (c.f., Williamson, Appelbaum, \& Epanchin, 1991). The "Matthew Effect" (coined by Merton, 1968) where the motivationally "rich" get "richer" and the "poor" get "poorer" has challenged psychologists and educators to identify the various factors that contribute to children's academic development.

Across the years, much attention has been given to those factors that can be explained by motivational theory (see Eccles \& Wigfield, 2002 and Wigfield, Eccles, Schiefele, Roeser, and Davis-Kean, 2006 for reviews). Much of motivational theory assumes that development resides within the individual (see Deci and Ryan's model of school motivation, 1985). In other words, it is posited that individuals develop naturally and deliberately toward more complex structures and organization. The environment is assumed to play a supporting, yet passive, role (see also Piaget, 1952). Following a selfsystem model, psychologists who adhere to such assumptions focus on processes that occur within the individual that influence his/her development. Such processes are often referred to in the literature as self-system processes. With regard to children's academic development, examples of self-system processes include self-perceptions such as self- 
efficacy, goal orientations, and autonomy (Eccles, Wigfield, \& Schiefle, 1998), feelings of control (e.g., Skinner, Zimmer-Gembeck, \& Connell, 1998), and intrinsic motivational tendencies (e.g., Deci \& Ryan, 1985; Deci, Vallerand, Pelletier, \& Ryan, 1991). These self-system processes have been shown to be powerful predictors of children's concurrent motivation as well as change in motivation across time (for reviews see Eccles, et al., 1998; Stripek, 2002; Wigfield, et al., 2006).

Other theorists hold assumptions that the environment plays a critical role in development. Rather than focusing on inner drives, attention is given to the contexts in which individuals develop and the processes of social exchange that occur within these contexts. These processes are referred to as socialization, and for many years socialization processes were assumed to be top-down. That is, influences from the environment are imposed on the individual and the (passive) individual changes accordingly. Psychologists who adhere to these beliefs about developmental change focus on those contexts that are assumed to be most influential for the target phenomenon.

In the case of children's academic development, parents and teachers have typically been regarded as the most important contexts for nurturing the basic needs that are necessary for maximizing academic engagement (c.f., Dornbusch, Ritter, Leiderman, Roberts, \& Fraleigh, 1987; Steinberg, Dornbusch, \& Brown, 1992, Brophy, 1986). Nonetheless, parents and educators assert that peers also exert powerful influences on children's school motivation and achievement. In fact, strong (and controversial) assertions have been made that peers may be even more influential to children's development than parents (Harris, 1995; 1998). While socialization from peers has been a 
central construct for psychological theorizing for many years, only recently has socialization from peers received a (much deserved) increase in research attention (for reviews see Birch \& Ladd, 1996; Hymel, Comfort, Schonert-Reichl, \& McDougall, 1996; Rubin, Bukowski, and Parker, 2006, Wentzel, 1999). Unfortunately, from the empirical evidence, it is not certain whether the effects of peers are as powerful, pervasive, or ubiquitous as theoretically assumed.

Much of this uncertainty is due to conceptual and methodological problems in peer group research (Rubin, Bukowski, and Parker, 1998; 2006). Such problems include identification of the peer context, reliably capturing the psychological characteristics of the group, and conceptualizing the underlying processes by which group members reciprocally influence each other. While arguments continue today among researchers regarding group identification techniques and measurements of group characteristics, there is a general agreement regarding the underlying processes. That is, group researchers acknowledge that there are three group processes of interest: socialization, selection, and elimination.

Socialization refers to the processes by which group members influence other group members toward conformity and/or similarity. Selection processes refer to how children choose the peers with whom they affiliate and how (once they belong to a group) they maintain existing members or recruit additional ones. Processes of elimination are those in which members leave voluntarily or are rejected by the group. The impact children can have on the nature of their peer group context should be highlighted. That is, with nearly all other important socializing contexts (e.g., parents, siblings, teachers), 
the child exerts no selection or elimination influences whatsoever. Whereas selection and elimination affect the structure of the group (i.e., which specific children are members of a group), mutual socialization processes influence what individuals and groups actually do to and for each other. Socialization, selection, and elimination occur simultaneously and it is difficult to disentangle their relative contributions to the development of the individual (see Cohen, 1977; Kandel, 1978; Kindermann, 1996).

Across the years, researchers have adopted a variety of strategies in order to examine peer group processes. The most common strategy has been to examine shortterm longitudinal data with the focus primarily on delineating processes of peer group socialization. Correlational analyses have been used where change in individuals (from Time 1 to Time 2; usually across a school year) is predicted from group characteristics on the target variable at Time 1. Although findings of significant relations between characteristics of peer affiliations and children's own characteristics can indicate influence processes, alternative explanations also are possible. The relations can be results of pre-existing conditions or concurrent external factors, without actual involvement of direct influences from peers (Sage \& Kindermann, 1999).

One such pre-existing factor is peer selection. In natural peer contexts, children can select (from a pool of candidates) other children with whom they would like to affiliate. These self-selected groups are based on mutual liking and shared activities, as well as similarity in interests, beliefs, and behaviors (Rubin, et al., 1998; 2006). Thus, high levels of similarity on a variety of variables are often the basis from which groups 
are created. Overall, selection processes in natural groups appear to be as powerful as socialization influences in creating person-to-group similarity (e.g., Kandel, 1978).

Peer selection can also explain group convergence across time because children can select others who are on similar developmental trajectories as themselves. For example, in their study on social deviancy, Dishion, Patterson, Stoolmiller, and Skinner (1991) found that children in families with low parental monitoring selected other children whose parents were also low on parental monitoring. Therefore, it may be low parental monitoring and not peer influence that led to future deviant behavior. Thus, part of what appears to be peer influence may be change within peers who have been on specific pathways themselves, and influence processes would only add to the enactment of this potential.

Finally, there are influences from outside of the peer group that can result in individuals within groups becoming more similar and differences between groups becoming greater. For example, teachers have been found to interact differently with students who are motivationally "rich" versus "poor" (Skinner and Belmont, 1993) and this may affect how children change across time (see Rosenthal \& Jacobsen, 1968, for a discussion of the Pygmalion Effect). Differential teacher treatment may extend to entire groups of students who are motivationally similar (Brophy, 1986). Teachers may treat students alike whom they perceive to be similar, and the students may change in a similar way even when they were not influencing each other at all.

In efforts to move away from correlational analyses, an additional avenue for examining socialization processes has been proposed, namely, to directly examine the 
specific mechanisms by which groups influence their members. This was the focus of my previous research studies (c.f., Sage, 1997; Sage \& Kindermann, 1999; 2000). Following a learning theoretical model, the social contingencies that children experienced following their on and off task classroom behaviors from peer group members and their teacher were observed across a period of six weeks at the beginning of the school year. It was expected that highly motivated students would tend to affiliate with others who were also highly motivated. Together, they would reinforce one another for their on task classroom behaviors whereas they would discourage one another from off task behaviors in the classroom. In contrast, low motivated students would affiliate with other low motivated students who in turn would encourage off task behaviors but discourage on task behaviors.

The findings suggested that specific social contingencies predicted initial engagement in the classroom (c.f., Sage, 1997; Sage \& Kindermann, 1999) as well as change in engagement across the school year (c.f., Sage \& Kindermann, 2000). Followup analyses of the same (but re-coded) data suggested that those group members who are also friends appear to be most important for influencing change in engagement across the school year (c.f., Sage \& Kindermann, 2001). In general, the results provided indications that specific mechanisms of influence exist in the classroom whereby the motivationally "rich" get "richer" and "poor" get "poorer" across time. Hence, it appears that peer affiliates provide an important context for children's academic development.

For the current study, it is acknowledged that a child's peer group plays a fundamental role in the classroom. While it is maintained that peer group members can 
and do provide socialization influences which may result in intra-individual change in engagement across the school year, it is argued that the child chooses those others with whom he/she affiliates. As described by Scarr \& McCartney (1983), people seek out environments that are stimulating and compatible to their personal traits. From these environments, they select aspects to respond to, learn from, or ignore. These selections are based on mutual liking, shared beliefs, and similarity in behaviors. Therefore, based on the child's self-system state, a child creates his/her own peer group context that will in turn be an important source of influence. Hence, while it is acknowledged that it is important to understand how groups socialize the individual, it is also important to understand how the individual selects group members and eliminates those he/she no longer wants to affiliate with. Thus, the goal of this dissertation was to examine more closely the changing nature of the child's peer group and identify the selection and elimination processes from which the group emerges.

In efforts to overcome some of the challenges that group researchers face, the dissertation uses methodologies argued to reliably capture children's natural peer groups and to measure the groups' psychological characteristics. In addition, a systems framework is presented whereby the underlying group processes (which are expected to explain why the motivationally "rich" get "richer" and "poor" get "poorer") can be examined across time. However, because these processes do not exist in isolation (i.e., children's academic development can be influenced by other sources), the framework provides an avenue for examining the multiple influences on children's academic engagement. The systems framework presented is hierarchical and identifies seven 
perceptual stances for examining children's academic development in the classroom (see Chapter 3). For the dissertation, only two of the perspectives are used: those that emphasize influences from the individual to his/her peer group. First, the focus is on the changing nature of a child's peer group context. Attention is given specifically to the change in structure and composition of the group, where structure refers to who comprises the group and composition refers to the psychological characteristics of the group. It is assumed that these attributes emerge as a result of the characteristics of each group member and the social interactions, that is, proximal processes, between them. Next the focus is shifted to the specific interaction patterns (i.e., proximal processes) by which the peer group context emerges; namely, selection and elimination processes. Research questions concerning these processes are presented that use longitudinal data collected for during the 2000-2001 academic year. These data contain information on fourth and fifth grade children's classroom engagement, actual peer affiliations, and associative preferences (who children would like to hang out with) and were collected as part of a larger project that aimed to examine the multiple influences on children's academic development. In contrast to traditional studies that examine change from one measurement time to another (usually the beginning and end of the school year), the current study uses data collected at multiple measurement points across the year to examine change between smaller increments of one to two months. Examination of change in children's peer groups at smaller increments of time allowed for the examination of the continuity and discontinuity within ongoing interactions, which Bronfenbrenner and Morris (1998) define as microtime interactions. As argued by the 
authors, it is necessary to focus on ongoing relationships and the microtime interactions in which they occur in order to understand and fully appreciate developmental process.

It should be noted that this dissertation is among the first to date to examine the changing nature of children's groups across small increments of time in a single school year (and the processes by which these groups emerge and change) ${ }^{1}$. Therefore, empirical expectations of what these data can tell us cannot postulated. Thus, the expectations are mostly descriptive and exploratory in nature. However, it is argued that in order to fully understand these processes, a rich description of the microtime interactions is necessary in order to derive future empirical questions regarding the changing nature of children's peer groups and how group processes contribute to intra-individual change in academic development. Hence, the focus of this dissertation is to provide descriptions of patterns of change across time as well as illustrate how a systems framework can be applied for studying peer group processes in the classroom.

\section{Brief Overview of the Dissertation Chapters}

Chapter 2 provides a review of the literature pertinent to the study of peer group processes. The first section discusses the relative importance of the peer group as a context for children's development. The second section provides a discussion of the conceptual and methodological challenges impeding peer group research. Arguments in favor of one method over another are presented when applicable. The third section provides a discussion of the strategies used to date to infer group processes. Key studies

\footnotetext{
${ }^{1}$ Chan and Poulin's (2007) study examined the stability of adolescent friendship groups across five onemonth intervals in the latter half of a school year. However, they did not examine networks nor did they assess the processes by which groups emerge.
} 
that have used these methods for examining academic outcomes are reviewed. At the end, an argument for employing a multiple systems perspective for studying group processes within the classroom is provided.

In $\underline{\text { Chapter } 3}$ systems theories are reviewed and applications of these theories to the study of peer group processes are discussed. The first section focuses on defining the system. Peer groups are described as complex open systems. Discussed is the notion of levels as well as the need for applying multiple perspectives to examine complex systems (Lendaris, 1986). The second section discusses the concept of systems dynamics and the need to examine process (Bronfenbrenner \& Morris, 1986). The final section describes a systems framework from which the current study is drawn.

An overview of the larger project's design is provided in Chapter 4. Information regarding subject recruitment, informed consent, and the demographics of the participants is given as well as detailed procedures for those measures to be used for the dissertation. Expectations for the dissertation are presented in Chapter 5. Expectations are provided with regard to change in groups (in both structure and composition) as well as the proximal processes by which the peer group emerges (namely selection and elimination of group members).

Chapter 6 begins with the results of preliminary analyses to determine individual engagement in the classroom and identify children's groups. Next the results of a series of analyses to examine the change in peer networks across the school year are presented. Finally, the results of another series of analyses to examine the proximal processes by which the peer group emerges are presented. The final chapter, Chapter 7 , begins with a 
brief summary of the dissertation's focus and analytic method followed by a discussion regarding the implications of the results. The significance of the dissertation is highlighted and limitations as well as suggestions for future research are provided. 


\section{CHAPTER 2}

\section{REVIEW OF THE LITERATURE}

In this chapter, literature pertinent to the study of peer group processes and their influence on children's engagement in the classroom is discussed. The chapter is divided into three sections. In the first section, the importance of the peer group context on children's development is reviewed; emphasis is placed on the importance of the peer group for academic outcomes. The second section discusses the conceptual and methodological issues that have challenged peer group researchers. The third section reviews those studies that have sought to overcome the challenges by proposing strategies for inferring peer group processes in the classroom. At the end of this section, an additional strategy is proposed which will be used for the current study. A summary of all three sections is provided at the end.

\section{THE IMPORTANCE OF THE PEER GROUP CONTEXT}

In 1995, Judith Harris rattled the academic world with her psychological review article called Where is the Child's Environment?: A Group Socialization Theory of Development. In this article she attempted to dissuade the reader of the traditional assumption that parents are most important for children's development. Rather, she contended that peers may be more influential than parents and parents have nominal influences (if at all). 
Her controversial views also captured laymen audiences in her book "The Nurture Assumption" which debuted in 1998. Shortly after the book was published I was sitting in the audience at a back-to-school night for my oldest daughter. The principal was discussing influences on children's academics. In her discussion on parental influence (and subsequent pep talk on parental participation in the school) she condemned Harris' strong assertions that parents do not matter. As she continued, I had to sit tightly on my hands to keep myself from raising them and bite my tongue to avoid speaking out. On the one hand, I agreed with the principal; parents do matter and do have influences on children's development. However, in her attempts to rally for parental participation by condemning Harris' book, the principal had completely missed the heart of Harris' message: that peers can (and do) have profound effects on children's development.

The controversy with Harris, however, was not with her assertions that peers are influential but her claim that peers are more influential than parents. Admittedly (at the time), I was a bit skeptical of this strong of an assertion against parents in favor of peers. However, as I have now experienced parenting my older daughter through elementary and high school I tend to agree with Harris: parents do indeed matter less than we think and peers matter more.

Looking at work outside of developmental psychology, such an assertion should not come as a surprise. In 1962, behaviorists Harlow and Harlow demonstrated the importance of peers (over mothers) for rhesus monkey's social development. In this study, a group of infant monkeys was reared with only their mothers; they were not introduced to any age mates during their infancy (hence, they were "peer deprived"). 
Although seemingly content during infancy, these monkeys unfortunately suffered longterm negative issues. When later paired with age mates these peer deprived monkeys were unable to engage in normal peer interactions with their age-mates. In the same study, another group of rhesus monkeys was not deprived of age-mates during infancy but rather was deprived of a mother figure. Contrary to the peer deprived monkeys, these monkeys turned out to be regularly functioning social adults.

From Harlow and Harlow's work, it appears that although peers can be a substitute for a mother a mother is not an adequate substitute for peers. A similar finding was demonstrated with humans a few years later by Anna Freud (Freud and Dann, 1967) in her narrative of six preschool aged children rescued from a concentration camp after the war. Motherless and without any other constant adult figure in their lives, these children became bonded to one another. Similar to Harlow and Harlow's mother deprived monkeys, these children grew up to be fully functioning adults (see also Maunders, 1994). On the other hand, there are cases of children who interact primarily with adults but very little with peers (e.g., little princes and princesses of bygone European kingdoms, children kept at home during childhood because of chronic physical disorders, and child prodigies). These children, like the peer deprived rhesus monkeys in Harlow and Harlow's (1962) study, had impaired social functioning with age mates and such effects were long-term (Harris, 1998).

Assertions regarding the importance of peers have also graced the area of developmental science. Contributions from peers have been a central construct for theorizing for years (e.g., Vygotsky and Piaget) and today it is widely acknowledged by 
researchers that experiences with peers constitute an important developmental context (c.f., Berndt, 1992; Brown, 1990; Cairns, Xie, \& Leung, 1996; Hartup, 1993; 1996, Parker \& Asher, 1987, Rubin, et al., 2006). Experiences with peers begin in infancy; infants as young as 6 months are capable of engaging in social interactions involving an age mate (Vandell, Wilson, \& Buchanan, 1980) and during the first two years, children become increasingly social with one another (Echerman \& Stein, 1990; Eckerman, Whatley, \& Kutz, 1975; Lewis, Young, Brooks, \& Michaelson, 1975). Once children begin school, their contact with peers increases and the proportion of social activities that occurs in interaction with peers (as opposed to other contacts) continues to increase throughout childhood. By age 11, 50\% of a child's social activity occurs within the context of peers (Hartup, 1983). By adolescence, time spent interacting with peers exceeds time spent interacting with any other socialization agent, including the parent (Csikszentmihalyi \& Larson, 1974; Larson \& Richards, 1991; Meldrich, Rosen, Rubin, \& Buckley, 1982).

Children's experiences with peers occur on several different levels: general interactions, relationships, and groups (Hinde, 1987, 1995; Rubin et al., 1998, 2006). Investigations concerning general interactions and relationships often concern children's social competence and popularity and such investigations have dominated the peer relationship literature for over 25 years (Rubin, et al., 2006). As illustrated by Ladd and colleagues, having friends and being liked by them is associated with early adjustment in school, and early adjustment problems may have lasting effects (Buhs, Ladd, \& Herald, 2006; Ladd, 1990; Ladd \& Koshenderfer, 1996; Ladd \& Troop-Gordon, 2003, see 
Morison \& Masten, 1991). In addition, Parker and Asher's (1987) review indicates that early peer rejection may lead to later life difficulties (see also Bagwell, Newcomb, and Bukoswki, 1998; Buhrmester, 1990). Dropping out of school and criminality appear to be the clearest consequences of poor peer relations.

Asher (1983) suggests that there is a causal link between peer social status and behavior. Aggressive, withdrawn, and unsociable children are often rejected by their peers. On the other hand, children who exhibit high levels of social competence are often accepted by their peers (Gottman, Gonso, \& Rasmussen, 1975; Newcomb, Bukowski, \& Pattee, 1993). Reports from rejected children confirm that they are lonelier, less socially satisfied (Asher \& Wheeler, 1985), and experience greater academic difficulties than children who are accepted by their peers (Green, Forehand, Besk \& Vock, 1980; Wentzel \& Asher, 1995).

While general interaction and relational features such as social competence and popularity are important for positive developmental outcomes, these are conceptually distinct from experiences within groups. It has been widely acknowledged that experiences within the peer group are important and the specific processes within the group context can account for significant developmental change. Nonetheless, research on group processes has received little attention compared to research on social competence and popularity (Kindermann, McCollam, \& Gibson, 1996; Magnussen \& Statin, 1998; Rubin, et al., 1998; 2006). Rubin and colleagues suggest that the lack of research attention to group experiences is likely due to the complex conceptual and methodological issues surrounding such research (see also Cairns et al., 1996). Therefore, 
the limited peer group effects that have been discovered thus far may actually be underestimated. Hence, as Harris (1998) alludes: peers may matter more than we think.

\section{METHODOLOGICAL ISSUES IN THE STUDY OF PEER GROUPS}

There are several conceptual and/or methodological challenges that impede peer group research (c.f., Berndt \& Murphy, 2002; Cairns, et al., 1996; Hayni \& Osgood, 2005; Jaccard, Blanton, \& Dodge, 2005; Kindermann, 2003; Rubin, et al., 1998, 2006; Ryan, 2000). Three of the main challenges are discussed below and involve: 1. identifying the peer group, 2. measuring peer group characteristics, and 3. conceptualizing peer group processes.

\section{Identifying the Peer Group}

A peer group is comprised of members with whom an individual interacts on a regular basis. Sometimes referred to as cliques (Rubin et al., 1998, 1993; Brown, 1990), the group may contain anywhere between 2 and 12 members with the average being around 5 or 6 (Ennett \& Bauman, 1994; Urberg, Degirmencioglu, \& Pilgram, 1997). Nonetheless, there seems to be a general lack of consensus among peer group researchers on the usage of the term peer group in their studies. As noted by Brown (1990) the term peer group has been applied to everything from a dyadic relationship with a friend to one's tie with an entire cohort of individuals. Defined as such, much of the research on peer influence has not examined peer groups per se, but rather other types of associative influence. 
Perhaps the longest-standing tradition of peer research is sociometry, a tradition that began in 1934 with Moreno's Sociometric Method. Contemporary psychologists who have adopted this method emphasize a shared consensus among individuals about social acceptance and/or social categories. Researchers who focus on social acceptance emphasize children's social status within a larger context (e.g., a classroom or school). Using sociometric nominations, children are placed in groups based on whether they are liked (“popular") or disliked ("rejected”) (c.f., Asher \& Coie, 1990; Coie, Dodge, Copetelli, 1982). Researchers who focus on social categories emphasize how children are perceived by their peers. Whether the child is perceived as an "emo", "nerd", "jock", etc., determines group membership (c.f., Brown, 1990; 1999). The main problem with these methods is that these "groups" are really merely categories of children; interpersonal relationships are not necessary among these "group" members. Instead, they are large loosely aggregated "crowds" of children and many may not even interact with one another. It is argued that crowds may represent quite distinct social groups from the group of peers with whom a child interacts (Kindermann, McCollam, \& Metzler, 1995). Another popular area of study is children's friendships (Berndt \& Murphy, 2002). This area of study has allowed researchers to study the more intimate bonds between children. In contrast to sociometry research where social acceptance and status are emphasized, friendship researchers view relationship quality and frequency of interaction as the most important features (e.g., Berdnt, 2002; Hartup \& Laursen, 1999; Ladd, Kochenderfer, \& Coleman, 1996). Researchers have examined dyadic relationships with best friends (e.g., Berndt, Laychak, and Park, 1990; Kandel, 1978; Wentzel, McNamara- 
Barry, \& Caldwell, 2004) as well as children's self-nominated groups of friends; this examination typically consists of having children list their three closest friends (e.g., Altermatt \& Pomerantz, 2003; Berndt \& Keefe, 1995; Chan and Poulin, 2007; Epstein, 1983). The problem, however, is that this method arbitrarily restricts the size of the group. Therefore children with more than three close friends have to choose which three to include. If the study involves more than one measurement point, stability issues may arise because the children may choose a different set of three close friends at the next measurement point. Then there are the children who have fewer than three close friends. They may feel compelled to name others who are not necessarily their close friends (Hallinan, 1981; Rubin, et al., 1998).

There is yet an additional problem that impedes research on friendship groups reliability of the reports and validity of the measure. Friendship research relies on selfreported nomination of affiliations and doubts have been raised about the accuracy of such reports because children may exaggerate their associations by nominating the more popular peers but may not actually be friends with them (Cairns \& Cairns, 1994; Leung, 1996). One solution to this problem has been to focus on reciprocity of nominations. That is, friendships are seen as constituted when both friends agree on the relationships. While this helps maximize accuracy of nominations, participation rates can pose serious limitations. That is, reciprocal nominations can be missed if one partner is absent or consent was not obtained.

A third (and relatively newer) tradition of study is that of children's peer networks. Peer networks are most commonly assessed via the Socio-Cognitive Mapping 
procedure (SCM; c.f., Cairns, Perrin, and Cairns, 1985). Similar to sociometric approaches, SCM focuses on a general consensus among reporters. However, instead of grouping children in large crowds based on general social acceptance and/or status, SCM groups children in smaller "cliques" based on who is known to naturally affiliate with one another. Following methods from observational research, SCM employs children as expert observers. Multiple children in the classroom are asked to report about those classmates who they know hang out together. Often, such affiliations are easily identifiable by the selective attention and proximity seeking behavior displayed by the individuals within the group. These reports are then aggregated into a co-occurrence matrix that provides the frequency with which each nominee is nominated to be in the same group as any other nominee.

The co-occurrence matrix can be analyzed using a variety of techniques to define group structures. These techniques seem to fall into two broad approaches; those that identify distinct (non-overlapping) group structures and those that aim to define the group structure for each individual person thereby preserving overlap among groups (see Kindermann and Gest, 2008 for a thorough discussion of these techniques). The latter of these two approaches is the one used in my prior work and in this dissertation. Using binomial z-tests to examine the co-occurrence matrix, the probability that any given child is connected to co-nominated peers (above those expected by chance) can be determined. These significant connections can then be depicted in composite maps, similar to Moreno's (1934) sociograms. Figure 2.1 depicts the composite map from Sage \& colleague's studies (e.g., Sage, 1997; Sage \& Kindermann 1999; 2000). 
Figure 2.1: Peer networks in one $5^{\text {th }}$ grade classroom - Fall 1996

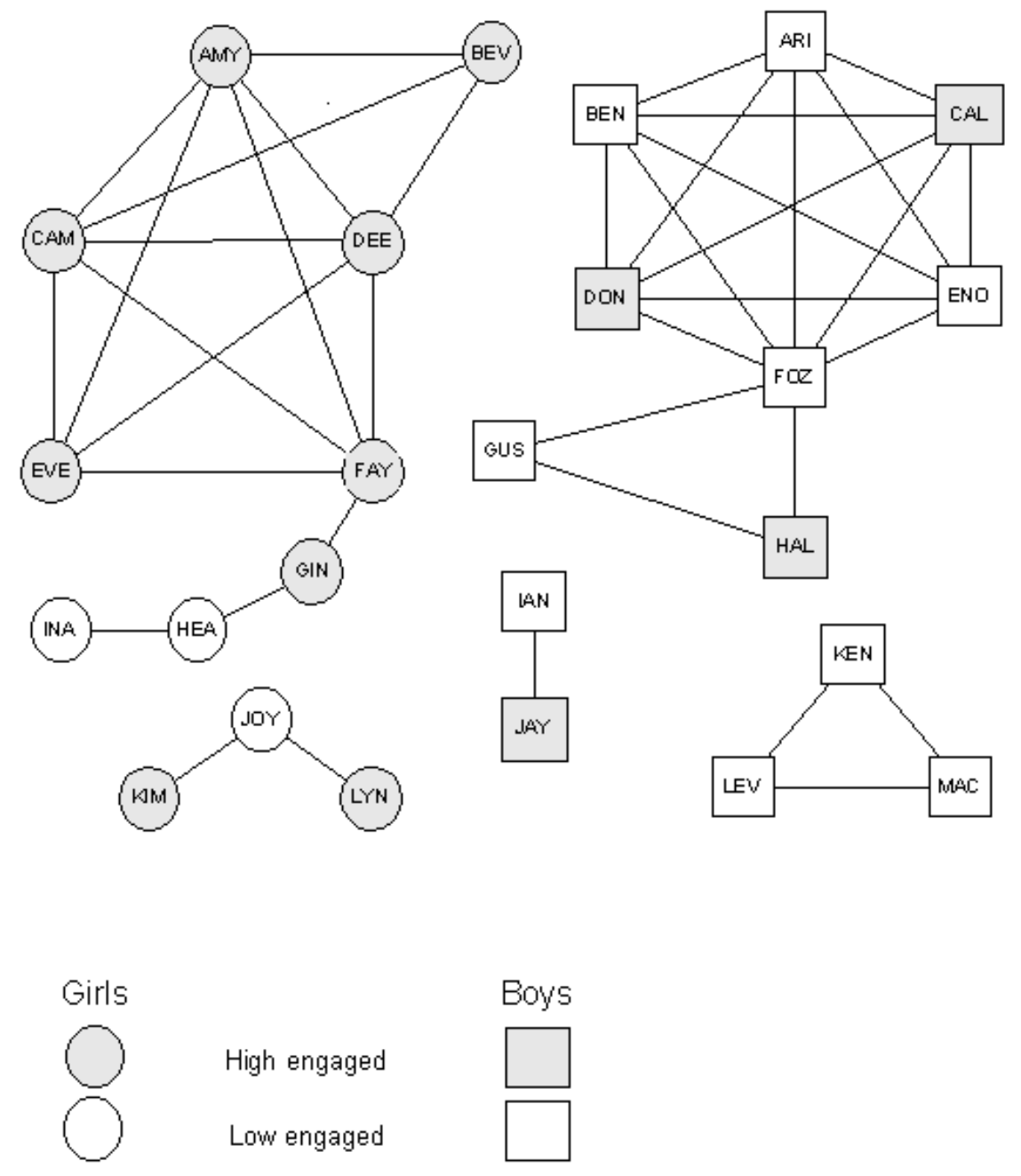

Figure 2.1. Social networks in a 5th grade classroom. Depicted are significant interconnections (identified via binomial z-tests, $p<.01$ ) among individuals. Note that individuals $\square$ positions are arbitrary and based on drawing convenience only.

There are many advantages of the SCM procedure. The first has to do with the reliability of reports. Because identification of groups is based on multiple observers, levels of agreement can be determined via Kappa analyses. The cognitive maps generated from these reports have been shown to be consistent with independent observations (c.f., Gest, Farmer, Cairns, \& Xie, 2003). A second advantage is that not everyone in the 
setting must be an informant to obtain reliable reports. If there are no systematic selection biases, sufficient information can be obtained with reports from about $50 \%$ of the members in the setting (Cairns et al., 1985). This reduces the difficulties often encountered with other methods (i.e., reciprocal friendship nominations) when individuals are absent (or consent has not been obtained) and thus potential reciprocal nominations are missed. In addition, the amount of information obtained from each respondent is greater than the information derived from other methods because respondents describe many groups, including, but not limited to, their own.

A third advantage is that the group structures derived from the peer network identification are more comprehensive than group structures derived from self-reports. Cairns, Leung, Buchanan, \& Cairns (1995) found that the peer network identification procedure yielded larger and more inclusive groups than groups derived from selfreports. In addition (and as noted earlier), self-reported groups may be biased. Leung's (1996) study of Chinese children's social networks and self-enhancement suggests that the students tend to have a self-enhancing bias when reporting their groups, omitting those members who have a low scholastic rank and who have low (teacher reported) competence scores.

A child's peer network may consist of a variety of the child's friends (both reciprocated and non-reciprocated). However, not all members of the network are the child's self-nominated friends. Unfortunately, not much is known about the overlap between self-nominated friendship groups and peer networks. Those studies that have examined the overlap have differed in their results. With a sample of 132 fifth and 
seventh graders, Cairns and colleagues (1995) found considerable overlap between selfnominated friendship groups and peer networks across two time periods in the second half of a school year (57\% and 82\%, respectively). Sage and Kindermann (2001) found similar results in a smaller sample of 26 fifth graders (67\% overlap at the beginning of the year) ${ }^{2}$. McCollam, Kindermann, and Metzler (1995), however, found only about a $40 \%$ overlap at the beginning of the year with a sample of 366 sixth graders (see also Kindermann, 1996).

While the investigations of overlap between self-nominated friendship groups and peer networks are relatively new and further specification of these results is needed, it should be clear that individuals spend time with others who are not necessarily their "friends" (either as self-reported or as reciprocally nominated friends). These other network members may still exert influences that alter the individual's beliefs and behaviors (see Kindermann, 1993 and Kindermann et al., 1996, for studies investigating socialization within peer group networks). Studies involving self-reported friendship groups generally do not include these other network members; therefore the individual's entire socialization network is not captured. When studying peer group influences within the realm of self-nominated groups, it is possible that important socialization agents are not included. This may mislead researchers when examining peer group influences. If children are placed in groups because they are known to spend time together, there is a high likelihood that these are the most frequent interaction partners in the classroom.

\footnotetext{
${ }^{2}$ In this study children's friendship groups were identified as those children who were either nominated as a friend and/or from whom nominations were received. This relatively liberal criterion was used in order to be able to include non-participating friends.
} 
While it could be argued that the SCM procedure does not allow for inclusion of all selfnominated friends, it is the standpoint of the current paper that it is more important to include all frequent interacting partners than all self-nominated friends.

\section{Measuring Peer Group Characteristics}

Once a peer group is identified, the next challenge is to assess the psychological characteristics of the group. It is argued that it is necessary to identify those aspects of groups that are posited to influence (or be influenced by) the individual (c.f., Kindermann, 1996). These factors can include beliefs, competencies, or behaviors. One method for measuring these factors is to ask the participants themselves to report about the group's behaviors. For example, researchers examining delinquency may ask participants to first disclose their own delinquent behavior and then to disclose the delinquent behavior of their peer group members. However, studies have found that such reports are not always accurate and that they may actually be projections of the participants' own values onto their group members (see Bauman \& Fisher, 1986; Donohew, Hoyle, Clayton, Skinner, Colon, \& Rice, 1999; Jaccard, Blanton, and Dodge, 2005; Kandel, 1996; Wilcox \& Undry, 1986; Elliot \& Vos, 1974). For example, Elliot and Vos found that delinquent youth overestimated their peer group members' delinquent behaviors whereas non delinquent youth underestimated the delinquent behaviors of their group members.

A contrasting method is to compute an aggregate of scores on the target variable to form a group profile based on actual reports of individuals. Based on assessments of 
each member of the group, an index of the peer context can be computed reflecting the ‘composite psychological profile' of an individual's group (c.f., Kindermann, 1996). Computations are dependent upon the exact question under study. It seems most researchers use the simplest strategy and compute group context scores by averaging the scores of each group member on the given variable to create a group composite (see Kindermann, 1993; 1996; Sage \& Kindermann, 1999; Ryan, 2001)³. However, as noted in Kindermann's 1996 paper, one could also choose to use the sum of the scores across all members or use the standard deviation of the scores of group members. Furthermore, if one wants to assume differential processes from different members, one could weight individual scores prior to aggregating them.

One advantage of using aggregated scores based on actual reports is that it eliminates the problems of over or under exaggeration of peer group characteristics that impede research using perceived reports. Another advantage is that when groups are independently defined, their characteristics can also be assessed independently because the peer context is defined uniquely for each individual participant. As an example, refer to Figure 2.1 again. AMY's peer network composite engagement score is derived by averaging BEV'S, CAM'S, DEE'S, EVE'S, and FAY'S individual engagement scores. FAY'S peer composite engagement score is derived by averaging AMY'S, CAM'S, DEE'S, EVE'S, AND GIN'S ${ }^{4}$. Although significantly connected to each other, AMY and

\footnotetext{
${ }^{3}$ Note: Kindermann and colleagues average the scores of all significantly connected members in the group; the target individual's scores are not included in the average.

${ }^{4}$ Note that in these studies the authors computed the scores of non-participants by averaging the participating children of the same gender; this made it possible to include children who had peer group averages but missing individual values.
} 
FAY each have a separate peer context. Therefore, unique but comparable scores can be computed for each child despite differences in group size, overlap among members, and change in groups across time.

\section{Conceptualizing Peer Group Processes}

A third challenge for peer group researchers is conceptualizing peer group processes. When studying groups, the focus has most often been on peer group influences. Such influences are often conceived as socialization processes. Traditionally, it has been experimental studies that have been credited with the potential to clearly show socialization processes. In such studies, individuals are randomly assigned to artificially created groups, and often, these influences are shown to be substantial (e.g., Sherif, Harvey, White, Hood, \& Sherif, 1961). However, for developmentalists, the more interesting questions do not concern effects of random strangers, but effects from peer affiliates whom children have selected as partners themselves and with whom they share a prior relationship.

Early work on socialization processes within groups of acquainted peers employed correlational techniques that examined the association between the characteristics of individuals and the characteristics of their groups (see Ide, Parkerson, Haertel, \& Walberg, 1981 for a review). Moderate to high correlations were then viewed as being indicative of peer influence. However as argued by critics, associations between individuals and their groups should not always be viewed as indicative of socialization processes. It could be that the individuals chose to associate with others who were similar 
to themselves to begin with (see Bauman and Ennett, 1996; Billy \& Udry, 1985; Cairns, Leung, \& Cairns, 1995; Kandel, 1978).

This tendency for people to affiliate with others similar to themselves is a social dynamic called "homophily" (Lazarsfeld \& Merton, 1954). High levels of homophily (also called homogeneity) have been found for a variety of variables including risk behaviors, academic achievement, and educational aspirations (e.g., Cohen, 1977; Estell, Farmer, Cairns, \& Cairns, 2002; Henrich, Kuperminc, Blatt, \& Leadbeater, 2000; Ide et al., 1981; Kandel, 1978; Wentzel \& Caldwell, 1997). However, as alluded to in Cohen's paper, observed homophily at one point in time can be a result of 1) socialization processes whereby group members are influenced toward conformity/similarity, 2) selection processes whereby assortive pairing occurs based on prior similarity (see also Kandel, 1978), and/or 3) elimination processes whereby those who deviate from group norms leave voluntarily or are rejected by the group. The processes are not mutually exclusive and may play a different role at various stages of relationships (c.f., Kandel, 1978). In order to capture their relative contributions, Kandal proposed obtaining longitudinal data on real-life relationships. Studies that have used such methods have accumulated across the years. Those that have focused on academic outcomes are discussed in the next section. 


\section{STRATEGIES FOR INFERRING PEER GROUP PROCESSES \\ WITH REGARD TO ACADEMIC OUTCOMES}

\section{Correlational Studies of Peer Group Processes}

Because processes of socialization, selection, and elimination occur simultaneously, researchers have employed a variety of methods in efforts to disentangle their relative contributions. With their focus primarily on delineating processes of socialization, researchers turned toward use of short-term longitudinal studies where predictions were made from Time 1 to Time 2 . The first two studies that employed this technique with regard to academic outcomes examined similarity among adolescent friendship dyads (Cohen, 1978; Kandel, 1978). In Kandel's study, levels of similarity were examined in

the Fall and again in the Spring of a school year with regard to four attributes: marijuana use, educational aspirations, political orientation, and delinquency. The students were also asked to report their best friends in school at each measurement time. Of the 957 friendship pairs reported in the Fall, 668 were stable reciprocal friendships (self report nominated at both time one and time two). Stable friendships yielded higher similarity scores at measurement point one than those friendships that were not stable. In addition, the initial similarities among stable members increased over time.

In 1983, Epstein expanded our understanding of the role of peers for academic outcomes by examining influence from middle and high school students' three close friends on adolescent's achievement and affect in school. Measurements were taken at the beginning and again at the end of the school year on students' grades, test scores, 
satisfaction with school, and reports of three best friends. While controlling for initial achievement levels (i.e., grades and test scores), predictions were made about the change in adolescents' achievement across the year (Time 1 to Time 2) based on the achievement level of their friends at Time 1. It was found that students who affiliated with high achieving friends increased in achievement across the year, whereas students who affiliated with low achieving friends decreased. Similar patterns were found with regard to affect; satisfaction with school increased for those students whose friends had a positive school affect whereas satisfaction decreased for those adolescents who affiliated with friends low in school affect.

Ten years later Kindermann (1993) used a similar method and found complimentary results among $4^{\text {th }}$ and $5^{\text {th }}$ graders. Among the first to examine academic outcomes among social networks, Kindermann aimed to assess the reciprocal influences (via selection, elimination, and socialization) between individuals and their groups. The SCM procedure was used to obtain information about peer networks in the Fall and again in the Spring of the school year. At the same measurement times, teacher-reports of children's engagement were obtained. Socialization effects were presumed when change in individual engagement was found to be significantly predicted from initial level of the group. Selection effects were presumed when the results showed that children and groups were initially similar in motivational tendencies (initial selection effects). Across the school year, this homogeneity remained consistent despite considerable change in group membership (providing indication of on-going selection and elimination processes). A 
few years later, these same findings were replicated with adolescent peer groups (grades 9-12; see Kindermann, et al., 1996).

At about the same time of Kindermann and colleague's (1996) replication study, Berndt and Keefe (1995) showed that friendships can influence adolescents' grades as well as disruptive behavior in school. The study included 297 seventh and eighth graders in three public schools. In the Fall and again in the Spring teachers provided reports on student's grades in their math and English classes. At the same measurement times, students reported about their involved versus disruptive behaviors in the classroom and nominated their three best friends. Similar to Epstein's (1983) and Kindermann's (1993) studies, change in behaviors from Time 1 to Time 2 for individuals were significantly predicted from the group's behaviors at Time 1. In specific, students became more disruptive across the school year if their friends were on average more disruptive at the beginning of the year. On the other hand, students' grades improved across the year if their friends had higher than average grades at the beginning of the year.

This trend of using short-term longitudinal studies whereby Time 1-Time 2 change in individuals is predicted from characteristics of groups at Time 1 has continued throughout the years. Findings have included predictions of change in social and cognitive competence as a function of best friends (Berndt, Hawkinsm, \& Jaio, 1999), change in children's liking and enjoyment of school as well as achievement in school as a function of social networks (Ryan, 2001), and change in classroom engagement as a function of peer networks (Hillier, Weaver, Newton-Curtis, \& Sage, 2003, Kindermann, 2007). 
The advantage of the later studies over earlier studies is that individual change was examined as an outcome of peer influence. The problem, however, is that these studies are still correlational in nature. Therefore, even if individual change is examined as an outcome, selection processes continue to jeopardize interpretations of influence. This is because it is possible that peers who had already been on similar developmental pathways beforehand have joined the group. For example, if children selected as friends other children who are low on parental monitoring (e.g., Dishion, et al., 1991), then it may be that the low monitoring (and not peer socialization) increases the probability of future deviant behavior. Thus, part of what appears to be influence may be change within children who had been on specific pathways themselves, and peer group processes would only allow for enactment of this potential.

Influences from outside of the peer context are yet another alternative explanation. For example, influences from parents and/or teachers can also produce individual change that looks like peer influence. Evidence of this phenomenon was provided in Skinner and Belmont's (1993) study where teachers were found to interact differently with students who enter a classroom motivationally "rich" than with students who enter the classroom motivationally "poor". And differential teacher treatment may have effects on how students change across time (see also Rosenthal \& Jacobsen, 1968). As noted by Brophy (1986), differential teacher treatment may extend to entire groups of students who are motivationally similar. Therefore, teachers may treat students alike whom they perceive to be similar, and those children may change in a similar way even when they are not influencing each other at all. 


\section{Identifying Potential Mechanisms of Peer Influence}

Because processes of selection, elimination, and socialization occur together and it is difficult to determine their relative contributions, Sage and Kindermann (1999) presented an additional route to studying peer group influences, namely the direct examination of the mechanisms that are expected to operate in natural peer contexts (see also Sage, 1997). Two types of mechanisms have been suggested. One is based on social-cognitive assumptions and one on learning theory. Studies examining social-cognitive mechanisms suggest that change in groups can come about in discussions, through joint work on tasks, via modeling, or internalization processes (e.g., Berndt, et al., 1990; Berndt \& Keefe, 1996; Schunk \& Zimmermann, 1996). Learning theoretical studies suggest that social contingencies in interactions with peer group members or friends can also constitute mechanisms that organize how individuals change (Dishion, et al., 1996; for reviews, see Hartup, 1983; 1993).

Sage and Kindermann (1999) adopted the learning theoretical model. Data were collected in one fifth grade classroom during the academic year 1996-1997. Out of 25 total students, 22 students and their teacher agreed to participate. Teacher report of engagement and student report of peer networks were obtained at the beginning and again at the end of the year. In the Fall, the 22 student's everyday classroom behaviors were observed. Targeted were the positive and negative contingencies that children experienced from classmates and teacher as consequences of their on and off task behavior. 
Sequential analyses (Bakeman and Quera, 1995) were used to examine patterns of interactions between peer network members, non-network members, and the teacher. The results suggested that peer network members and non-network members provided different learning contingencies. Students who were highly motivated for classroom activities were found to be with peer networks that were also highly motivated, and these students were more likely than low motivated students to receive approval contingencies for their on task efforts from the members of these networks. Conversely, less motivated students were found to be with slightly less motivated peer networks, and the only source of approval for on task behavior was the teacher. The results for off task behaviors were less clear. In contrast to expectations, peer network members were not more supportive of members' off task behavior than non-network members; however, when children who were less motivated were off task, they were more likely to receive contingent disapproval from classmates who were not members of their networks. While these findings are consistent with assumptions of learning theoretical mechanisms of peer influence and indicate that reinforcement patterns have the potential to lead to change in children's motivation, it is not clear whether such mechanisms have the potential to actually produce intra-individual change.

In 2000, Sage and Kindermann presented a longitudinal study to explore whether the contingency patterns found to be predictive of initial engagement could actually predict change in individual engagement across the year. Using the same data set from their 1999 study, a regression analysis was employed to determine which contingency patterns at the beginning of the year best predicted intra-individual change across the 
year. Six contingency patterns were found to be the best predictors, explaining $69 \%$ of the variance: 1) teacher approval following children's active on task behavior, 2) teacher disapproval following active off task behavior, 3) peer networks members' approval following active on task behavior, 4) peer network members' disapproval following active off task behavior, 5) non-network members' disapproval following active on task behavior and 6) non-network members' disapproval following active off task behavior. A second regression analysis indicated that the two contingencies found to be predictive of initial engagement (i.e., approval from peer network members for children's on task behaviors and disapproval from non-network group members for off task behaviors) predicted change in children's engagement above and beyond the other contingencies. In 2001, Sage and Kindermann recoded their observational data set in order to examine contingency patterns that originated from different types of peer affiliates. Sequential analyses (Bakeman \& Querra, 1995) were used to examine contingencies from affiliates who were "just network members", "just friends", "network members and friends", and "non-affiliates". Most influential for positive change in a child's motivation appeared to be those network members who were the child's friends at the same time (influence mechanisms were contingent approval of on task behavior and contingent disapproval of off task behavior). A 'deviancy training' mechanism which can undermine motivation through contingent approval of off task behavior (see Dishion, Spracklen, Andrews, \& Patterson, 1996) was also found from friends (including "just friends" and "network members and friends"). 


\section{Limitations of Research Thus Far}

All of these studies have been invaluable for expanding our knowledge about how peer group processes operate and for outlining strategies for identifying specific socialization mechanisms that can contribute to intra-individual change. While peer group researchers acknowledge that three group processes (socialization, selection, and elimination) can be responsible for change across time, the majority of research has focused primarily on processes of socialization. Those handful of studies that have examined selection and elimination processes have done so only in light of their efforts to uncover socialization effects. Furthermore, methods used to identify selection and elimination processes have employed correlational analyses of stability of homogeneity at two time points compared to percent of group turnover. Such methods don't provide much indication of the actual underlying processes of selection and elimination by which the peer context emerges.

In the next chapter, a framework for examining these processes is presented. Bronfenbrenner and Morris' (1998) Bioecological Model is adopted where action is seen as situated in its contextual settings. At the core of this model are the reciprocal interactions between the individual and his/her environment (called Proximal Processes; PPs). In order to examine the continuity and discontinuity of these interactions across time (i.e., microtime interactions), longitudinal examination of the processes in small intervals is necessary. Traditional methods where snapshots of behavior at the beginning and end of a school year are examined do not provide us with the information to completely understand how group processes operate. However, because group processes do not occur in isolation, a multiple systems perspective is suggested where the 
researcher attends to different perceptual levels (c.f., Lendaris, 1986) so that processes of selection, elimination, and socialization can be delineated and explained in relation to other influences that contribute to children's academic development.

\section{CHAPTER SUMMARY}

Peers are considered to be important developmental contexts; some argue that peers may be even more important than other developmental contexts. Unfortunately, it is not certain from empirical evidence whether peers are as important as theoretically assumed. While experimental studies seem to provide the strongest evidence for group effects, they often are conducted on randomly assigned groups of strangers. For developmentalists, more interesting questions concern the processes within groups of individuals who already share a prior relationship (i.e., natural groups). Nevertheless, research on natural groups is impeded by several conceptual and methodological challenges. Three of the most critical challenges are identifying the peer group, measuring group characteristics, and conceptualizing group processes.

While arguments continue today regarding group identification methods, there is

a general consensus that there are three group processes that occur within natural groups: socialization, selection, and elimination. The processes occur simultaneously and it is difficult to disentangle their relative contributions. Across the years, researchers have proposed a variety of methods in order to capture peer group processes and their contributions to academic outcomes. With the focus primarily on examining group socialization processes, short-term longitudinal studies have been employed and 
examinations have included change in person-to-group homogeneity, change in individuals across time as a function of initial group behavior, and direct examinations of the mechanisms that are assumed to contribute to individual change across time. These studies have been invaluable for expanding our knowledge about how peer group processes operate and for outlining strategies for identifying specific socialization mechanisms that can contribute to intra-individual change in development.

What appears to be lacking in the peer research literature is an emphasis on group selection and elimination processes. Those that have attended to such processes have resorted primarily to traditional methods to indicate selection processes (i.e., homophily) and have done so only in light of their efforts to uncover socialization processes. Advances in our understanding of peer group processes can be obtained by employing systems strategies to the study of groups whereby different perceptual levels are attended to so that processes of selection, elimination, and socialization can be delineated and explained in relation to other influences that contribute to children's academic development. Furthermore, by focusing on smaller increments of change, researchers can examine the microtime interactions in which the processes occur. 
Systems Theory: Peer Network Emergence

\section{CHAPTER 3}

\section{SYSTEMS THEORY APPLIED TO THE STUDY OF PEER GROUP PROCESSES IN THE CLASSROOM}

In this chapter, systems theories are reviewed and application of such theories to the study of peer group processes in the classroom is discussed. The first section focuses on defining the system. Peer groups are described as complex open systems. Discussed are the notions of levels as well as the need for applying multiple perspectives to examine complex systems (Lendaris, 1986). The second section discusses the concept of systems dynamics and the need to examine developmental process (Bronfenbrenner \& Morris, 1986). The final section describes a systems framework from which the current study is drawn.

\section{DEFINING THE PEER GROUP SYSTEM}

\section{Peer Groups as Complex Open Systems}

Peer groups differ from other types of groups (such as work groups or social clubs) in that they exist "naturally"; there is no activity or project that binds the group together. Rather they are self-organizing and emerge as a result of mutual liking and/or similarity (c.f., Hinde, 1979). Whereas the mere count of who is "in" the group defines its overall structure, it is the interaction among these members (what they do to and for each other) from which the composition or attribute of the group emerges. Nonetheless, the peer group is not a rigidly ordered system with predictable interconnectivity and outcomes. 
Peer groups are comprised of members who are both connected to and distinguished from each other in highly articulated roles, relationships, and activities. Across time, both the structure and the composition of the peer group changes. That is, new members are added (members gained), old ones leave (members lost); and the stable members themselves are changing to their adapting environment (Kindermann, 1993, 2007; Kindermann et al., 1996). Furthermore, with group change comes new regularities and patterns of behavior and as the group develops, the number and variety of regularities in structure and behavior proliferate. Hence, peer groups are not only complex systems, but they tend to increase in complexity across time (c.f., Arrow, McGrath, and Berdahl, 2000; Rubin et al., 2006).

Peer groups are also open systems. That is, while peer groups behave as intact systems, they do not exist in isolation. Rather, they are embedded within larger contexts which contain other groups (with embedded members). Bronfenbrenner (1979) described four layers of embedded contexts. The first layer is the microsystem which includes the individual and at least one other social partner. Hence, a group is one example of a microsystem. However, the individual group members are not fully embedded within a single group. Instead, they are often simultaneously engaged in other microsystem groups. Examples include, but are not limited to, a teacher/student dyad, a family, and school work groups. The interaction of two or more microsystems constitutes Bronfenbrenner's second layer, the mesosystem. A classroom context is one example of a mesosystem because it includes at least three microsystems that overlap (e.g., a student 
with his/her teacher, a student with his/her peer group members, a student with his/her classmates who are not group members).

The third layer of embedded context is the exosystem (the exosystem includes those influences that occur outside of a target individual's microystems but nonetheless affect this individual indirectly). For example, a child's teacher engages in groups outside of the classroom such as his/her own family members and his/her friends. These are microsystem groups for the teacher that the child is not directly involved with. However, these interactions subsequently affect the teacher and therefore indirectly impact the child. The fourth layer is the macrosystem which includes overarching beliefs, values, and governmental policy of the society in which the individual resides. In 1998, Bronfenbrenner added a fifth layer called the chronosystem which constitutes the concepts of time, history, and developmental change and/or stability (see Bronfenbrenner and Morris, 1998). Figure 3.1 provides an example of a child's embedded contexts based on Bronfenbrenner \& Morris' Bioecological Model of Development.

Similar in view to open systems theory, Bronfennbrenner (1979; Bronfenbrenner \& Morris, 1998) noted that the boundaries among the various layers are permeable; that is, information passes within and between the layers resulting in change at all levels. As an open system, group members are not fully embedded within a single group. Instead they are simultaneously engaged in other groups. The boundaries between the multiple groups and their respective members are "fuzzy". It is these fuzzy boundaries that both distinguish groups from and connect them to their members as well as their embedded contexts (c.f., Arrow, McGrath, Berdhahl, 2000; see also Katz \& Kahn, 1978 for 
discussion of open systems theory). Nonetheless, it is these fuzzy boundaries that make it difficult for peer group researchers to study peer group processes.

Figure 3.1: Example of layers of embedded contexts

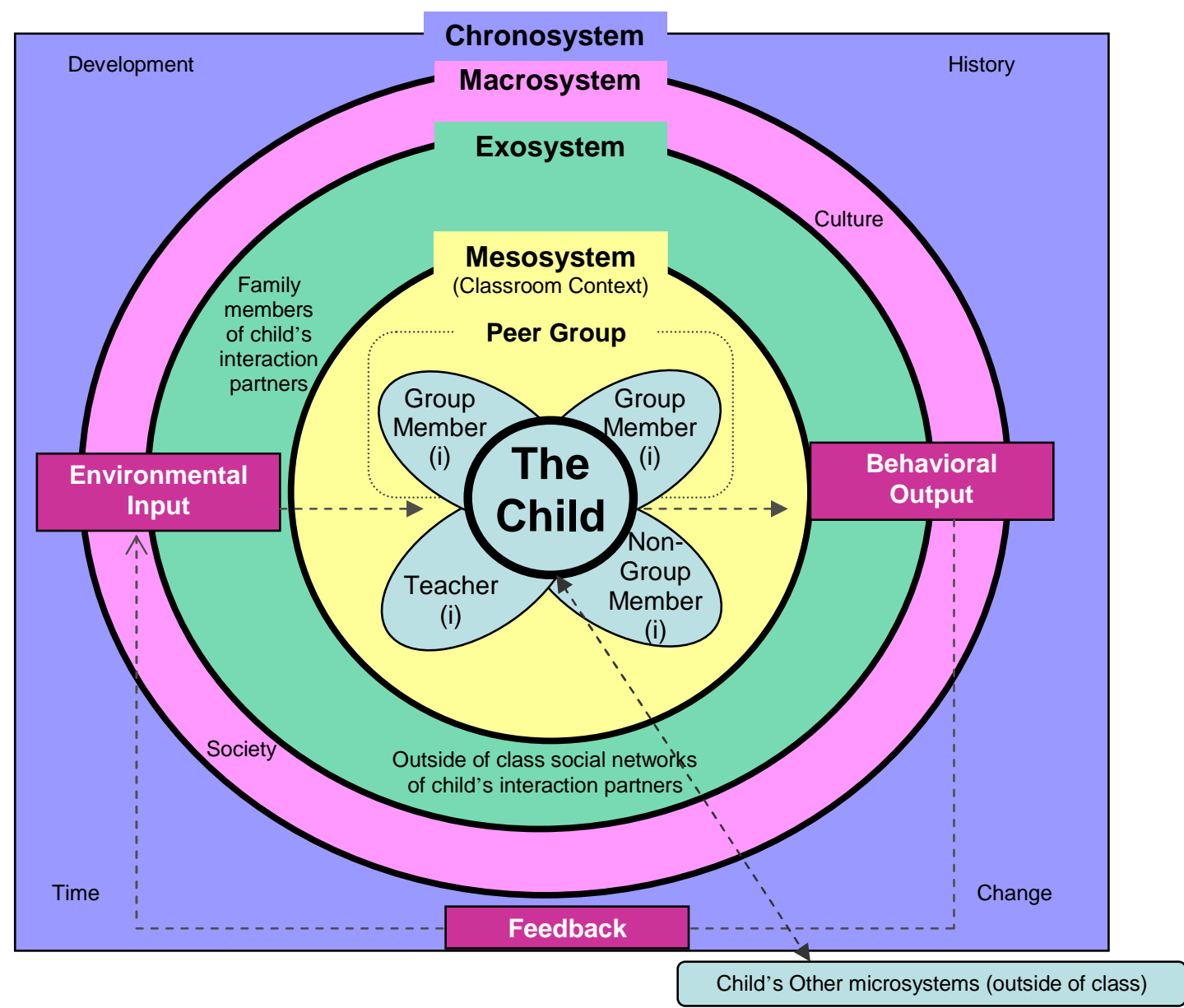

Figure 3.1. Example of layers of embedded contexts based on Bronfenbrenner's (1979) Ecological Systems Theory and Bronfenbrenner \& Morris' (1998) Bioecological Model of Development. In this example, the child is a member of multiple microsystems in the classroom context (self and teacher, self and peer group contexts, self and non-group members in the classroom). He also is a member of other microsystems outside of the classroom (e.g., self with parents). The interaction of all microsystems constitute this child's mesosystem. Members of his microsystems engage in interaction in other groups with whom this child does not interact (e.g., peer group members interact with their family members, teachers interact with the social networks outside of the classroom). These interactions can indirectly impinge on the child's development and are referred to as exosystem influences. Microsystems, mesosystems, and exosystems are embedded within a larger society (the macrosystem) and all of these systems change and adapt over time (the chronosystem). 
As viewed by Arrow and colleagues, [Peer groups are]... "intact social systems embedded within physical, temporal, sociocultural, and organizational contexts. Embedded within groups are the group members, who are also complex, adaptive systems embedded within multiple contexts - including multiple groups" (p. 37). The authors argue that in order to effectively study groups, attention to three systems levels is necessary: individual members, the group as a system, and the various layers of the embedded contexts. These levels are described in the next section.

\section{Levels of the Peer Group System}

Lendaris (1986) describes a system as ..."a) a unit with certain attributes perceived relative to its external environment, and b) a unit that has the quality that it contains subunits that operate to manifest the perceived attributes of the unit" (p. 604). Implicit in this definition are three levels:

1. The System as a Whole - this is what Lendaris refers to as the unit.

2. Environment - this is the context in which the unit is embedded and is referred to by Lendaris as the suprasystem. However, this definition of the environment (alluding to an infinite environment) is too broad for most systems purposes. For systems definitions, the environment does not have to include all infinite components. Rather, more appropriate are the "relevant" components of the environment. It is the task of the person defining the system to distinguish between those components of the environment that are relevant from those that are not. Because a general understanding of a system is needed for systems definition, one can safely assume that the person defining the system has enough 
knowledge about the phenomenon under investigation to extract from the environment the relevant components. Thus, in the context of systems definition, the environment can be defined as the relevant environment.

3. The Subunits - these are the smaller systems that are embedded within the system as a whole; this level is referred to by Lendaris as the subsystem.

This definition parallels the three levels of systems that Arrow and colleagues (2000) argue that researchers should attend to in order to effectively study groups: the peer group as a system, the various layers of the embedded context, and the individuals. Nonetheless, on its own, this definition says nothing about where we start the analysis nor how we draw boundaries. Lendaris (1986) argues that the choice is dependent upon what our focus is. That is, begin with what we are most interested in (because of the problem we want to examine), then look one level down and then one level up. The next section clarifies what is meant by looking one level down and one level up.

\section{The Need for Multiple Perspectives}

In his 1986 paper, Lendaris also advocates for the importance of using multiple perspectives. It is argued that every beholder is impacted by his/her own perceptual filters and that by applying multiple perspectives to a problem, the beholder is able to role play a variety of perspectives and hence obtain a better understanding of complex systems. Applying multiple perspectives means to vertically go up and down the system and horizontally to adopt different roles. 
Let's take the case in point (peer group processes in the classroom) as an example (Figure 3.2). One could argue that the focal system in this example is the peer group. Hence, a child's peer group would be considered to be the unit or system as a whole. Lendaris (1986) would refer to this as the " $\mathrm{A}$ " level of analysis. The next step is to look one level down and include the smaller systems embedded within the system as a whole. In this example, the individual members that comprise the group could be defined as the subsystem; also called the "B" level of analysis. The A and B levels are the basis for initial inquiry into the system of interest. However, in order to fully understand the peer group as a system, it is necessary to also understand the demands made upon it by the environment. Therefore, the researchers should look one level up to the relevant environments in which the system is embedded.

For the case in point, is seems plausible to deem the classroom environment as "relevant". Hence, the classroom is a system in its own environment (the school) which contains subunits (of which the peer group is one of them). Furthermore, a complete understanding of the peer group as a system requires understanding of its subsystems (each individual member) as systems in their own right. Therefore, each individual member is situated within an environment (which in this case is the peer group) and contains subunits of their own (which can include specific personal characteristics of each member; for example, motivational level, intelligence, and gender). What this means is that in order to fully understand a system, one needs to focus his/her perspective on at least five layers of associated supra and subsystems; this is the vertical component of Lendaris' multiple systems perspective. 
Figure 3.2. Levels and multiple perspectives: The case of children's peer groups

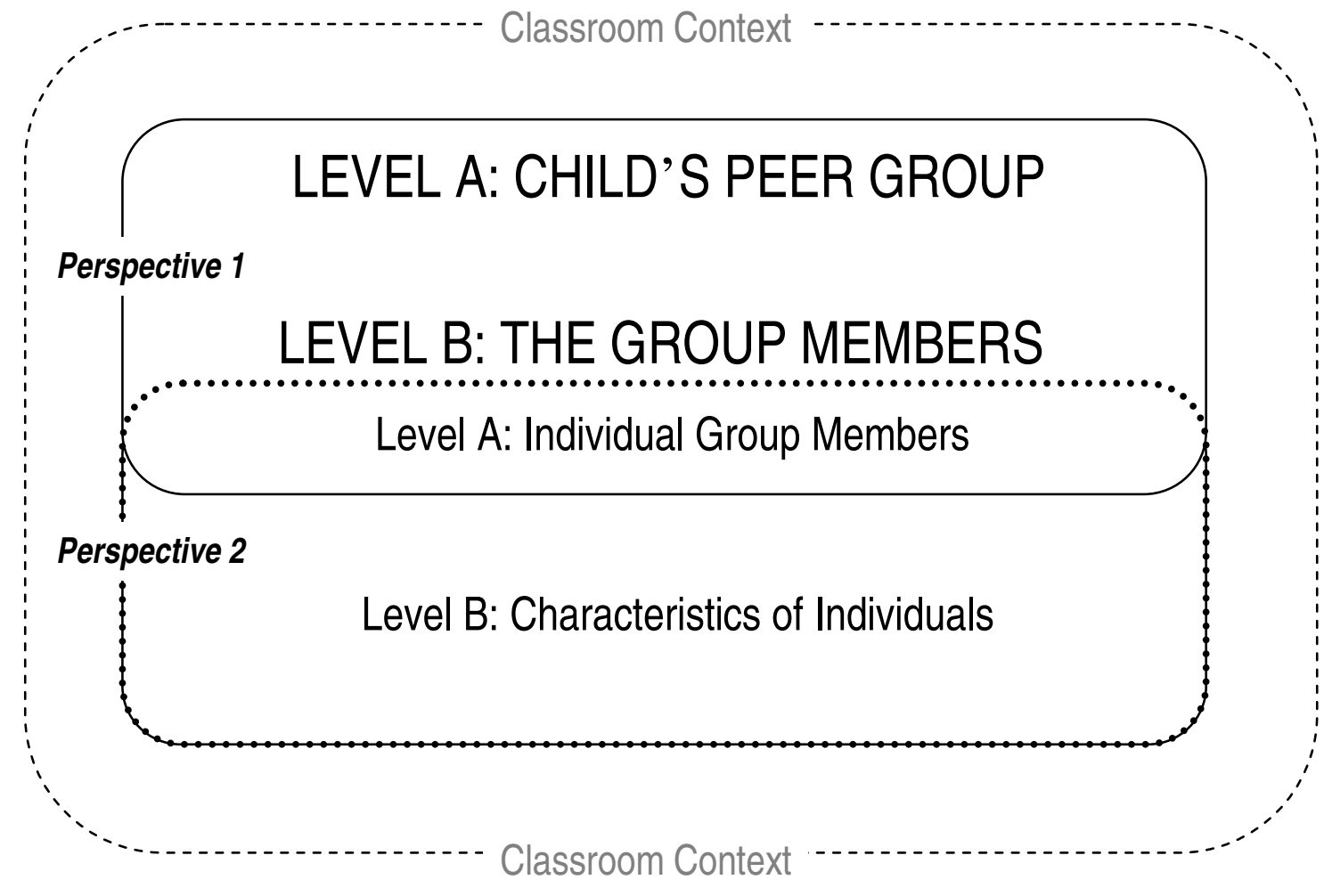

Figure 3.2: Example of applying multiple perspectives to examination of a system (Lenaris, 1986). Depicted are two different perspectives for understanding the peer group system. In perspective \#1, the focus (A level unit) is the peer group. One level down is the B level units (the members that comprise the group). One level up is the context in which the system is embedded. In perspective \#2, the B level unit in perspective \#1 becomes the A level unit. Therefore, in perspective \#2, the individual members become the focal unit. One level down is the characteristics of those individual members at the A level.

\section{EXPLORING THE DYNAMICS OF THE PEER GROUP SYSTEM}

At this point, we have a relative general model of a child's peer group system. That is, a child's peer group is a unit, embedded within a context (the classroom). This unit contains subunits (individual members) that interact together to manifest the attribute of the whole (academic ability). Although this model provides us with information about the 
Systems Theory: Peer Network Emergence 46

hierarchical structure of the system (i.e., each level is subordinate to the one above it), it tells us virtually nothing about the underlying processes.

To obtain an understanding of these processes, two approaches are necessary: wholism and holism. Both are required because emergence is dependent upon the results of these approaches. Emergence describes the appearance of attribute(s) at the "A" level of analysis. These attributes are not readily predictable from a simple examination of the subunits. Therefore, in order to understand emergence we must look at the system:

1. Wholistically in order to see the emergent qualities. This (wholism) means to concentrate on the whole system within its environment and look at the attributes it expresses therein.

2. Holistically in order to understand the relationships which create the emergent qualities. This (holism) means to look at the subsystems and their relations, while being mindful of the whole (i.e., the attributes observed at the higher level). Much of the information about the nature of children's peer groups in academic settings has been derived from rather simple cause-effect (antecedent-consequence) models. These types of models consider the system as a "black box", something that takes in input, and produces output, without us being able to see what happens in between (the throughput). Furthermore, such models provide a rather static view of the system being examined.

Although researchers and theorists recognize that groups of peers are complex systems and behavior is not necessarily linear, tools for examining complex systems have not been readily available; that is, until recently. Within the past decade or so, the field of 
psychology has seen a surge of interest in systems approaches for examining psychological phenomena. Though this approach appears to be a "new" methodology within the social sciences, it has enjoyed a long and rich history within the hard sciences, such as engineering, mathematics and physics. The systems approach integrates the analytic and the synthetic method, encompassing both holism and reductionism. It was first proposed by Ludwig von Bertalanffy (1950) and referred to by him as "General Systems Theory".

As formulated by Bertalanffy, general systems theory postulates the notion of "openness" in every system. That is, the system changes its behavior in response to conditions outside its boundaries. Drawing on the concept of the peer group as an open system, it can be assumed that the behavior of a peer group changes as a result of the contingencies that are experienced from environmental influence. The behavior of the peer group (the output) is therefore a direct or indirect result of the input. However, this behavioral output is quite different from the input. That is, the peer group is not a passive recipient, but rather, an active processor. The transformation of input into output of a system is typically called throughput. Input, throughput, and output are the basic components of a system as it is understood in systems theory.

Therefore, at this point, the systems model for children's peer group can be expanded from mere levels (or hierarchical structure) to include the idea of process and can be illustrated as such. 


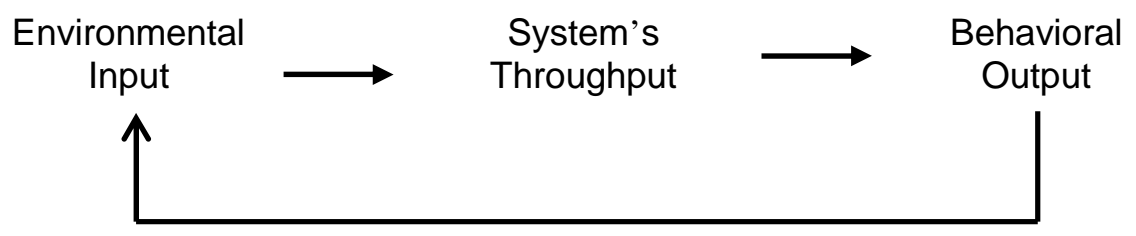

Feedback

\section{Examination of Process}

Nonetheless, the question remains, how does one go about examining process? In 1998 Bronfenbrenner and Morris proposed a model for examining developmental processes. They refer to this model as the Bioecological Model of Development. The defining properties of this model consist of four components [process, person, context, and time (PPCT)] and the dynamic relationships among them. Process is considered to be at the core of the model and encompasses the reciprocal interactions between the individual and his/her environment (called proximal processes; $P P s$ ). These processes operate over time and are posited to be the primary mechanism of development (see Gottlieb, Wahlsten, \& Lickliter, 1998). However, the degree of influence of these processes varies as a function of the characteristics of the developing person, the immediate as well as the external environmental contexts, and the time in which these processes occur. As noted by Bronfenbrenner and Morris (1998), time has a prominent place at three successive levels: micro, meso, and macro. Microtime refers to the continuity and discontinuity of ongoing episodes of proximal processes. Mesotime refers to proximal processes across longer episodes such as days and weeks, and macrotime focuses on changes in beliefs, values, and events across the larger society. 
Bronfenbrenner and Morris (1998) argue that in order to understand the underlying dynamics of the system (and hence development), one must focus on the proximal processes and microtime interactions in which they occur. Application of dynamical systems tools may be useful for examination of microtime interactions. This examination would first require more explicit definition of the group, with greater emphasis on the subunits (the individual group members) and the interrelationships among them through which the phenomenon being examined (e.g., academic ability) emerges.

The second step would be to be precise about the notions of system state and evolution of the system state over time. The system state at time $t$ is an instantaneous description of the system which is sufficient to predict the future states of the system (given all future inputs) without recourse to states prior to t. The evolution of the system state refers to a sequence or continuous trajectory through the space of possible system states. These system states can be plotted in a time series which provides the value of a single system variable on one axis and increments of time on the other. The space of possible system states is called the state space of the dynamical system (and a time trajectory can be described in this space). In complexity theory, the evolution of the system plotted in this way can be examined to detect movement within the system toward one or more attractors (i.e., system states that the system tends to evolve and gravitate toward under a set of contextual conditions, c.f., Arrow, et al., 2000). The path assumed in social psychological theories is that the system shows an initial short period of rapid change, evolves quickly toward a stable (attractor) state, and then maintains that state; a 
Systems Theory: Peer Network Emergence 50

pattern Arrow and colleagues refer to as robust equilibrium (Arrow, 1997). For any group variable being examined, trajectories for this pattern can show (a) random fluctuations of the variable at the onset of group interactions followed by a settling down to a steady state, (b) a steep increase at the onset of group interactions with a tapering off to a steady state, or (c) a cycle of extremely high and extremely low values on the target variable followed by a steady, sustained pace.

\section{THEORETICAL FRAMEWORK FOR THE CURRENT STUDY}

The current study is part of a larger project conducted by the Social Networks Research Group (SONET). SONET was a team of undergraduate and graduate level students from the Department of Psychology at Portland State University that I directed (under the supervision of Dr. Thomas Kindermann). Data for the larger project were collected during the 2000-2001 academic year as part of a replication and extension of an earlier study conducted by SONET during the 1995-1997 academic years (Sage, 1997; Sage \& Kindermann, 1999; Sage \& Kindermann, 2000; see also Kindermann, 1993, 1996, 2007, Kindermann, McCollom, and Gibson, 1996 for results of data collected prior to 1995$)^{5}$. The goal of the 2000-01 project was to examine the multiple influences on children's academic development and to specifically address whether peer groups were important in addition to parents and teachers.

The 2000-01 project incorporated a multi-level (nested) model for examining peer group processes that can contribute to intra-individual change in children's academic

\footnotetext{
${ }^{5}$ Note: the 1995-1997 study is referred to hereafter as the 1995-97 project; the 2000-2001 study is referred to hereafter as the 2000-01 project.
} 
Systems Theory: Peer Network Emergence 51

development. Note that for this project, the primary focus was on the development of the child. For my dissertation, the focus is on the development of the each child's peer group. The 2000-01 project adopted Bronfenbrenner and Morris' (1998) Bioecological Model of Development and Lendaris' (1986) concepts of levels and multiple perspectives. On the basis of these two frameworks, a hierarchical model was identified that specified seven perceptual stances for examining the multiple influences on children's academic development. Note that for the dissertation, only perceptual stances \#6 and \#7 were used.

\section{Perceptual Stance \#1}

For this perceptual stance children's classroom and family mesoystems are considered to be the focal (A level) unit and the focal attribute attended to is intra-individual change in children's academic achievement (see Figure 3.3). The B level attribute being attended to is the relevant set of PPCTs that contribute to intra-individual change in children's academic achievement. The B level subunits include:

- $\quad$ The Child

- Microsystem \#1: The classroom context - (relevant) social partners are teachers, peer group members, and non-group members.

- Microsystem \#2: The family context - (relevant) social partners are parents, siblings, and other key family members (e.g., aunts who are involved in child's academic activities). 
Characteristics of the child, his/her social partners in each microsystem, as well as the interactions within (proximal processes) and between (exosystem influences) the two microsystems contribute to the attributes at the A level.

While the attributes at the B level are expected to explain change in children's academic development (and were the focus for the 2000-2001 project), it is acknowledged that other variables can also influence children's academic development. Relevant variables include culture, SES, other peers (not in class), and school level variables. These are considered to be the suprasystem. 
Figure 3.3: Perceptual stance \#1

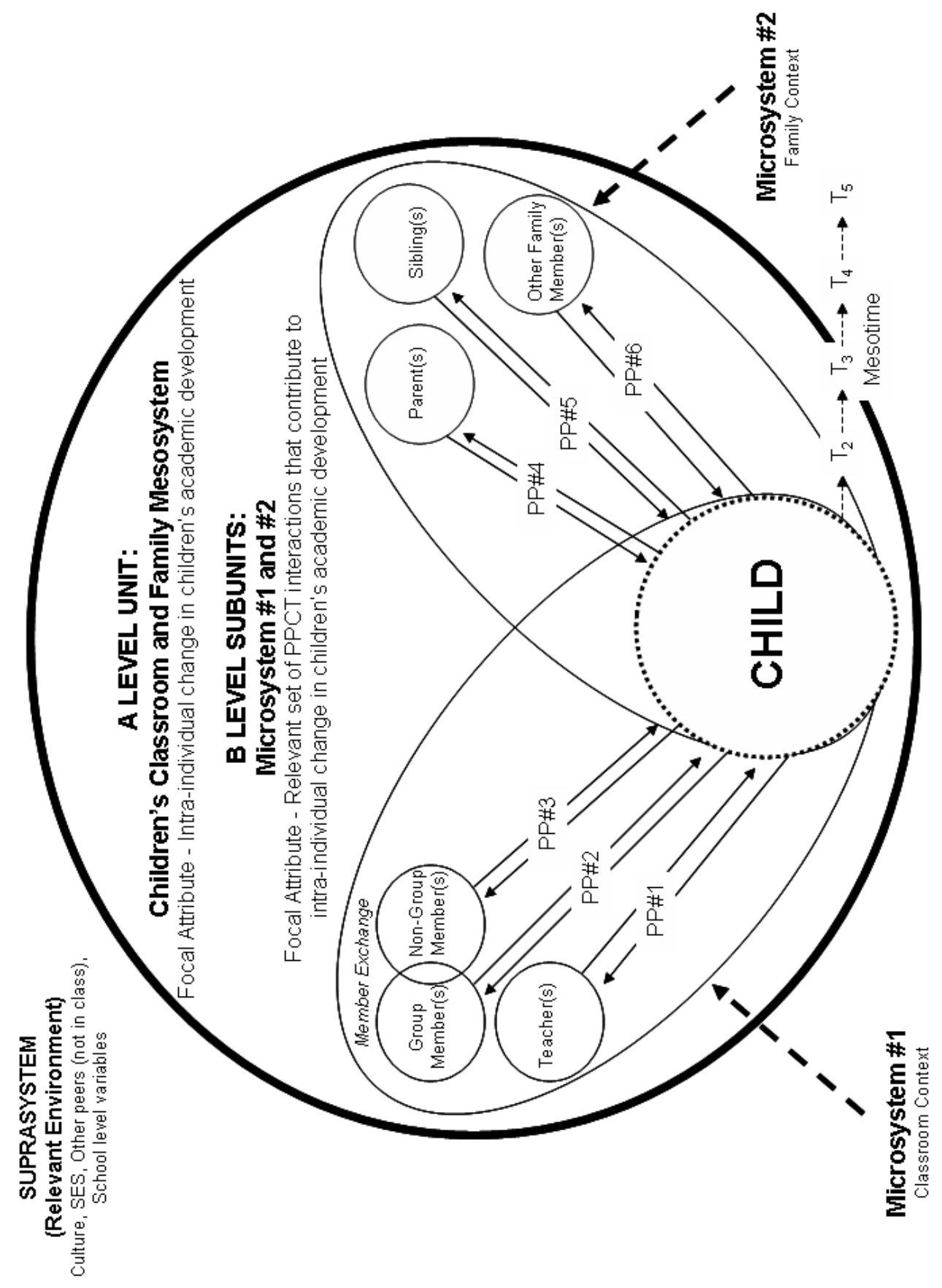




\section{Perceptual Stance \#2}

For this perceptual stance the focus is shifted to the family context, hence the A Level becomes the family mesosystem and the B level subunits are the three key microsystems in this context. At this perceptual stance, the focus is first placed on the A level attribute of structure versus chaos in the family environment (see perceptual stance \#2a in Figure 3.4), a contextual dimension that describes the extent to which the context is consistent and contingent (Skinner, Johnson, \& Snyder, 2005; Skinner \& Wellborn, 1994; 1997). Next the focus is placed on the A level attribute of intra-individual change in children's academic development (see perceptual stance \#2b in Figure 3.5). In both foci, the characteristics of the child, characteristics of his/her social partners in each microsystem, as well as the relevant set of PPCT interactions within and between the three microsystems are assumed to contribute to the attribute at the A level. Nevertheless, other factors can also play a role such as influences outside of the family context (e.g., peers within the classroom, school level variables), exosystem influences [e.g., interactions of the child's siblings or parents with others outside of the family], and macrosystem influences such as SES and culture. These other factors are considered to be the suprasystem. 
Figure 3.4: Perceptual stance \#2a

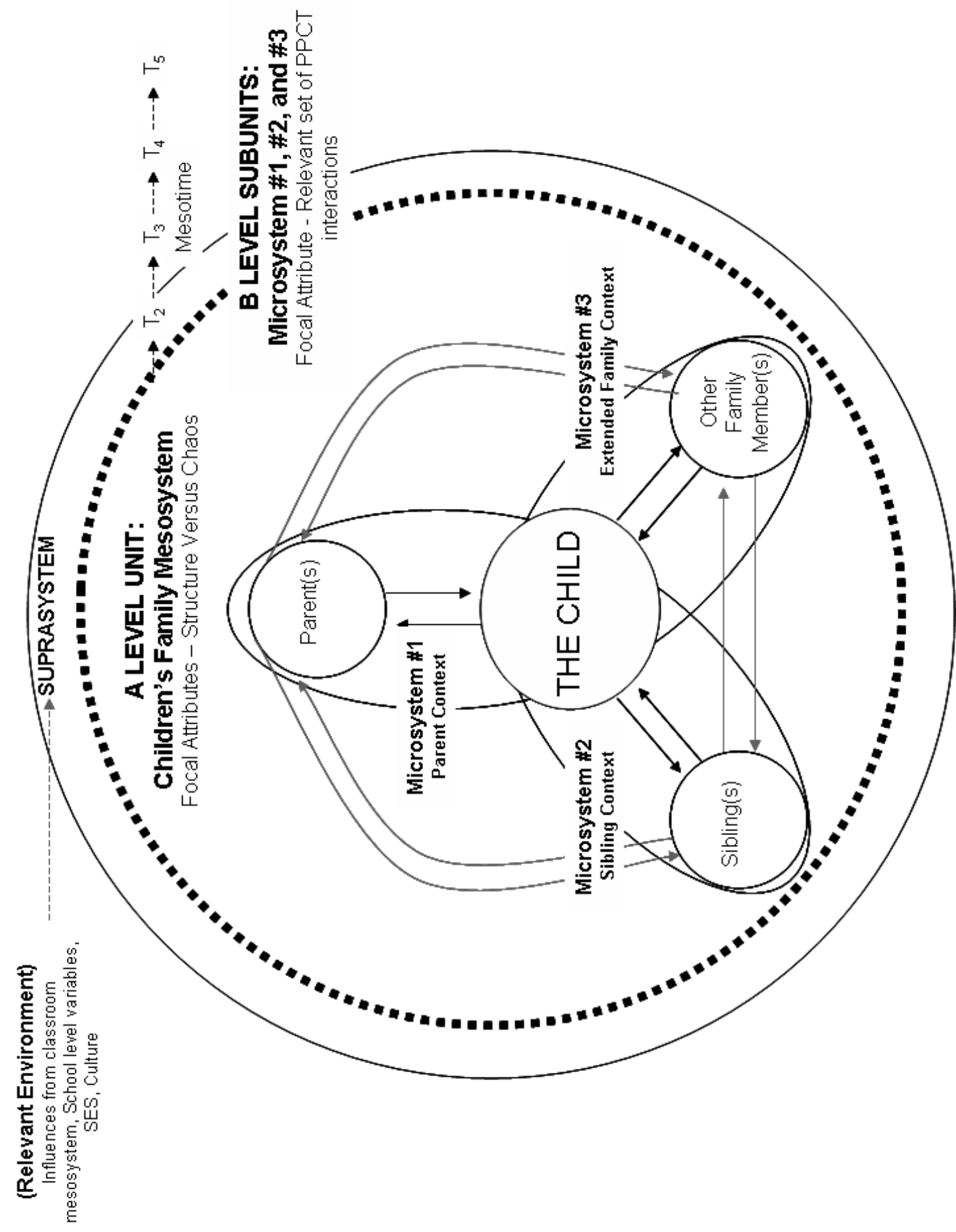


Figure 3.5: Perceptual stance \#2b

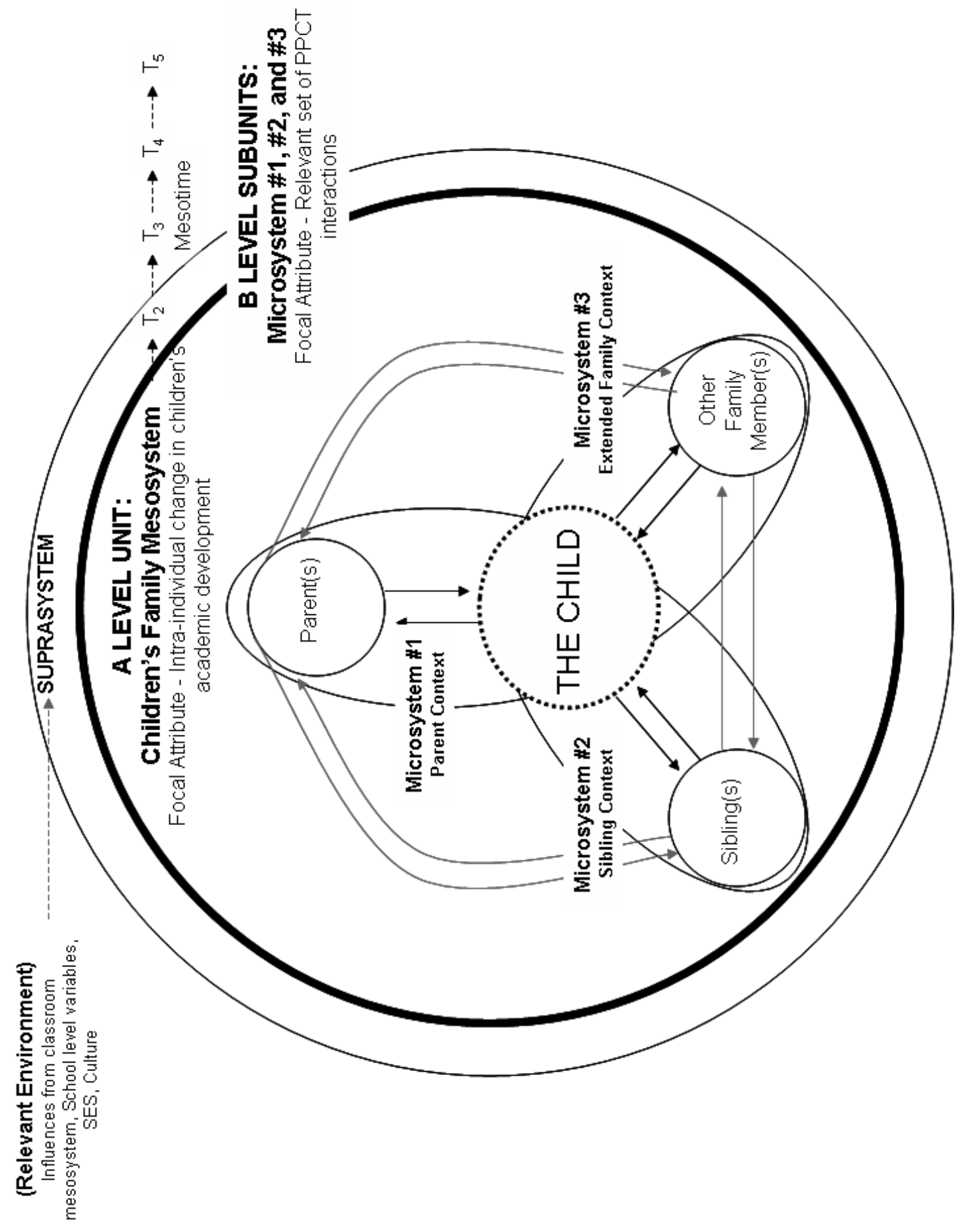




\section{Perceptual Stance \#3}

Figure 3.6 shows perceptual stance \#3a-c. At this stance, each of the microsystems in the family context is considered to be an A Level unit and the attribute for each is the quality of the relationship between the child and the relevant social partner(s). The B level attribute is the proximal processes that occur within each microsystem and these proximal processes are assumed to contribute to the attribute at the A level. The suprasystem for all three microsystems is the other two family microsystems, School level variables, Classroom mesoystem, SES, and Culture.

Figure 3.6: Perceptual stance \#3a-c SUPRASYSTEM (Relevant Environment)
Other two family microsystems, School level variables, Classroom mesosystem, SES, Culture
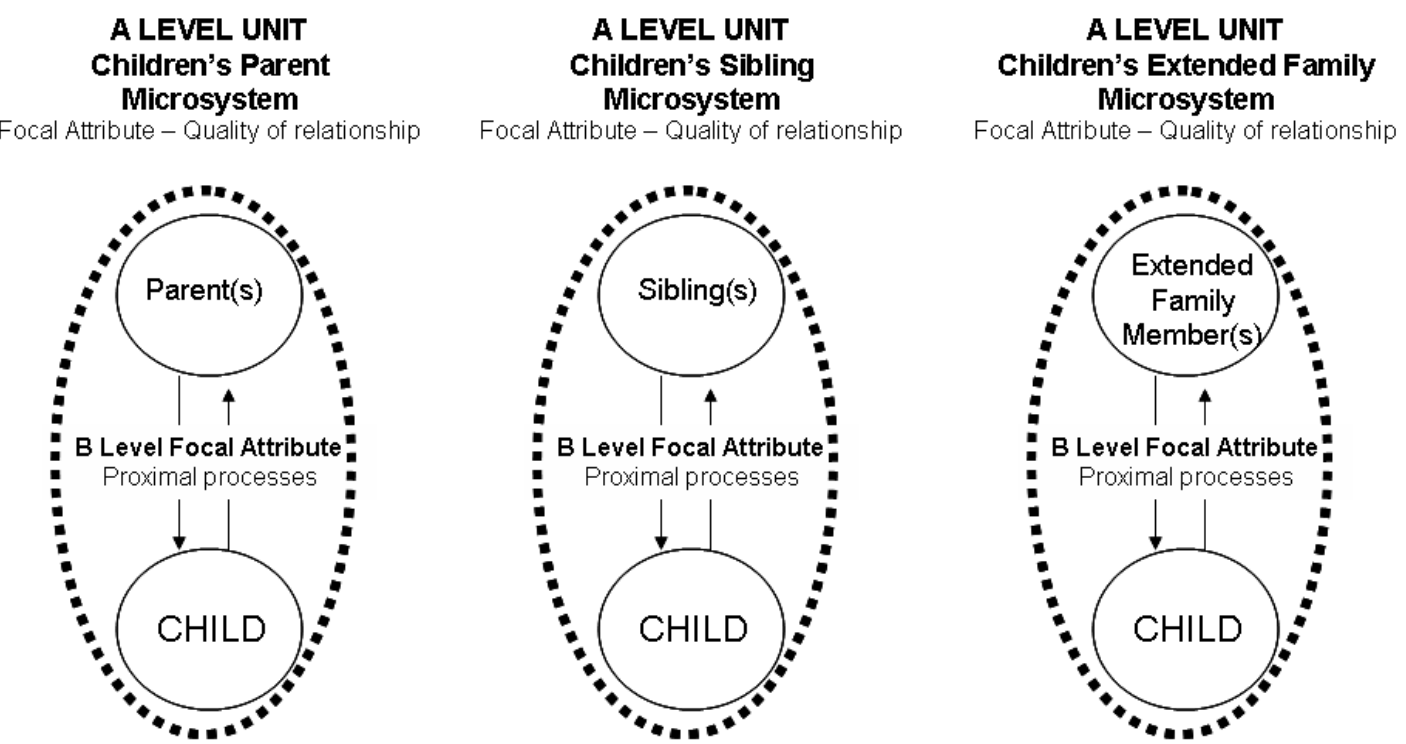

MESOSYSTEM: FAMILY CONTEXT 


\section{Perceptual Stance \#4}

For this perceptual stance the focus is shifted to the classroom context, hence the A Level becomes the classroom mesosystem and the B level subunits are the three key microsystems in this context. Similar to perceptual stance \#2, this stance has two different foci. First, attention is given to the A level attribute of structure versus chaos in the classroom (see perceptual stance \#4a in Figure 3.7), a contextual dimension that describes the extent to which the context is consistent and contingent (Skinner, Johnson, \& Snyder, 2005; Skinner \& Wellborn, 1994; 1997). Next the focus is placed on the A level attribute of intra-individual change in children's academic development (see perceptual stance \#4b in Figure 3.8). In both foci, the characteristics of the child, characteristics of the child's social partners in each microsystem, as well as the relevant set of PPCT interactions within and between the three microsystems are assumed to contribute to the attributes at the A level. Nevertheless, other factors can also play a role, such as influences outside of the classroom (e.g., from family, other peers not in class, and school level variables), exosystem influences [e.g., interactions of the child's classmates with his/her (the classmates') family members, siblings, and peers outside of the classroom], and macrosystem influences such as SES and culture. These other factors are considered to be the suprasystem. Note: Perceptual stance $3 b$ was the one used for my previous research studies (c.f., Sage, 1997, Sage \& Kindermann, 1999, Sage \& Kindermann, 2000). 
Figure 3.7: Perceptual stance \#4a

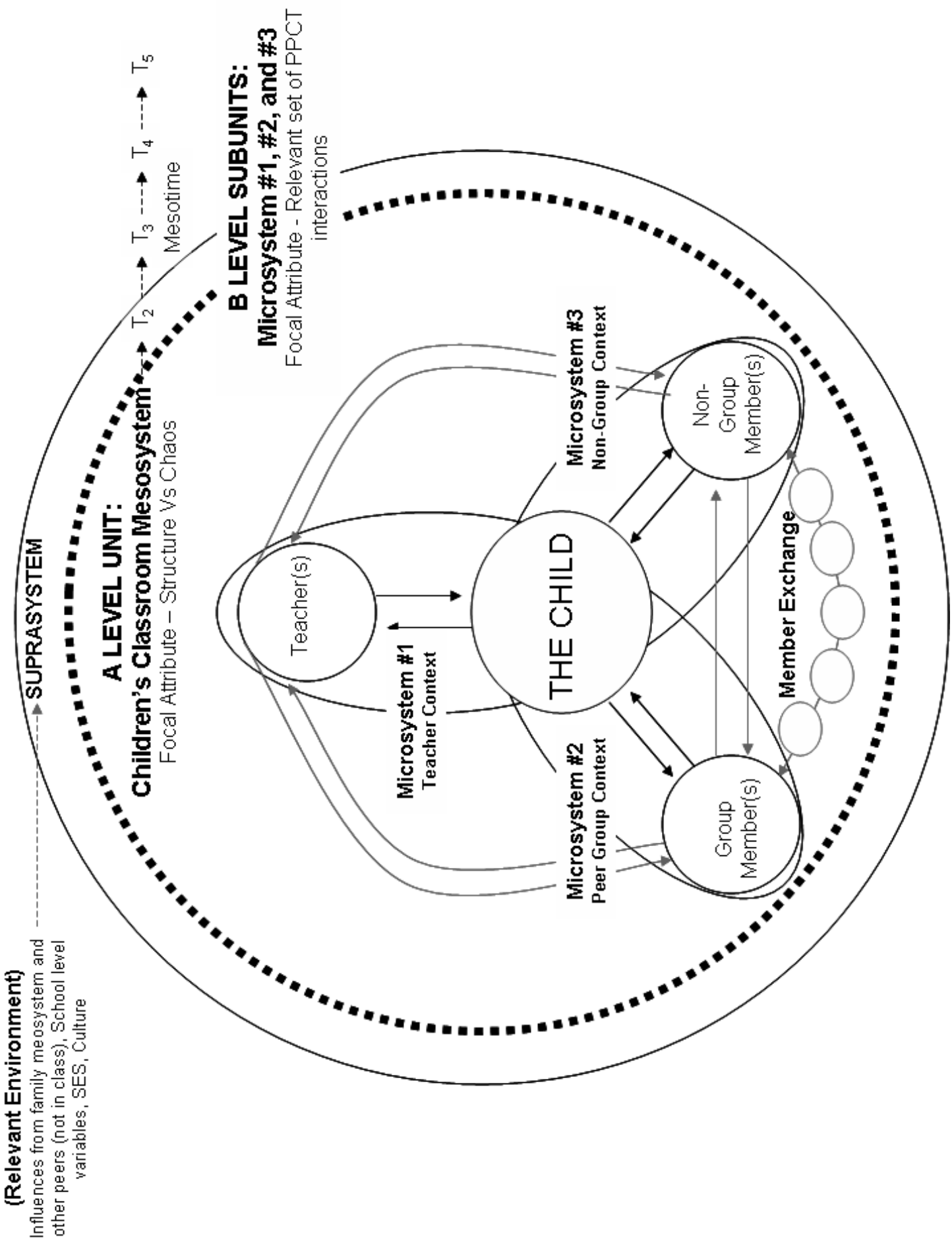


Figure 3.8: Perceptual stance \#4b

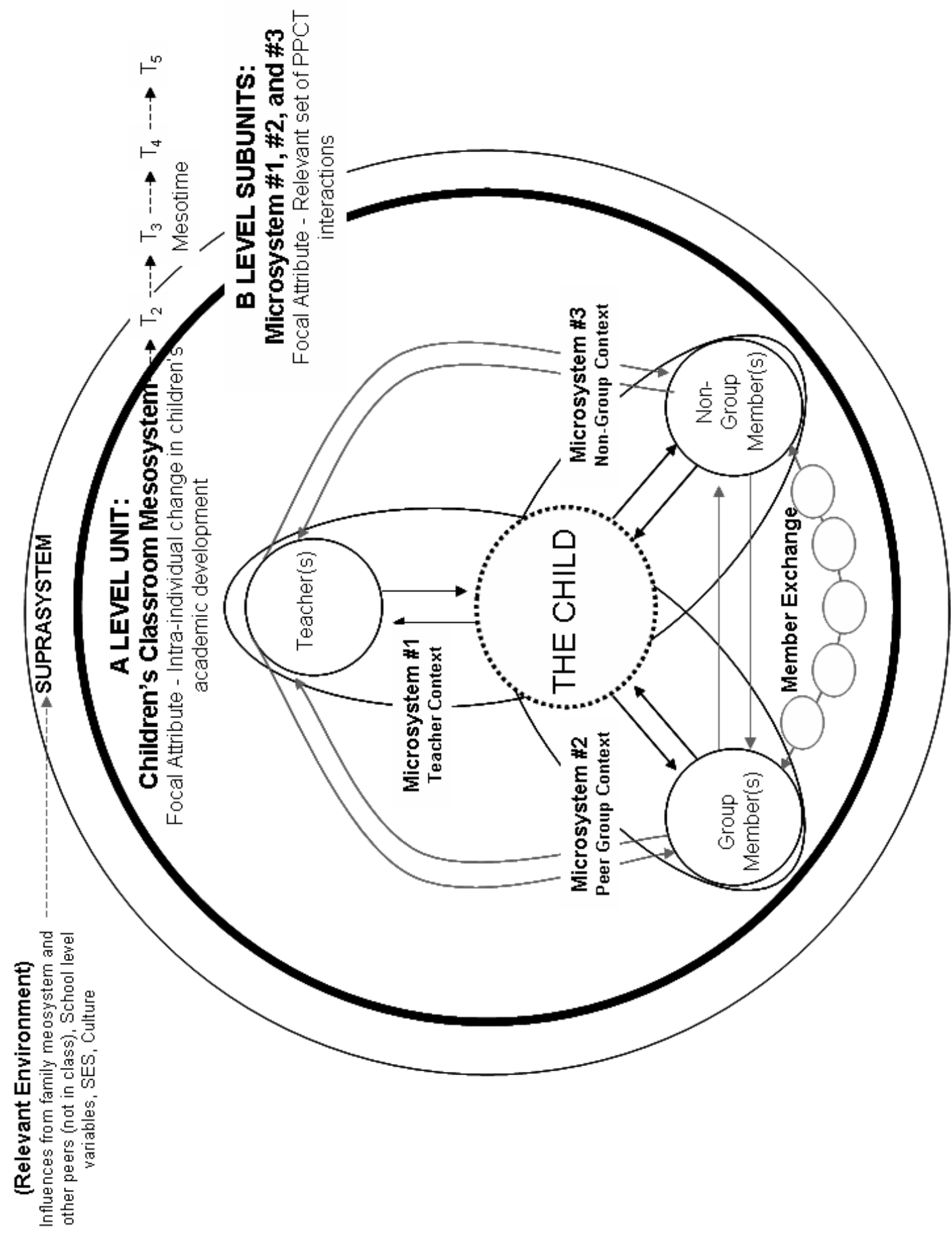




\section{Perceptual Stance \#5}

Figure 3.9 shows perceptual stance \#5a-c. At this stance, each of the microsystems in the classroom context is considered to be an A Level unit and the attribute for each is the quality of the relationship between the child and the relevant social partner(s). The B level attribute is the proximal processes that occur within each microsystem and these proximal processes are considered to contribute to the attribute at the A level. The suprasystem for all three microsystems is the other two classroom microsystems, School level variables, Family mesoystem, SES, and Culture.

Figure 3.9: Perceptual stance \#5a-c

SUPRASYSTEM (Relevant Environment)

Other two classroom microsystems, School level variables, Peers outside of class, Family mesosystem, SES, Culture
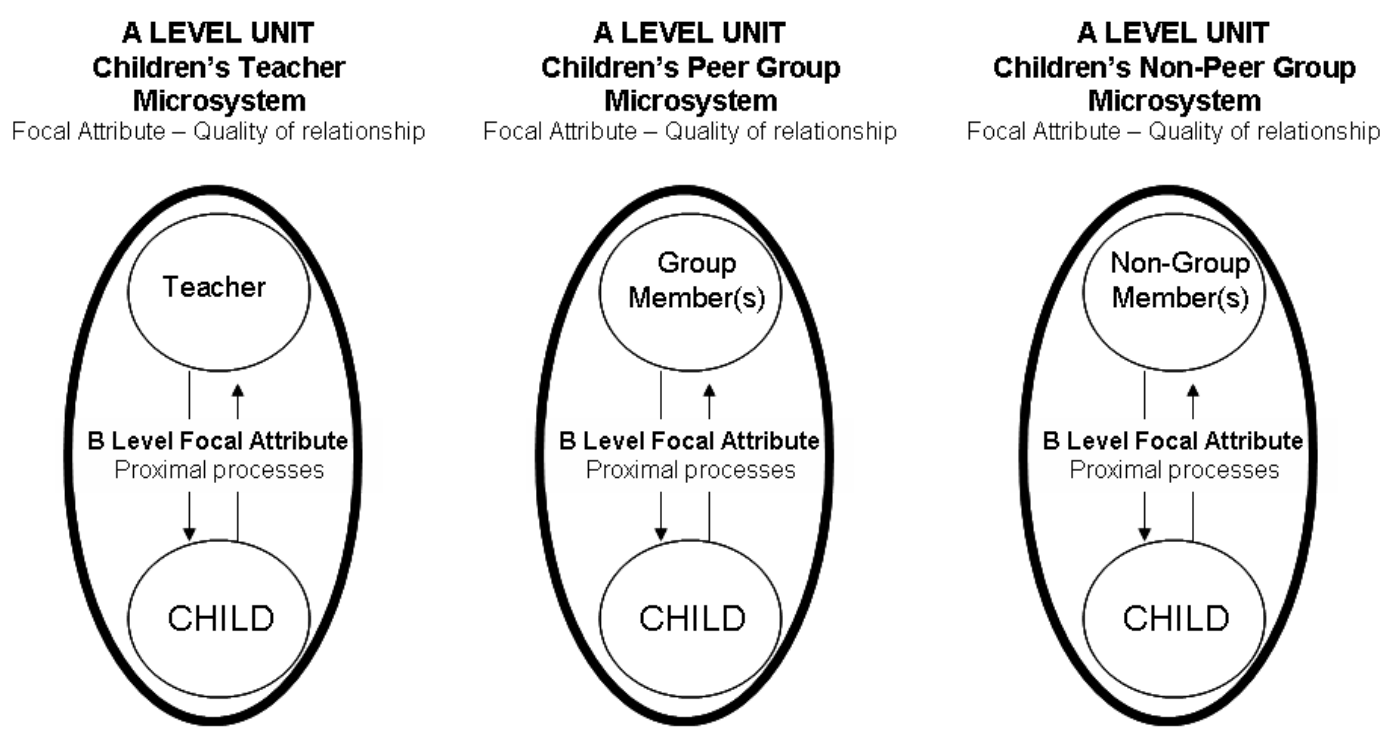

MESOSYSTEM: CLASSROOM CONTEXT 


\section{Perceptual Stance \#6}

This is the first of two perceptual stances used in this dissertation. For this perceptual stance, specific attention is given to the peer group context. In this stance, the A level unit is the peer group microsystem and the corresponding B level subunits are the specific group members (see Figure 3.10). Focal attributes at the A level are group structure and profile. Focal attributes at the B level are characteristics of the members that comprise the group. These characteristics are assumed to contribute to the attribute of the A Level unit.

\section{Perceptual Stance \#7}

At any given measurement point across the school year, a child's group member can become a non-group member and a non-group member can become a group member. To examine this exchange in membership, perceptual stance \#7 was created, which focuses on the combination of children's group and non-group microsystems as the A level unit (see Figure 3.10); this is the second of two perceptual stances for the dissertation. The attribute attended to at the A level is member exchange. The B level attributes are the proximal processes, namely selection and elimination, that occur between the child and his/her group versus non group members. It is from these interactions that a child's peer group emerges and changes across time. 
Figure 3.10: Perceptual stance \#6 and \#7
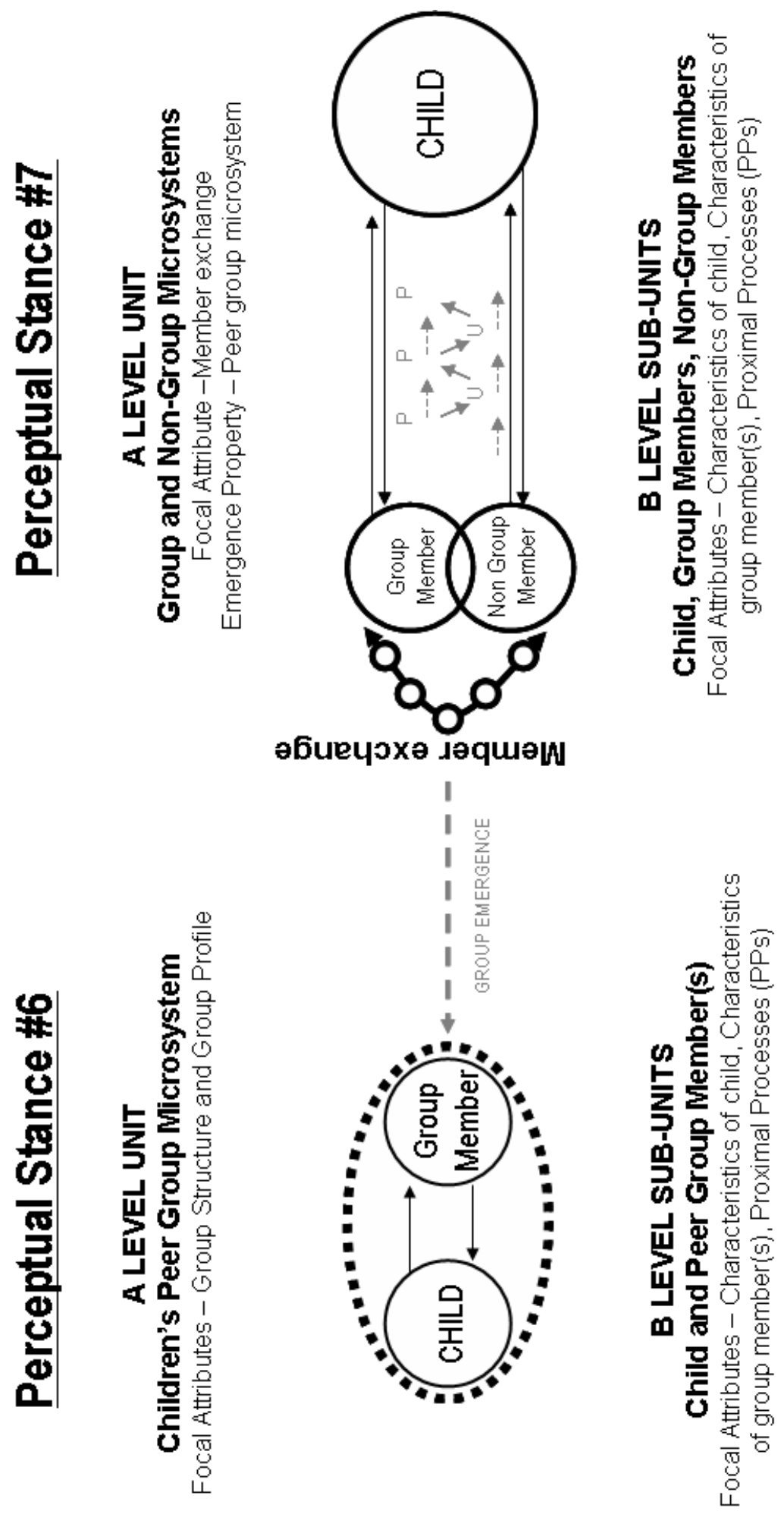


\section{CHAPTER SUMMARY}

Peer groups are considered to be complex open systems. That is, they ...."interact with smaller systems (i.e., the members) embedded within them and the larger systems (e.g., organizations) within which they are embedded. Groups have fuzzy boundaries that both distinguish them from and connect them to their members and embedded contexts"

(Arrow et al., 2000, p. 24). In order to fully understand groups one must attend to at least three different levels: individual members, the group as a system, and the larger environment in which the group is embedded. Furthermore, because systems are in the eye of the beholder (c.f., Lendaris, 1986), his/her own perceptual filters can impact how he/she views the system. Therefore, it is important to apply multiple perspectives when examining complex systems. While levels and multiple perspectives provide a basis for identifying a hierarchical structure of the system, they do not tell us much about the underlying processes. Because process appears to be the core of developmental change (c.f., Gottlieb et al., 1998), application of Bronfenbrenner \& Morris' (1998) Biological Ecological Model of Development seems plausible for examining peer group processes in the classroom.

The current study is part of a larger project conducted during the academic year of 2000-2001. The goal of the 2000-2001 project was to examine the multiple influences on children's academic development with specific attention given to whether peer groups are important in addition to parents and teachers. The 2000-2001 project incorporated Bronfenbrenner \& Morris' (1998) model as well as Lendaris' (1986) notions of levels and multiple perspectives whereby a hierarchical model was identified that specified 
seven perceptual stances. For the dissertation, only two of the perceptual stances were used. First the peer group context was the focal unit and the specific attributes attended to were structure and composition of the group. In the second stance, the interactions between children and their peers in the classroom became the focal unit. The specific attribute attended to was member exchange which was assumed to have occurred as a result of selection and elimination processes. It is from these interactions that the peer group context emerges. 


\section{CHAPTER 4}

\section{METHOD AND DESIGN}

As noted in Chapter 3, this study is part of a larger study conducted by the Social Networks Research Group (SONET) during the 2001-2002 academic year (referred to herein as the $2000-01$ project). Those data were collected to provide a replication and extension of an earlier study conducted by SONET during the 1995-1997 academic years (referred to herein as the 1995-97 project; see Sage, 1997; Sage \& Kindermann, 1999; Sage \& Kindermann, 2000). The goal of the $2000-01$ project was to examine the multiple influences on children's academic development; specifically addressing whether peer groups were important in addition to parents and teachers. Only a small subset of the data collected for the 2000-2001 project was used for the dissertation. Only those methods pertinent to the dissertation research are described in detail in this chapter.

\section{RESEARCH SETTING}

Observation, interview, and questionnaire data were collected from students and teachers at multiple measurement points across the school year in four $4^{\text {th }} / 5^{\text {th }}$ grade (mixed level) classrooms at a suburban elementary school outside the Portland, Oregon metropolitan area. The school is located in a relatively affluent area in the suburbs and contains primarily Caucasian children.

Data were also collected in the family homes at two measurement points: Fall and Spring. Targeted were the parents of each participating student as well as other family members who were knowledgeable of the student's academic activities both within and 
outside of school (e.g., older siblings, aunts, uncles, grandparents). Interview and questionnaire data were collected from family members of about half of the participating students. Note: these data are not of interest for the current document but are nonetheless mentioned here briefly as they were collected as part of the $2000-01$ project. For more information about these data, refer to Kindermann \& Newton-Curtis (2003), NewtonCurtis (2006), and Newton-Curtis \& Kindermann (2002).

\section{PARTICPANTS AND INFORMED CONSENT}

\section{Recruiting Classroom Participants}

Contact was maintained with the teacher and principal from the 1995-97 project. Between the 1995-97 and 2000-01 projects, both had re-located to a different school. Nonetheless, both had agreed to allow SONET to collect data during the 2000-2001 school year at their current school.

The classrooms at this school were located in specific wings of the building (referred to as pods). Each pod contained three to four classrooms that face inward toward a common area containing computers for students to use and areas where they could interact with each other. Some of the classrooms were separated only by a sliding partition which could be closed when independent classroom activities were conducted. Most of the time however, the partitions remained partially open. Although students were assigned to one specific homeroom teacher, they switched classrooms throughout the day to be taught by the other teachers within the pod. 
Because of the overlapping of teaching responsibilities and the opportunities for interaction among all students within a pod, all the classes located in the entire wing in which the teacher from the preliminary study taught were targeted for this study. This pod included four classrooms of mixed-grade $\left(4^{\text {th }}\right.$ and $\left.5^{\text {th }}\right)$ level students. This pod was suitable for replication as the age of the children remained similar to the SONET's previous studies. Students' participation was dependent on parental permission and their own written consent.

\section{Informed Consent}

Prior to the beginning of the school year, contact was made with each of the four classroom teachers. The study was verbally explained to them and any questions were answered. An information letter and consent form was given to each teacher to fill out. The information letter explained that data would be collected from the students in the classroom and what the data collection entailed. Each teacher was assured that any information obtained would be kept strictly confidential and that reconsideration and termination of participation was an option at any time.

During the first week of school a researcher went to each classroom and talked to the students about the study. A description of the events of the project was given as well as an assurance that participation (or lack thereof) would in no way affect the student's grades or status in school. An information letter detailing the events of the study and a parental consent form was given to the students to take home for their parents to review, fill out, and return. The parents were asked to indicate whether or not they gave permission for their child to participate. 
Consent forms not returned were regarded as though the parents had not consented to their child's participation. A reminder was sent out two weeks later to those parents from whom no consent form was returned. Those students from whom parental consent was obtained were then asked for their own written consent.

\section{Participants}

Across the entire school year, there were 112 total students (62 male; 50 female) in the four classrooms and four teachers (1 male, 3 female $)^{6}$. Of the total number of students, 94 participated (51 male, 43 female) and 18 did not for an overall participation rate of $84 \%$. Twelve of the non-participants were a result of consent forms not being returned by the parents, three were a result of parents indicating non-consent for their child, and two had received parental consent but did not give their own consent.

The year began with 109 students (60 male; 49 female). From these students 93 (50 male, 43 female) received parental permission to participate and also gave their own consent to participate. Three students moved out of district early in the study. One of these students was a participating student, the other two were non-participating students. While three students left, three new students arrived during the school year. Parental and self consent was received from only one of these new students. With the exchange of students across the year, there were 109 students in the Spring with 93 of them as participants (51 male, 42 female).

Aside from the one participating student who moved, no other student completely dropped out of the study. Nonetheless, there were times participating children were either

\footnotetext{
${ }^{6}$ The male teacher was the one who also participated in the 1995-1997 study.
} 
absent or chose to opt out of the self-report measures. Opting out of the self-report measures seemed to be a popular choice in one classroom in particular where two initially non-participating children were vocal about their desire not to participate. By the second measurement point, there were a couple of originally participating students who chose to selectively opt out of one or more of the measures and by the end of the year, this group of children choosing to opt out grew from a small group of about four children to a larger group of about eight children in one classroom. The lack of data on some of these measures can pose limitations to the study which are discussed in the limitations section in Chapter 7.

\section{MEASURES AND DESIGN}

Table 4.1 provides an overview of the measures used and the time intervals each were administered for the entire data collection. Of particular interest for the current study are those measures that tap children's classroom engagement, peer networks, and ideal peer groups (obtained in Nov, Dec, Jan, Feb, and Apr; referred to hereafter as $\mathrm{T}_{1}-\mathrm{Nov}, \mathrm{T}_{2}$-Dec, $\mathrm{T}_{3}$-Jan, $\mathrm{T}_{4}-\mathrm{Feb}$, and $\mathrm{T}_{5}$-Apr). Measures used to assess these variables are discussed in detail in the following sections. 
Table 4.1

Measures for the 2000-2001 Project Conducted by the Social Network Research Group (SONET) During the 2000-2001 academic year

\section{CLASSROOM CONTEXT}

$\frac{\text { CHILD LEVEL VARIABLES }}{\text { Student Engagement in Class }}$

Teacher report Self report

Nov $\frac{4}{\text { MEASUREMENT POINT }}$

(Self-Report) Relatedness

to Parents

to Teachers

to Groups of Friends

To Best Friend

$\begin{array}{lllll}X & X & X & X\end{array}$

Peer Affiliations

Peer Networks

Network Names

Permeability of Networks

Groups of friends

Ideal Work Groups

Ideal Play Groups

$\begin{array}{lllll}\text { X } & \text { X } & \text { X } & \text { X } & \text { X } \\ \text { X } & \text { X } & \text { X } & \text { X } & \text { X } \\ \text { X } & \text { X } & \text { X } & \text { X } & \text { X } \\ \text { X } & \text { X } & \text { X } & \text { X } & \text { X } \\ \text { X } & \text { X } & \text { X } & \text { X } & \text { X }\end{array}$

Classroom Interactions

$\begin{array}{llll}X & X & X & X \\ X & X & X & X \\ X & X & X & X \\ X & X & X & X\end{array}$
On and Off task Behaviors
llowing classmates' on and off task behaviors

Demographics

Parental report on a variety of demographic

variables

$\mathrm{X}$

TEACHER LEVEL VARIABLES

Teacher Engagement in Class

Self-Report

Observational Rating

$$
\begin{aligned}
& X \\
& X
\end{aligned}
$$


Table 4.1 (Cont)

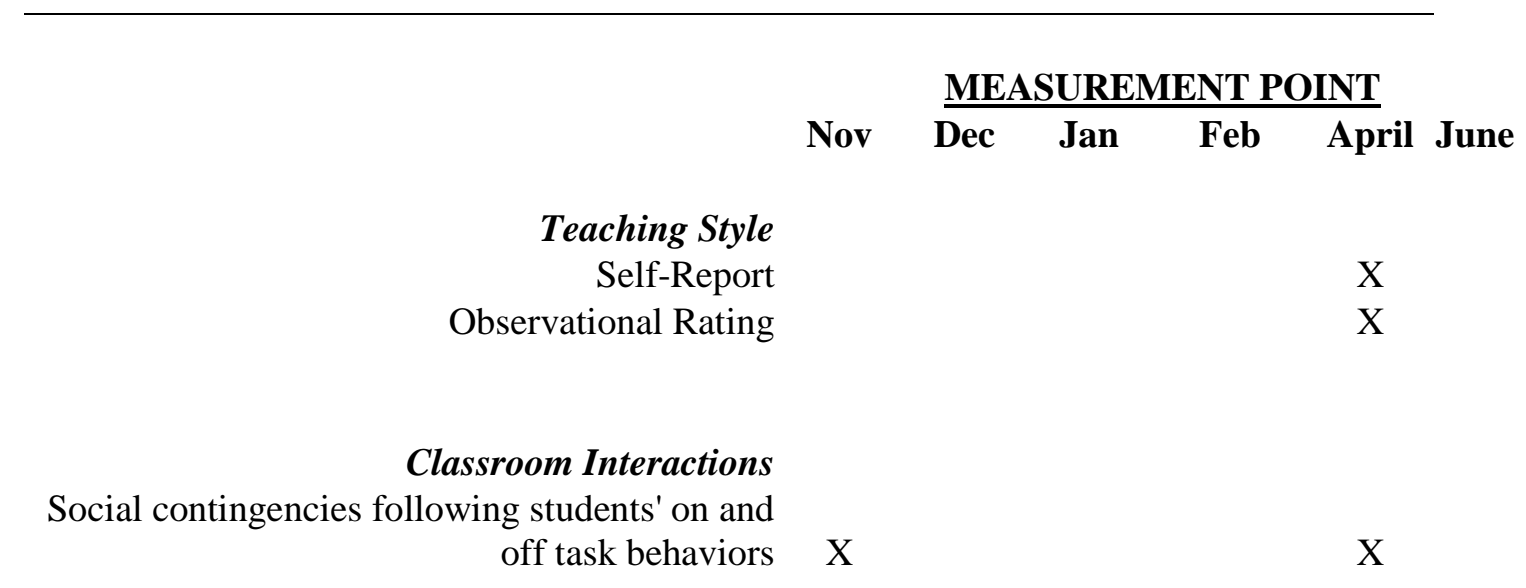

\section{CLASSROOM LEVEL VARIABLES}

Structure Versus Chaos in the Classroom Teacher Report Observational Rating

$\mathrm{X}$

$\mathrm{X}$

\section{FAMILY CONTEXT}

\section{PARENTAL LEVEL MEASURES}

Parental Engagement When Helping with

Homework

Self-report X X

\section{Parenting Style}

Self-report

Parental Involvement With, Reinforcement of, and Modeling of Academic Activities

Self-report $\mathrm{X}$

HOME LEVEL VARIABLES

Structure Versus Chaos in the Home

Self-report X X X

Observational Rating $\quad \mathrm{X}$ 


\section{Children's Classroom Engagement}

Wellborn's (1991) teacher and student-reports of classroom engagement were used to assess children's engagement versus disaffection in the classroom. This construct was used because it is central to most current theories of motivation and it is an observable manifestation of motivation and hence salient to social partners (Skinner, Kindermann, Connell, and Wellborn, 2007). Teacher reports of each student's engagement were administered two times across the school year in $\mathrm{T}_{1}$-Nov and $\mathrm{T}_{5}$-Apr. Student-reports of their own engagement were administered four times across the school year in $T_{2}$-Dec, $T_{3}$ Jan, $\mathrm{T}_{4}-\mathrm{Feb}$ and $\mathrm{T}_{5}$-Apr (see Appendix A for the teacher and self-reports of engagement). Self-reports of perceived feelings of relatedness with parents, teachers, peer groups, and best friends were administered along with the engagement questionnaire given to the students; the data from the relatedness measures are not of interest to the current study and therefore not discussed here.

The teacher report consisted of 28 items and asked each teacher to indicate his/her perceptions of each participating student in his/her homeroom class on three scales: behavioral engagement, emotional engagement, and motivational orientation. Behavioral engagement items tap each child's efforts, persistence, and attention during classroom learning activities (e.g., In my class, this child pays attention). Emotional engagement items assess emotional reactions during the classroom, such as happiness, interest, anxiety, and anger (e.g., In my class, this student appears anxious). Questions pertaining to motivational orientation tap into the child's preference for challenge, independent mastery, judgment, and the child's flexibility in the classroom (e.g., This student depends 
on me to make all decisions regarding his/her schoolwork). Note that only the behavioral and emotional engagement subscales are used for the dissertation research.

The teachers were asked to rate each participating student on a 4-point scale from "Very characteristic of this child" to "Not at all characteristic of this child." In the original sample from which the scales were developed, Cronbach's alpha coefficient showed high internal consistencies for behavior, emotion, and orientation $(\alpha=.95, .75$, .94 , respectively; Wellborn \& Connell, 1991). Ratings were found to be stable across the school year for a sample of 144 third through fifth grade students $(r=.73, \underline{p}<.001$; Skinner \& Belmont, 1993).

The student report consisted of thirteen items and assessed the child's behavioral and emotional engagement in school (e.g., When I'm in class, I just act like I'm working.) In previous research, the behavioral/emotional engagement scales showed high internal consistency $(\alpha=.87)$ and were relatively stable across the school year $(\mathrm{r}=.72, \underline{\mathrm{p}}<.001, \underline{\mathrm{n}}=144 ;$ Skinner \& Belmont, 1993).

The students were asked to circle the answer that was most true for them for each statement, on a scale from "Very true" to "Not true at all". Three additional questions were added that the researcher read out loud to the participants prior to their completing the questionnaire. These questions were regarded as practice items only and were not used in the analysis. The practice items were structured to ensure that the participants understood the scale. The first two questions, "I am in fifth grade" and "I am in third grade", were answered by everyone in the two extremes. The third question, "I like icecream", resulted in various answers on the scale. The researcher explained to the 
students that the remaining statements would be similar to the third statement, that is, there would be no right or wrong answer.

The questionnaire was administered to the class as a whole. Those students for whom parental or individual consent was not obtained were also allowed to fill out the questionnaire; however, they were asked to not turn it in to the researcher. This eliminated the need for the teacher to assign another task to non participants and also helped to reduce any potential feelings of being left out for those not participating.

\section{Children's Peer Affiliations}

Four different types of peer affiliations were obtained: peer networks, ideal work groups, ideal play groups, and friendship groups. All four types of affiliations were measured in either an interview or questionnaire format five times across the school year within one week of the administration of the self/teacher reports of engagement (i.e., in $\mathrm{T}_{1}-\mathrm{Nov}, \mathrm{T}_{2^{-}}$ Dec, $\mathrm{T}_{3}-\mathrm{Jan}, \mathrm{T}_{4}-\mathrm{Feb}$, and $\left.\mathrm{T}_{5}-\mathrm{Apr}\right)$. The interview format of this procedure was implemented for the first and last measurement points; a questionnaire format was used for all other measurement points (see Appendix B for both the interview and questionnaire format of the peer affiliations measure). Note that information on children's friendships was not used for the dissertation.

Part one of the peer affiliations measure contained Cairn's and colleague's (1995) $\underline{\text { SCM }}$ procedure which is used to gather reports of "who hangs out with whom" in the classroom (i.e., peer networks). This method is based on the assumption that a child's membership in peer networks can be observed with regard to time spent together with 
members and their physical proximity. Hence it is expected that others in the setting can reliably identify these groups because children's affiliations are public knowledge. Thus students were used as expert observers and the accounts of many student reporters should converge on the setting's natural structure.

For the interviews, participants were individually taken outside of the classroom into another room by the interviewer. The interviewer introduced him/herself and then briefly summarized the entire study, informing each participant that the study's focus was on how students got along together in school. After being given the opportunity to ask any questions, the participant was asked to fill out the student consent form. The interview began with the inquiry: "There are students in the $4^{\text {th }} / 5^{\text {th }}$ grade pod that hang out together all the time, is that right? They may be just working or just do a lot of things together. I would like you to think about the groups of students in the pod who hang out together. Starting with any group, who hangs out together'?

This procedure requires the informants to nominate, from free-recall (no lists or pictures), who they believe hang out together. Students were encouraged to name an unlimited number of groups (including at least two people) and were informed that they could nominate an individual as belonging to more than one group. Depending on the responses to the initial question, additional probes were used. For example, if the participant named only groups of boys, he or she was asked if there were any groups of girls. If individuals did not name themselves as being a part of a group, they were asked whether they had a group of their own. 
At the end of Part I, the student was asked about people who did not hang out in a group, but preferred to be (or were) alone. Once each list of nominations for each group was completed, the following open-ended questions pertaining to the group were asked: “Does this group have any name?", "What activities does this group do together", and "If you wanted to join this group how easy or hard would it be to join?"”

Part II and III of the peer affiliations measure contained questions about children's associative preferences (i.e., ideal groups). For this part of the interview, students were asked to nominate those children in the pod who they would like to hang out with (this is assumed to denote their ideal group). Because ideal groups could differ based on the reason for the group (e.g., academic functions versus social functions), students were asked to list both their ideal work and ideal play group.

First, students were asked about their ideal work group. They were asked to think about all the children in the pod and nominate those classmates with whom they would like to do a school project. They were informed that this group could include classmates they were already doing a project with as well as those they have never done a school project with but would like to. Next they were asked to list the names of children with whom they would like to hang out (this is assumed to denote their ideal play groups). Examples such as hanging out at lunch, recess, or music class were given.

The fourth part of the interview asked students about their friendship connections and characteristics of the individual friends. First the participants were asked to think about all of their close friendships and list them. They were then asked to identify

\footnotetext{
${ }^{7}$ See Cairns, Gariépy, \& Kindermann (1990) and Kindermann (1996) for thorough discussions of this method.
} 
whether each friend is a friend in the pod, in the school, or outside of school. Next they were asked to indicate whether each friend is a very good friend, good friend, or sort-of good friend. Finally, the student was asked to nominate his or her very best friend. If the name of the friend was not a child in the $4^{\text {th }} / 5^{\text {th }}$ grade pod, they were asked about their best friend in the $4^{\text {th }} / 5^{\text {th }}$ grade pod.

The questionnaire format of the interview procedure was administered to the class as a whole. The instructions were verbally explained to the students and then they were allowed to complete the questions themselves. For the peer network identification part, the form provided space for up to 12 groups and 10 members in each group. Space was provided to allow up to 12 nominations for ideal work, ideal play, and friendship groups. Students were told that they didn't have to fill all the spaces if they did not want. They were also told that if they needed more space for additional groups or members that additional sheets would be provided to them upon request.

\section{CHAPTER SUMMARY}

The dissertation study is part of a larger project conducted by the Social Networks Research Group (SONET) at Portland State University during the 2000-2001 academic year. Observational, interview, and questionnaire data were collected at five different measurement points across the school year in four $4^{\text {th }}$ and $5^{\text {th }}$ multi-grade classrooms. From a total of 112 students, 93 participated. Of interest for the dissertation are the self and teacher reports of students' classroom engagement, peer network nominations, and self-reports of ideal work and play groups at the multiple measurement points. 


\section{CHAPTER 5}

\section{HYPOTHESES}

The general research question being addressed in this dissertation is, why do those children who are motivationally "rich" get "richer" across time whereas those who are motivationally “poor” get "poorer”? In my previous research studies, I have emphasized children's natural peer groups (peer networks) with specific focus on socialization influences from the peer network context that contribute to intra-individual change in motivation across the school year (c.f., Sage, 1997, Sage \& Kindermann, 1999, Sage \& Kindermann, 2000). For this dissertation, the emphasis remains on children's peer networks and intra-individual change in motivation. However, the focus is not what the peer group does to the child but rather what the child does to his/her peer group.

Two different perspectives from the systems framework presented in chapter 3 are used to examine influences from the individual to his/her peer group. First, the focus is on the changing nature of a child's peer network context. Attention is given specifically to the change in structure and composition of the network. It is assumed that these attributes emerge as a result of the characteristics of each network member and the interactions or proximal processes between them (see perceptual stance \#6). Next the focus is shifted to the specific interaction patterns (or proximal processes) by which the peer network context emerges; namely selection and elimination processes (see perceptual stance \#7).

For this study, change is examined across a school year. Typically, researchers examining change within a school year focus on change between the beginning (Fall) and 
end of the year (Spring). For the current study, it was argued that a better understanding of change across a year could be obtained by obtaining measurements in smaller intervals. Hence, data were collected at five different measurement points across the school year on children's own engagement, peer group contexts, and ideal groups (referred to here also as associative preferences). With the exception of Chan and Poulin (2007) who examined adolescent friendship groups, there is no research study to date that examines patterns of group change across a school year in small measurement intervals. Furthermore, this is the first study to date where information about children's associative preferences (ideal groups) has been obtained. Therefore direct expectations of what these data will tell us cannot be postulated. Nonetheless, expectations regarding general tendencies can be inferred. It should be noted that the expectations provided herein are mostly descriptive and exploratory in nature. These are assumed to provide the foundation necessary for higher order hypotheses regarding how children contribute to change in their peer group contexts. Because such higher order hypotheses cannot be generated without first having a rich description of the data, the focus of this dissertation is to provide descriptions of patterns of change across time as well as illustrate how a systems framework can be applied for studying peer group processes in the classroom. 


\section{CHANGE IN CHILDREN'S PEER NETWORKS ACROSS TIME}

For this set of hypotheses, the focus is on children's peer networks as determined by Cairns and colleague's (1985) SCM procedure (for more detailed description of this procedure see Chapter 2 under the section "Identifying the Peer Group" and Chapter 5 under the section "Children's Peer Affiliations"). The focal attributes to be examined are the structure and composition of children's networks. As described earlier, the structure refers to who comprises the peer group and the composition is the psychological characteristics of the group. For the current project, the structure of children's peer network is assumed to be a global property (see Kolowski \& Klein, 2000) and is therefore observable by any (or all) individuals in the classroom. Thus the use of Cairns and colleagues' (1985) social cognitive procedure was applicable.

While the structure of children's peer networks is assumed to be a global property, the composition of the network is, on the other hand, assumed to be a shared property, originating at the individual level. Using measures of the individual members' psychological characteristics, a group profile score can be calculated for each child, reflecting the unique aggregate peer context of that child at the time. Adjacent to Kozlowski and Klein's (2000) concept of bottom-up processes, a child's peer network composition is assumed to emerge as a result of the characteristics of the lower-level units (i.e., the individuals).

In contrast to traditional methods that identify classroom peer groups at two measurement points (at the beginning of the school year and at the end), in this 
dissertation peer networks were identified at multiple measurement points across the school year. The following research questions are posed:

1. How does the structure of the peer network change across the school year?

2. How does the composition of the peer network change across the school year? Note: Currently, there is no research study that identifies children's peer groups in intervals as small as one to two months apart. One noted exception is Chan and Poulin's (2007) study that examined the stability of adolescent friendship groups in five monthly assessments during the latter half of a school year. These authors used an entirely different method for identifying the group and focused merely on the stability of the group rather than the processes by which the group emerges and changes.

Because no study has yet to examine the processes by which children's natural groups emerge and change across an entire school year, empirical expectations cannot be derived with regard to member turnover or change in the groups' composition in such small intervals. As a result, the focus for the current study regarding network structure and composition at each of the smaller intervals is merely descriptive and no specific hypotheses are posited. Nonetheless, some assumptions can be made that the peer network system will orient toward robust equilibrium (c.f., Arrow, 1997); that is, move quickly toward a stable state and then maintain itself at this state.

Chan and Poulin's study gives some indication of this as they found that the stability of friendship groups did not change from month to month during the latter part of the school year. As discussed in Chapter 3, trajectories for robust equilibrium can show (a) random fluctuations of the variable at the onset of group interactions followed 
by a settling down to a steady state, (b) a steep increase at the onset of group interactions with a tapering off to a steady state, or (c) a cycle of extremely high and extremely low values on the target variable followed by a steady, sustained pace.

\section{Change in Structure of the Peer Network}

Structure refers to the number of members in the group and change in structure is measured via the turnover of membership across time. Previous data suggest that peer networks usually contain about 3-6 members (c.g., Kindermann, 1993; 2007, Sage \& Kindermann, 1999); a similar network size is expected at all measurement points across the school year. With regard to change in the network structure, we already know that the data show a 56\% turnover in membership between the Fall and Spring of the school year (c.f., Hillier et al., 2003). This is congruent with previous research suggesting approximately 50\% turnover in group membership in an academic year (c.f., Kindermann, 1993, Neckerman, 1996; Sage \& Kindermann, 1999). What we do not know is the change in membership at smaller intervals. This change in membership at smaller intervals is the focus of the dissertation regarding change in children's network structures across the school year.

\section{Change in Composition of the Peer Network}

Prior research suggests that on a 1-4 scale, peer networks on average tend to have high composition scores and these scores remain relatively stable across the school year (c.f., Kindermann, 1993, Sage \& Kindermann, 1999). While a similar expectation of relative stability between the first and last measurement point can be postulated, of more interest 
for the current study are the general patterns of change across the school year in smaller time intervals. It seems reasonable to assume that if there is stability in composition from the first part of the year to the last part of the year, that network composition is stable during the middle part of the year as well.

\section{PROXIMAL PROCESSES FROM WHICH THE PEER CONTEXT EMERGES}

For this set of research questions we shift our focus and examine the interaction patterns (proximal processes) between the child and his/her classmates. Specific attention is given to selection and elimination processes. The current data set does not include data on these actual processes per se. However, it is argued that comparisons of children's actual peer networks with their ideal groups (referred to here also as associative preferences) at each measurement point can provide indication of the potential for selection and elimination processes. For example (see Figure 5.1), if a child nominates a peer at $\mathrm{T}_{\mathrm{i}}$ for his/her ideal group but this peer is not observed to be part of his/her actual network at $T_{i}$, then this could indicate that the child may want to potentially "select" this peer as part of his/her group. In contrast, if at $\mathrm{T}_{\mathrm{i}}$ a peer is not nominated for the child's ideal group but is a part of this child's actual network, then this could indicate that the child may want to potentially "eliminate" this peer from his/her group. In order to examine these potential processes, the following research questions were posed:

3. Are there structural and compositional differences among peer networks, ideal work groups, and ideal play groups? 
4. Are children more similar in engagement to those classmates whom they would like to potentially "select" than those classmates whom they would like to potentially "eliminate"? If so, do the differences in homogeneity continue across a school year?

Figure 5.1: Example of potential "selection" and "elimination" processes JOY'S Peer Network at $T_{i}$ JOY'S Ideal Group $T_{i}$
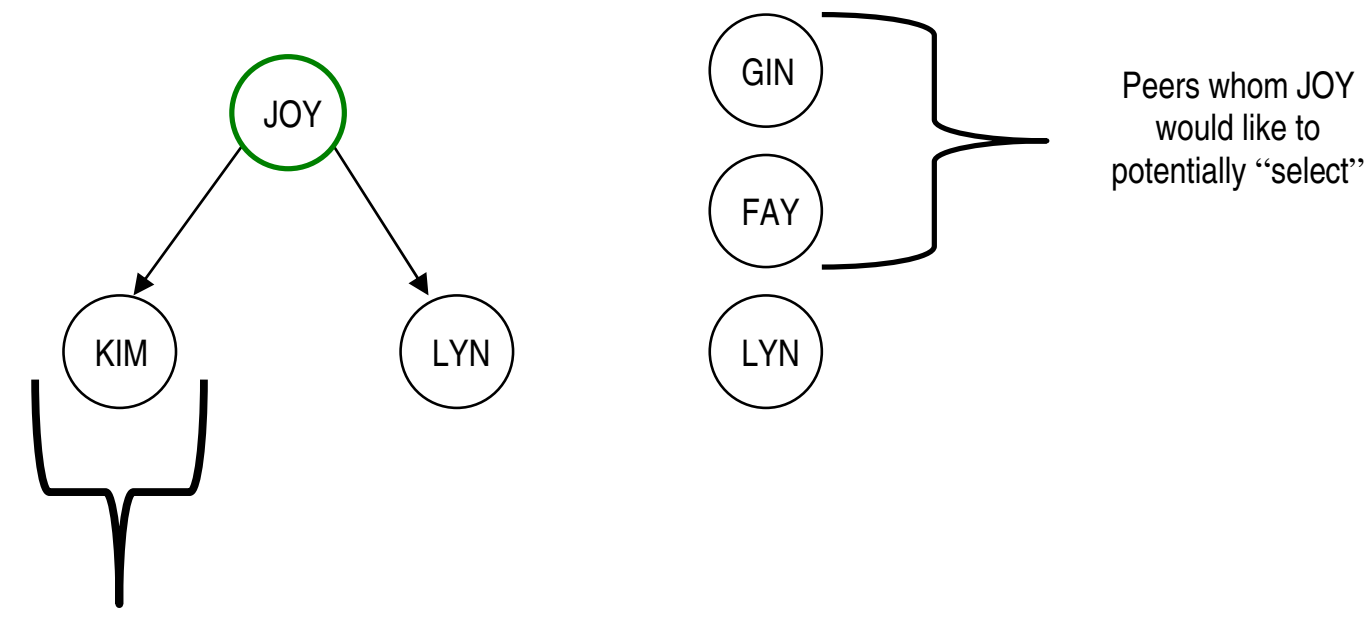

Peer whom JOY would like to potentially "eliminate"

\section{Differences in Structure and Composition Among Network, Ideal Work, and Ideal}

\section{Play Groups}

There are currently no data on reports of ideal work or ideal play groups. Therefore, empirical expectations regarding differences among these groups (compared to peer networks) cannot be posited. Analyses will focus on descriptions of the differences 
Hypotheses: Peer Network Emergence 86

among all three types of groups on structural as well as compositional attributes at all five measurement points.

\section{Similarity Between Classmates to be Potentially "Selected" Versus "Eliminated"}

Prior research suggests that children select others as peer group members who are similar to themselves in motivation (e.g., Kindermann, 1993, Ryan, 2001). Therefore, one could expect homogeneity in engagement with those peers whom the child indicates he/she would like to potentially "select". While some homogeneity can be expected with those peers whom the child indicates he/she would like to potentially "eliminate" (due to socialization effects within the group), it can be inferred that this homogeneity may be less than the homogeneity found with those peers the child would like to select. This is assumed to be the case at each measurement point. Nonetheless, there are no explicit expectations regarding the patterns of change from one measurement point to another across the school year. Note that whether comparisons are done with ideal work or ideal play groups separately or aggregated will depend on the outcomes from the comparisons of actual, ideal work, and ideal play groups.

\section{CHAPTER SUMMARY}

The general research question being addressed is, why do those children who are motivationally "rich" get "richer" whereas those who are motivationally "poor" get "poorer" across time? In my previous research studies, the focus has been on intraindividual change in development with emphasis placed on the socialization influences 
from peer groups to the individual. For the current study, emphasis remained on peer groups and intra-individual change. However, instead of focusing on what groups do to the child, the focus was on what the child does to his/her group(s).

Two different perspectives from a hierarchical systems framework (presented in chapter 3) were used to derive expectations regarding change in children's peer groups across a school year and the proximal processes by which these groups emerge. The research questions that were explored were:

1. How does the structure of the peer network change across time?

2. How does the composition of the peer network change across time?

3. Are there structural and compositional differences between peer networks, ideal work groups, and ideal play groups?

4. Are children more similar in engagement to those classmates whom they would like to potentially "select" than those classmates whom they would like to potentially "eliminate"?

Because this study is among the first to date to examine group change across a school year in intervals as small as one to two months apart, expectations are more tentative and exploratory. Hence, the goal is to provide descriptions of how individuals influence patterns of group change across time as well as illustrate how a systems framework can be applied for studying peer group processes in the classroom. 
Analyses and Results: Peer Network Emergence

\section{CHAPTER 6}

\section{ANALYSES AND RESULTS}

This chapter provides the analyses that were conducted in order to examine the emergence of and changing nature of children's natural peer groups in the classroom (referred to as peer networks). Two of the seven perspectives from the hierarchical systems model presented in Chapter 3 were used to examine group processes within children's peer networks in the classroom (namely selection and elimination). In chapter 5, four research questions were presented. The first two focus on change in children's peer group networks across five measurement points in a single school year. The second two focus on the proximal processes from which the peer network emerges.

Prior to conducting the analyses to address the research questions, initial analyses were needed to determine children's engagement levels in the classroom, identify their peer group networks and associative preferences (also referred to as ideal groups), determine classmates to be potentially "selected" or "eliminated" for group membership, and compute the psychological characteristics (composition) of peer networks and ideal groups. These analyses are described and the results are presented in the first section called "Initial Analyses". This section is followed by a section called "Change in Peer Networks Across Time" which provides a description of the analyses and the results for the two research questions addressing change in the structure and composition of children's peer networks. The third section called "Proximal Process From Which the Peer Context Emerges" provides a description of the analyses and results for the final two 
research questions that propose to examine the selection and elimination processes in the classroom. A summary of the results concludes this chapter.

\section{INITIAL ANALYSES}

\section{Children's Engagement Scores}

Classroom engagement was measured via self and teacher reports of engagement (Wellborn, 1991; see Appendix A). Teacher report of engagement was obtained for the first and last measurement points $\left(\mathrm{T}_{1}-\mathrm{Nov}\right.$ and $\mathrm{T}_{5}$-Apr). Self report of engagement was obtained for the second through fifth measurement points $\left(\mathrm{T}_{2}\right.$-Dec through $\mathrm{T}_{5}$ Apr $)$. For the analyses, teacher report engagement was used for $\mathrm{T}_{1}-\mathrm{Nov}$ and self report of engagement was used for $\mathrm{T}_{2}-\mathrm{Dec}, \mathrm{T}_{3}-\mathrm{Jan}, \mathrm{T}_{4}-\mathrm{Feb}$, and $\mathrm{T}_{5}-\mathrm{Apr}$. The engagement level of each individual child was computed by averaging the behavioral and emotional engagement items within each scale of the respective reports (prior to calculating the engagement scores, negative items were reversed so that the scale ranged from 0 - 4 with four being high).

It should be noted that teacher and self reports are considered to be parallel reports. Skinner and Belmont's (1993) analyses of the consistency across reports indicate positive correlations between self and teacher report of engagement both in the Fall and in the Spring of a school year. A similar result was found with the current dataset for the behavioral and engagement subscales (combined) for the measurement point where 

reports from both teacher and self were obtained at the same time (i.e., T5-Apr $r=.90, n$ $=73, p<.001)$.

Figure 6.1 illustrates the general trend in the mean level of engagement for the entire sample of children across the school year as well as the general trend in engagement by gender. Table 6.1 provides the range, mean, and standard deviation for each measurement point.

Figure 6.1: Average individual engagement levels across the school year

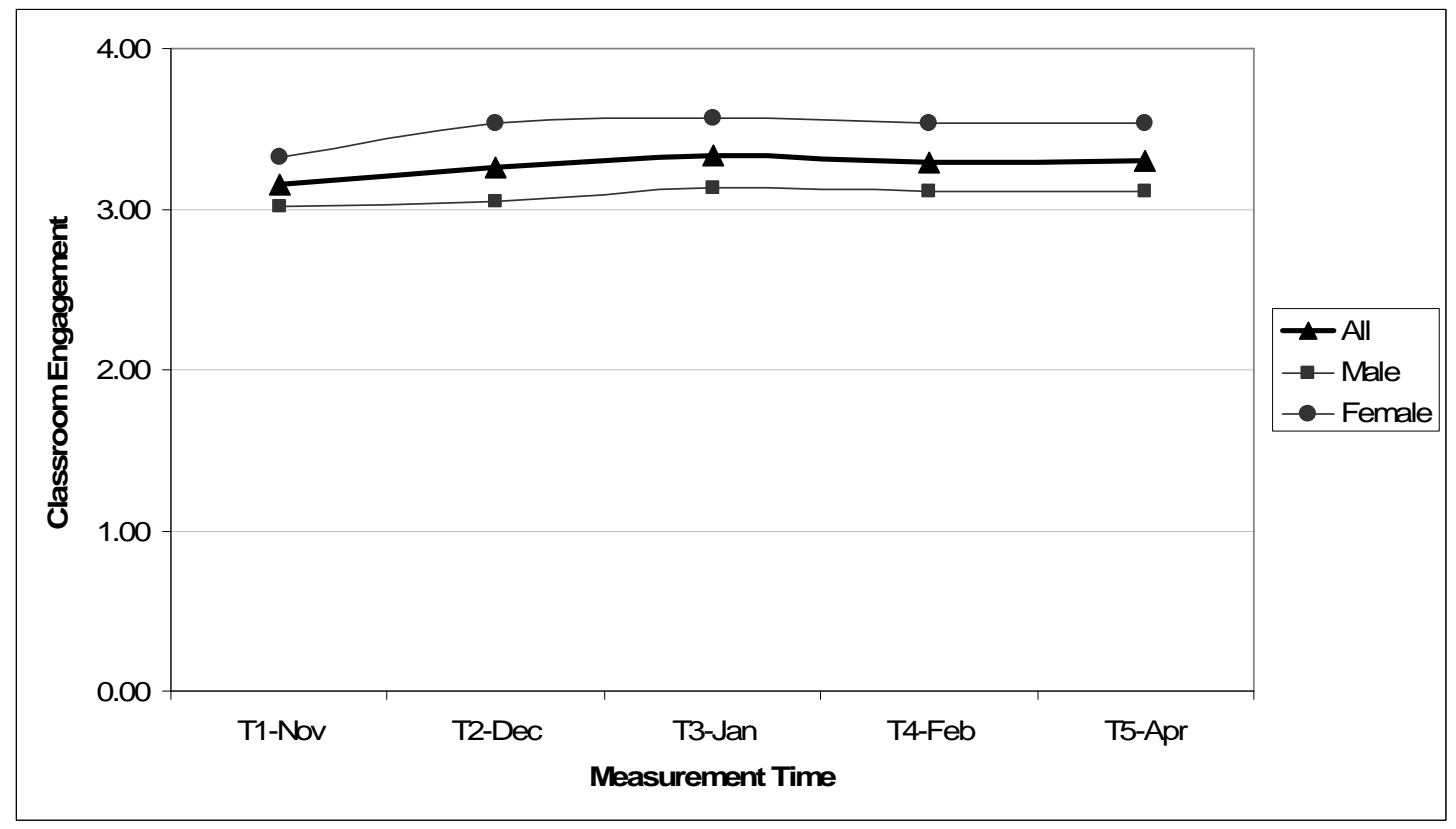


Analyses and Results: Peer Network Emergence 91

\section{Table 6.1}

Individual Engagement Levels Across the School Year

\begin{tabular}{|c|c|c|c|c|c|}
\hline & \multicolumn{5}{|c|}{ Measurement Point } \\
\hline & $\mathrm{T}_{1}$-Nov & $T_{2}$-Dec & $\mathbf{T}_{3}$-Jan & $\mathrm{T}_{4}$-Feb & $\mathbf{T}_{5}$-Apr \\
\hline \multicolumn{6}{|l|}{ Total Sample } \\
\hline Range & $1.13-4.00$ & $1.60-4.00$ & $1.46-4.00$ & $1.49-3.99$ & $1.67-4.00$ \\
\hline Mean & 3.15 & 3.26 & 3.33 & 3.29 & 3.31 \\
\hline SD & 0.67 & 0.55 & 0.58 & 0.58 & 0.54 \\
\hline $\mathrm{N}$ & 94 & 95 & 86 & 86 & 75 \\
\hline \multicolumn{6}{|l|}{ Boys } \\
\hline Range & $1.13-4.00$ & $1.60-3.83$ & $1.46-4.00$ & $1.49-3.99$ & $1.67-4.00$ \\
\hline Mean & 3.02 & 3.04 & 3.13 & 3.12 & 3.11 \\
\hline SD & 0.66 & 0.56 & 0.61 & 0.62 & 0.59 \\
\hline $\mathrm{N}$ & 54 & 53 & 46 & 49 & 40 \\
\hline \multicolumn{6}{|l|}{ Girls } \\
\hline Range & $1.13-4.00$ & $2.44-4.00$ & $2.38-4.00$ & 2.24-3.99 & $2.40-4.00$ \\
\hline Mean & 3.33 & 3.54 & 3.56 & 3.53 & 3.53 \\
\hline SD & 0.66 & 0.41 & 0.45 & 0.44 & 0.38 \\
\hline $\mathrm{N}$ & 40 & 42 & 40 & 37 & 35 \\
\hline
\end{tabular}

Change in engagement across the school year. On average, children showed high engagement at the beginning of the year (3.15 at $\mathrm{T}_{1}$-Nov) and remained engaged throughout the school year (3.31 at $\mathrm{T}_{5}$-Apr). A repeated measures ANOVA was used to determine whether there were any significant changes in children's engagement across the school year. Time was entered as the within subjects dependent factor with five levels $\left(\mathrm{T}_{1}, \mathrm{~T}_{2}, \mathrm{~T}_{3}, \mathrm{~T}_{4}\right.$, and $\left.\mathrm{T}_{5}\right)$. Within subject independent variables were the student engagement levels at each of the respective measurement points. Gender was entered as a between-subjects independent variable. Mauchly's test indicated that the assumption of 
sphericity had been violated, $X^{2}(9)=109.17, p<.001$; therefore, degrees of freedom were corrected using Greenhouse-Geisser estimates of sphericity $(\dot{\varepsilon}=.53)$. There was no significant main effect for time, $\mathrm{F}(2.36,127.57)=.781, \mathrm{p}>.05$, but there was a significant main effect for gender, $\mathrm{F}(1,54)=14.41, \mathrm{p}<.001$, suggesting that girls were significantly higher in classroom engagement than boys.

\section{Identifying Children's Peer Networks}

Children's peer networks were identified at each measurement point using a computer program called Networks 4.0 (Kindermann, Kwee, \& Sage, 2000). This program aggregates children's nomination of who hangs out with whom into a co-occurrence matrix. The matrix contains frequencies with which each nominee is nominated to be in the same group as any other nominee. This matrix was analyzed via binomial $z$-tests (computed by the Networks 4.0 program) to determine, for any given child, the probability that he or she is connected to other children. A $1 \%$ significance level was used to determine the interconnections for each child (i.e., his/her peer group or network). As noted in Chapter 1, this approach is advantageous over methods that identify district groups in that it allowed for multiple groups memberships to be retained. That is, a child can have connections with classmates that are not shared with the other members. Also, it allows for an individual child's group context to be captured that is specific to that child so that interindividual differences in group contexts can be examined.

Table 6.2 presents an example of the co-occurrence matrix with 12 students in the sample at $\mathrm{T}_{1}$-Nov. EARL was nominated to have a group 26 times. ABBY was 
nominated a total of 18 times. Of the 26 times EARL was nominated to have a group, ABBY was nominated to be a member of the same group 15 times. The conditional probability that EARL is nominated to be in a group with ABBY is $.83(15 / 18)$. The total number of groups generated by the 84 respondents was 309, therefore, the expected (unconditional) probability for EARL to be found in any group is .08 (26/309). For EARL to be nominated as being in a group with ABBY, the test yields a $z$ score of 7.91 which is significant $(p<.001)$. Thus, EARL is significantly connected to ABBY and is therefore considered as being in the same peer network as ABBY.

This procedure was applied to each individual's co-nominations in class. The information from this procedure was then used to extract the network structures for each individual child at each measurement point. A composition cognitive social map (see Figure 6.2) illustrates children's peer networks at $\mathrm{T}_{1}$-Nov. In this figure, boys are depicted using squares and girls are depicted using circles. Shaded squares or circles indicate that the child engaged; non-shaded squares or circles indicate that the child is disaffected. Engagement versus disaffected was defined by using a median split (defined separately for boys and girls) of the individual engagement variable at $\mathrm{T}_{1}$-Nov; a method used in my previous studies (c.f., Sage \& Kindermann, 1999, 2001). The median splits computed here were done for drawing purposes only. All analyses in this dissertation examine engagement as a continuous variable ranging from 1-4. 
Table 6.2

November Co-Nomination Matrix for 12 Students In Sample

\begin{tabular}{|c|c|c|c|c|c|c|c|c|c|c|c|c|c|}
\hline \multirow[b]{2}{*}{ Students } & \multicolumn{12}{|c|}{ Classmates with Whom Students Were Nominated to Be in the Same Group } & \multirow{2}{*}{$\begin{array}{c}\text { Total } \\
\text { Nominations }\end{array}$} \\
\hline & JOSH & GREG & DANY & EARL & OLGA & ABBY & KERI & KALI & SADE & OSKA & JEFF & BUCK & \\
\hline JOSH & - & 2 & 1 & 3 & 1 & 2 & 0 & 0 & 0 & 0 & 0 & 0 & 11 \\
\hline GREG & 2 & - & 2 & 1 & 0 & 0 & 0 & 0 & 0 & 0 & 0 & 0 & 6 \\
\hline DANY & 1 & 2 & - & 1 & 0 & 0 & 0 & 2 & 0 & 0 & 0 & 0 & 9 \\
\hline EARL & 3 & 1 & 1 & - & 9 & 15 & 9 & 0 & 7 & 1 & 0 & 0 & 26 \\
\hline OLGA & 1 & 0 & 0 & 9 & - & 7 & 3 & 0 & 1 & 0 & 0 & 0 & 12 \\
\hline ABBY & 2 & 0 & 0 & 15 & 7 & - & 7 & 0 & 6 & 0 & 0 & 0 & 18 \\
\hline KERI & 0 & 0 & 0 & 9 & 3 & 7 & - & 0 & 22 & 0 & 0 & 0 & 27 \\
\hline KALI & 0 & 0 & 2 & 0 & 0 & 0 & 0 & - & 1 & 0 & 1 & 0 & 25 \\
\hline SADE & 0 & 0 & 0 & 7 & 1 & 6 & 22 & 1 & - & 0 & 0 & 0 & 27 \\
\hline OSKA & 0 & 0 & 0 & 1 & 0 & 0 & 0 & 0 & 0 & - & 2 & 1 & 11 \\
\hline JEFF & 0 & 0 & 0 & 0 & 0 & 0 & 0 & 1 & 0 & 2 & - & 2 & 12 \\
\hline BUCK & 0 & 0 & 0 & 0 & 0 & 0 & 0 & 0 & 0 & 1 & 2 & - & 7 \\
\hline
\end{tabular}


Figure 6.2: Children's peer networks at $\mathrm{T}_{1}-\mathrm{Nov}$<smiles>C=CC1=CC(C=C)C=C1</smiles>

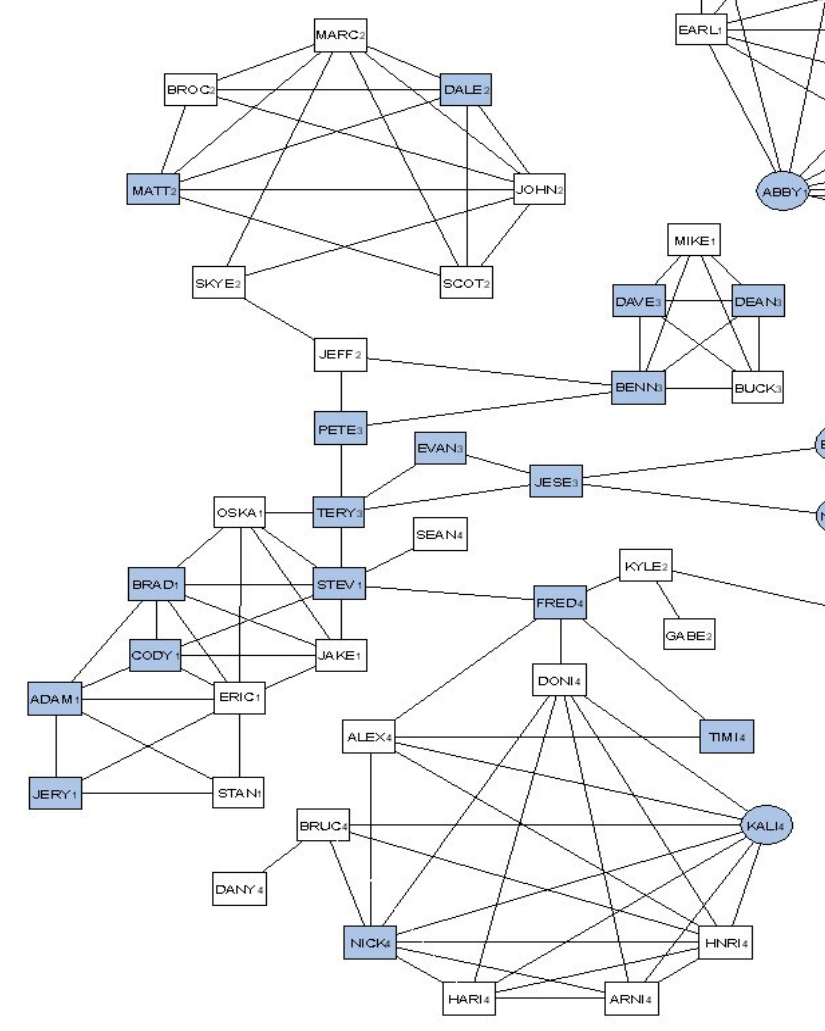

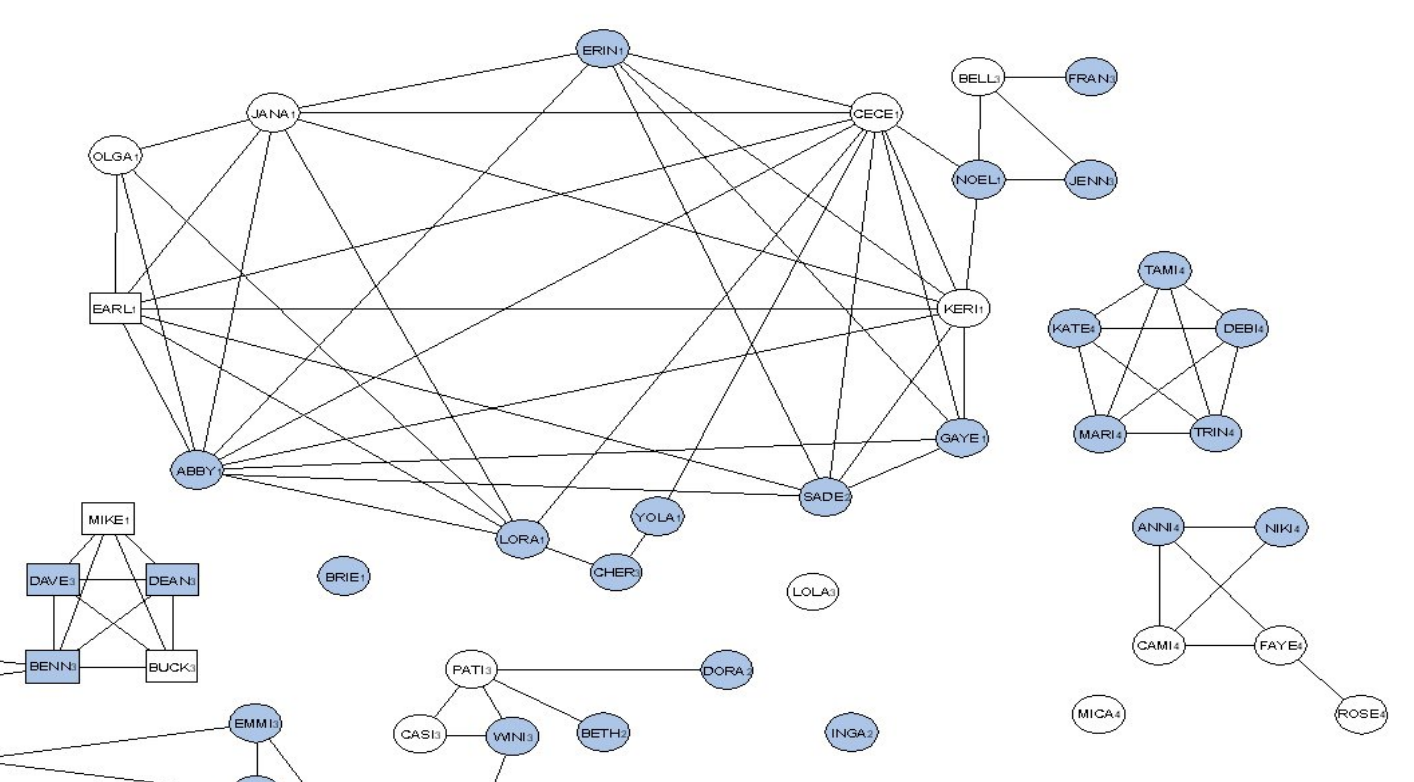

LANEA PAUL FROYA B⿴囗十

LOSES LUKE2 EDDI2 (MAGI) (AGEF

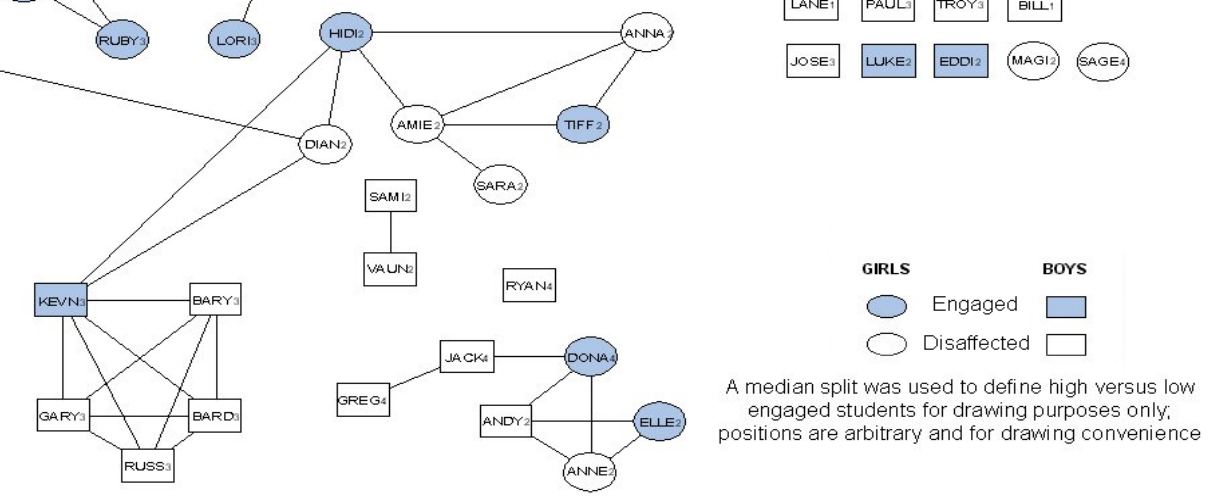


Analyses and Results: Peer Network Emergence 96

\section{Identifying Children's Associative Preferences (Ideal Groups)}

At the same time that children reported about who hangs out with who (peer networks), self-reports of children's associative preferences (i.e., ideal groups) were also obtained. Children were first asked to report who they would like to do a school project with (referred to as ideal work groups). They were then asked to report who they would simply like to hang out with, for example, at recess or lunch (referred to as ideal play groups). Those classmates nominated by the child for each respective group were used to determine the child's ideal work and ideal play group.

\section{Identifying Classmates to Be Selected Versus Eliminated}

Comparisons were made between those reported as being members in a child's peer network group and those whom the child nominated for his/her ideal group(s); this was done at each measurement point. As described in chapter 5, it is assumed that a child would like to potentially "select" a peer if the named child was nominated as a peer at $\mathrm{T}_{\mathrm{i}}$ for his/her ideal group but was not observed as being part of his/her actual network at the same measurement point. On the other hand it is assumed that a child would like to potentially "eliminate" a peer if the named child was not nominated for the ideal group, but was observed as being part of this child's actual network (see Figure 5.1 in Chapter $5)$. 


\section{Measuring Group Composition}

Group composition refers to the psychological characteristics of the group. For the current study, classroom engagement is the characteristic of interest. Group composition was obtained by averaging the individual engagement scores of the members in each group, reflecting the unique aggregate group characteristic for each child (see Figure 6.3 for an example of peer network composition).

Figure 6.3: Example-Anni's peer network composition

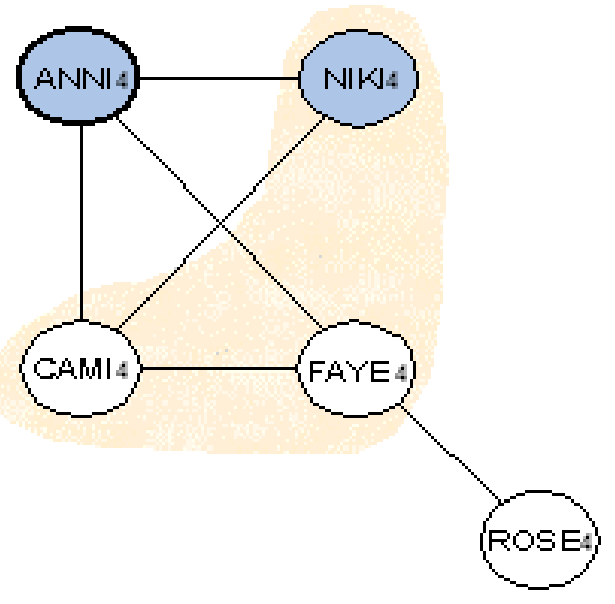

Figure 6.3. Anni's peer network composition is the average of Niki's, Cami's, and Faye's individual engagement scores. Niki's, on the other hand, is the average of Anni \& Cami's individual engagement scores. For children like Rose who has only one network member, the peer network composition is the individual engagement score of that one member.

As argued in Chapter 2 (see Measuring Group Characteristics), one advantage of using an aggregate of scores on the target variable is that groups are independently defined and therefore their characteristics can also be assessed independently because the 
Analyses and Results: Peer Network Emergence 98 peer context is defined uniquely for each individual participant. Group composition was computed (at each measurement point) for each child's peer networks, ideal work group, ideal play group, those classmates whom the child would like to potentially "select", and those classmates whom the child would like to potentially "eliminate".

Estimating missing values. Missing values were estimated to make it possible to include children who were part of a child's group but did not have individual classroom engagement scores (e.g., children from whom permission to participate was not obtained or those absent when the survey was administered). Individual scores for non-participants and/or those who had missing values for all five measurement points were estimated as the average engagement level of the participating other children of the same gender at the respective measurement point. Individual scores for participating children who were missing values due to being absent when the survey was administered but had values from previous and/or subsequent measurement points were estimated as follows:

- $\quad$ Missing for $\mathrm{T}_{1}$-Nov: estimated using the average of the individual's engagement scores for $\mathrm{T}_{2}$-Dec and the average of the participating other children of the same gender for $\mathrm{T}_{1}-\mathrm{Nov}$.

- Missing $\mathrm{T}_{2}$-Dec: estimated using the average of the individual's engagement scores for $\mathrm{T}_{1}$-Dec and $\mathrm{T}_{3}$-Jan.

- $\quad$ Missing $\mathrm{T}_{3}$-Jan: estimated using the average of the individual's engagement scores for $\mathrm{T}_{2}$-Dec and $\mathrm{T}_{4}$-Feb. 
- $\quad$ Missing $\mathrm{T}_{4}$-Feb: estimated using the average of the individual's engagement scores for $\mathrm{T}_{3}$-Jan and $\mathrm{T}_{5}$-Apr.

- Missing $\mathrm{T}_{5}$-Apr: estimated using the average of the individual's engagement scores for $\mathrm{T}_{4}$-Feb and the average of the participating other children of the same gender for $\mathrm{T}_{5}$-Apr.

\section{CHANGE IN PEER NETWORKS ACROSS TIME}

Of interest for this set of analyses is the change in children's peer networks across the school year. As depicted in perceptual stance \#5 (see Chapter 3), the A-Level analysis is the child's peer network with the focal attributes being the peer network structure (who comprises the peer network) and peer network composition (the psychological characteristics of the network). Analyses are provided below regarding the average change in network structure and composition across five measurement points in a single school year.

\section{Change in Peer Network Structure}

Question: How does the structure of the peer network change across the school year? Hypotheses: No specific hypotheses postulated

Of interest for this research question is the total number of members in a given peer network (at each measurement point) and the change and/or stability of the peer network 
structure with regard to members retained, members lost, members gained, and total member turnover at each successive measurement point (i.e., from $T_{n}$ to $T_{n+1}$ ).

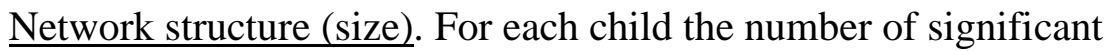
interconnections (as determined by the network computations described earlier) was counted at each measurement point. This defines the total number of peer network members for any given child at each respective measurement point. Figure 6.4 illustrates the general trend in the average network size for the entire sample of children across the school year; Figure 6.5 shows the general trend for the average network size for males and females separately. Table 6.3 provides the range, mean, and standard deviation for each measurement point for the sample overall and by gender.

Figure 6.4. Average number of children in a peer network (network size)

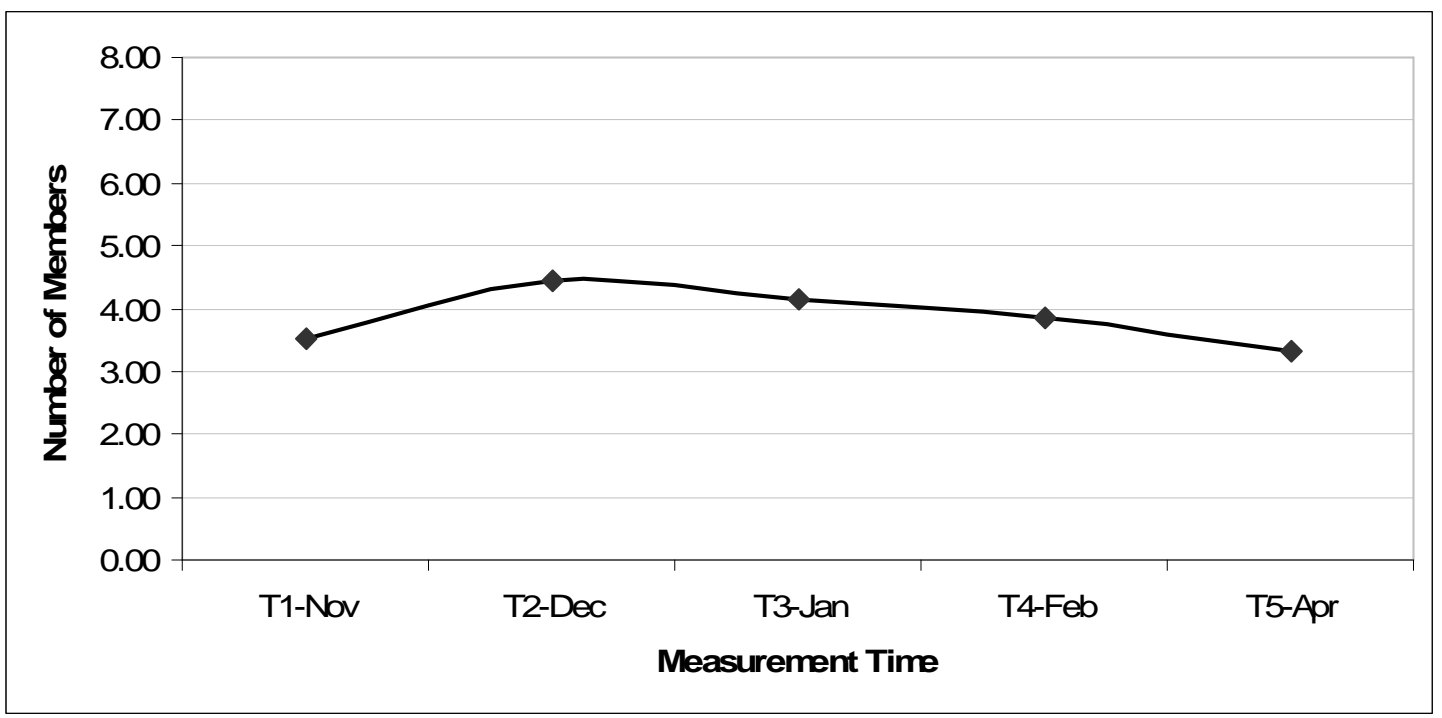


Figure 6.5. Average number of children in a peer network by gender

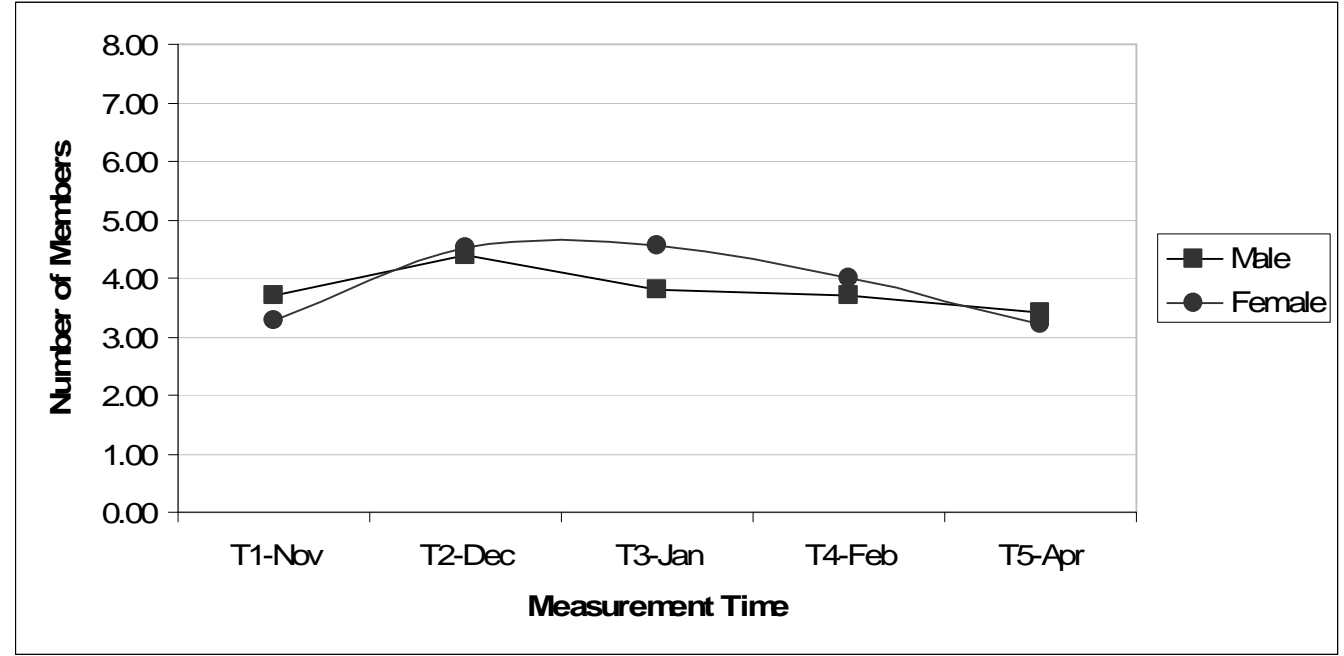

Table 6.3

Peer Network Size Across the School Year

Measurement Point

\begin{tabular}{rccccc} 
& $\mathbf{T}_{\mathbf{1}}$-Nov & $\mathbf{T}_{\mathbf{2}}$-Dec & $\mathbf{T}_{\mathbf{3}}$-Jan & $\mathbf{T}_{\mathbf{4}}$-Feb & $\mathbf{T}_{\mathbf{5}}$-Apr \\
\hline Total Sample & & & & & \\
Range & $0-10$ & $0-15$ & $0-10$ & $0-8$ & $0-8$ \\
Mean & 3.51 & 4.45 & 4.14 & 3.85 & 3.32 \\
SD & 2.16 & 2.71 & 2.18 & 2.16 & 2.17 \\
$\mathrm{~N}$ & 107 & 107 & 106 & 106 & 109
\end{tabular}

Boys

$\begin{array}{rccccc}\text { Range } & 0-7 & 0-15 & 0-9 & 0-8 & 0-8 \\ \text { Mean } & 3.71 & 4.38 & 3.79 & 3.72 & 3.42 \\ \text { SD } & 2.06 & 2.80 & 2.23 & 2.30 & 2.42 \\ \text { N } & 58 & 58 & 58 & 58 & 60\end{array}$

Girls

\begin{tabular}{rccccc} 
Range & $0-10$ & $0-11$ & $0-10$ & $0-8$ & $0-7$ \\
Mean & 3.29 & 4.53 & 4.56 & 4.00 & 3.20 \\
SD & 2.28 & 2.62 & 2.05 & 1.99 & 1.85 \\
$\mathrm{~N}$ & 49 & 49 & 48 & 48 & 49 \\
\hline
\end{tabular}


Change in network size across the school year. Peer networks ranged in size from zero to 15 (boys 0 - 15; girls 0 - 11). On average, children had a total of 3.51 children (not including themselves) in their peer networks at the beginning of the school year. These groups increased by about one child during the middle part of the school year and then reduced in size to an average of 3.32 by the end of the school year. A repeated measures ANOVA was used to determine whether there were any significant changes in peer network size across the school year. Time was entered as the within subjects dependent factor with five levels ( $\mathrm{T}_{1}-\mathrm{Nov}, \mathrm{T}_{2}$-Dec, $\mathrm{T}_{3}-\mathrm{Jan}, \mathrm{T}_{4}-\mathrm{Feb}$, and $\mathrm{T}_{5}$-Apr). Within subjects independent variables were the total number of children in individual children's peer network at each of the respective measurement points. Gender was entered as a between-subjects independent variable. Mauchly's test indicated that the assumption of sphericity had been violated, $X^{2}(9)=155.69, p<.001$; therefore, degrees of freedom were corrected using Greenhouse-Geisser estimates of sphericity $(\varepsilon=.64)$. There was a significant main effect for time, $\mathrm{F}(2.56,265.93)=11.44, \mathrm{p}<.001$, but no significant main effect for gender, $\mathrm{F}(1,104)=1.00, \mathrm{p}>.5$.

Post hoc pair wise comparisons for the within subjects variables using the Bonferroni correction revealed no significant differences in peer network size between measurement points in the middle of the school year: $\mathrm{T}_{2}$-Dec $(\mathrm{M}=4.45)$ and $\mathrm{T}_{3}$-Jan $(M=$ 4.14) or $\mathrm{T}_{3}$-Jan $(M=4.14)$ and $\mathrm{T}_{4}$-Feb $(M=3.85)$. There were, however, significant changes in peer network size between the first and second measurement points: $\mathrm{T}_{1}$-Nov 
$(M=3.52)$ and $\mathrm{T}_{2}-\operatorname{Dec}(M=4.48), p<.001$ and also between the fourth and fifth measurement points: $\mathrm{T}_{4}-\mathrm{Feb}(M=3.85)$ and $\mathrm{T}_{5}-\mathrm{Apr}(M=3.32), p<.001$.

Member turnover across the school year. To better explore the dynamic aspect of the structure of children's peer networks, the identities of the classmates in each child's network at $\mathrm{T}_{\mathrm{n}}$ were compared to the identities of the classmates at each child's network at $T_{n+1}$ (i.e., comparisons between $T_{1} \& T_{2} ; T_{2} \& T_{3}, T_{3} \& T_{4}, T_{4} \& T_{5}$ ). An excel spreadsheet was used to make the comparisons (see Figure 6.6 for an example of the comparisons of one student's networks between $\mathrm{T}_{1}$-Nov and $\mathrm{T}_{2}$-Dec). Stable or members maintained are those classmates who were found to be part of a child's peer network at $\mathrm{T}_{\mathrm{n}}$ and $\mathrm{T}_{\mathrm{n}+1}$. Members lost are those members found to be part of the child's peer network at $T_{n}$ but not at $T_{n+1}$. Members gained are those members not found to be part of the child's network at $T_{n}$ but are part of the child's peer network at $T_{n+1}$. The sum of the members lost and members gained represent the total member turnover.

Total counts for members maintained, lost, gained, and total member turnover were computed for each child at each successive measurement point. These counts were divided by the total number of different classmates that the child was connected to within the successive measurement points to arrive at percent members maintained, percent members lost, percent members gained, and percent member turnover (total number of different classmates was computed by taking the sum of network members at $T_{n}$ and $T_{n+1}$ less the number of members maintained). The total number of different classmates is used as the denominator because they are considered to be a child's social context between 
measurement points which, for these analyses, is the focus. While there could be an argument for alternative denominators (see Appendix $\mathrm{C}$ for a discussion of these alternatives), using number of different classmates between the two measurement points is advantageous for the current study because it captures those classmates who served as socialization agents for that child (either continuously or temporarily).

Figure 6.6: Comparisons of DONA's networks from $\mathrm{T}_{1}$-Nov to $\mathrm{T}_{2}$-Dec

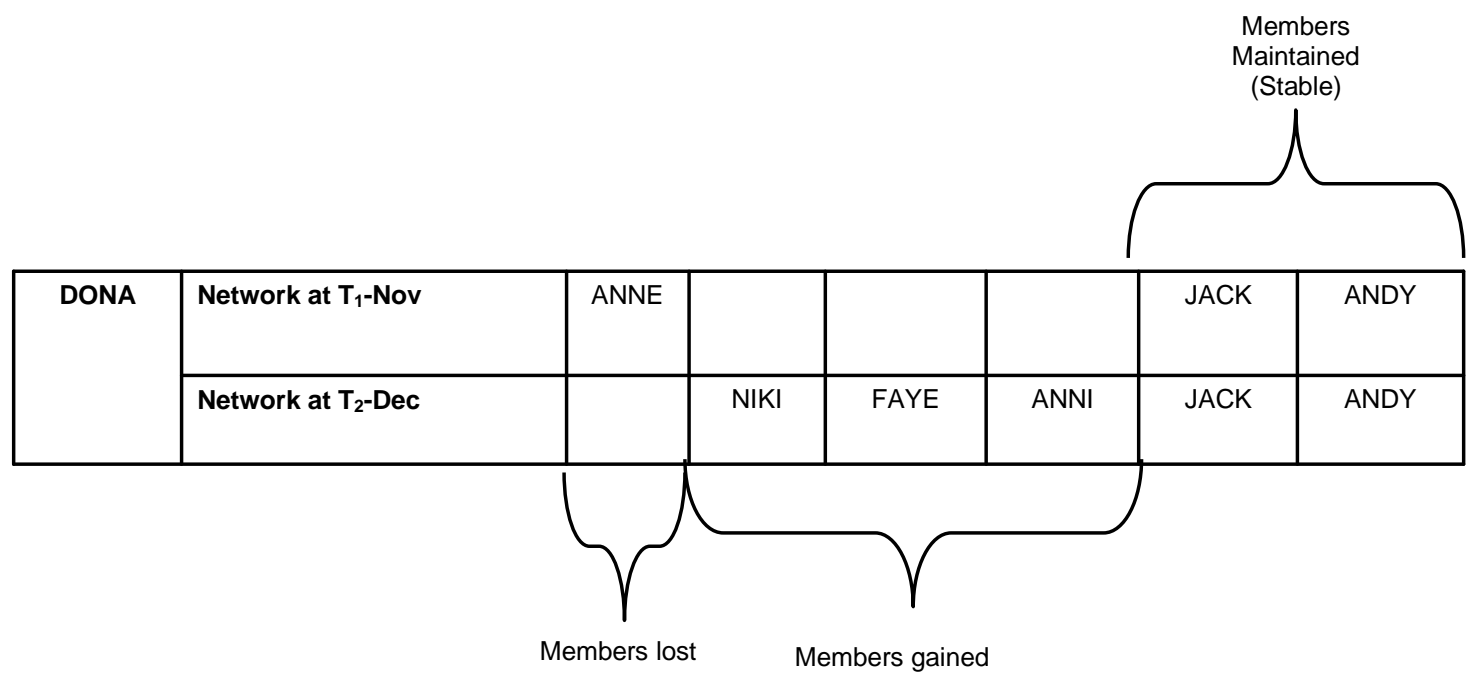

\begin{tabular}{|c|c|c|c|c|c|c|c|c|c|c|}
\hline \#Net-F & \#Net-S & \#Stable & $\begin{array}{l}\text { Tot Mem } \\
\text { F\&S } \\
\text { (Net-F+\#Net- } \\
\text { S)-\#Net-F }\end{array}$ & \#Lost & \#Gain & $\begin{array}{l}\text { \#TrnOvr } \\
\text { \#Lost+\#G } \\
\text { ain }\end{array}$ & $\begin{array}{c}\text { \%Stable } \\
\text { \#Stable/ } \\
\text { Tot } \\
\text { Mem }\end{array}$ & $\begin{array}{l}\text { \%Lost } \\
\text { \#Lost/To } \\
\text { t Mem } \\
\text { F\&S }\end{array}$ & $\begin{array}{l}\text { \%Gaine } \\
\text { d } \\
\text { \#Gain/T } \\
\text { ot Mem } \\
\text { F\&S }\end{array}$ & $\begin{array}{l}\text { \%TrnOvr } \\
\text { \#TrnOvr/ } \\
\text { Tot Mem } \\
\text { F\&S }\end{array}$ \\
\hline 3 & 5 & 2 & 6 & 1 & 3 & 4 & 0.33 & 0.17 & 0.50 & 0.67 \\
\hline
\end{tabular}

Figure 6.6. DONA had three peer network members (ANNE, JACK, and ANDY) at $\mathrm{T}_{1}$-Nov and five peer network members at $\mathrm{T}_{2}$-Dec (NIKI, FAYE, ANNI, JACK, and ANDY). There were two classmates (JACK and ANDY) who were members at both measurement points; these classmates were considered to be maintained (stable) members. Therefore, from $\mathrm{T}_{1}$-Nov and $\mathrm{T}_{2}$-Dec, DONA had six different peer network members. One of DONA's members at $T_{1}$-Nov was not part of her peer network at $T_{2}$-Dec (ANNE). This member is considered to be members lost. At $\mathrm{T}_{2}$-Dec, three classmates were part of DONA's peer network (NIKI, FAYE, and ANNI) that were not part of DONA's peer network at $\mathrm{T}_{1}$-Nov. They are considered to be members gained. Of DONA's six peer network members from $\mathrm{T}_{1}$-Nov to $\mathrm{T}_{2}$-Dec, four of them were either lost or gained, for a total peer network turnover of $67 \%$. The two maintained members made up 33\% of DONA's peer network members from $\mathrm{T}_{1}$-Nov to $\mathrm{T}_{2}$-Dec. 
Computations for children who were not found to be connected to any children (social isolates) at any of the respective measurement points were done as follows:

- Social isolate at $\mathrm{T}_{\mathrm{n}}$ and also at $\mathrm{T}_{\mathrm{n}+1}$ : indicated as having zero percent of members, lost, gained, stable, and turnover.

- Social isolate at $\mathrm{T}_{\mathrm{n}}$ but not isolate at $\mathrm{T}_{\mathrm{n}+1}$ : indicated as having zero members lost and stable; members gained and member turnover computed as described earlier.

- Not a social isolate at $\mathrm{T}_{\mathrm{n}}$ but a social isolate at $\mathrm{T}_{\mathrm{n}+1}$ : indicated as having zero members gained and stable; members lost and member turnover computed as described earlier.

Figure 6.7 illustrates the percentage of members retained (stable members), lost, and gained between each respective measurement point. Figure 6.8 illustrates the general trend in total member turnover for the entire sample of children across the school year and Figure 6.9 shows the general trend in total member turnover for males and females separately. 
Figure 6.7. Percentage of stable members, members lost, and members gained
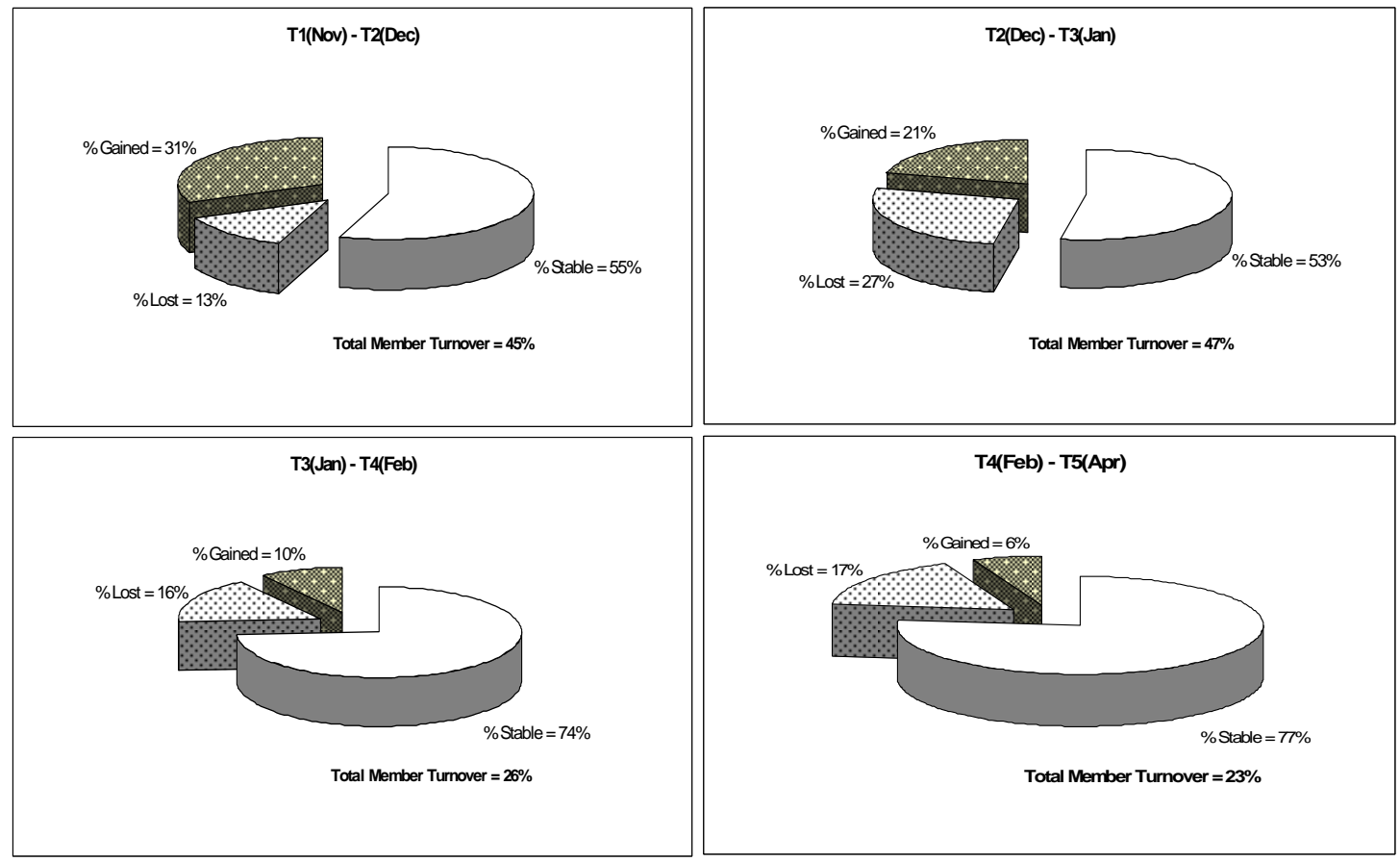

Figure 6.8. Average member turnover

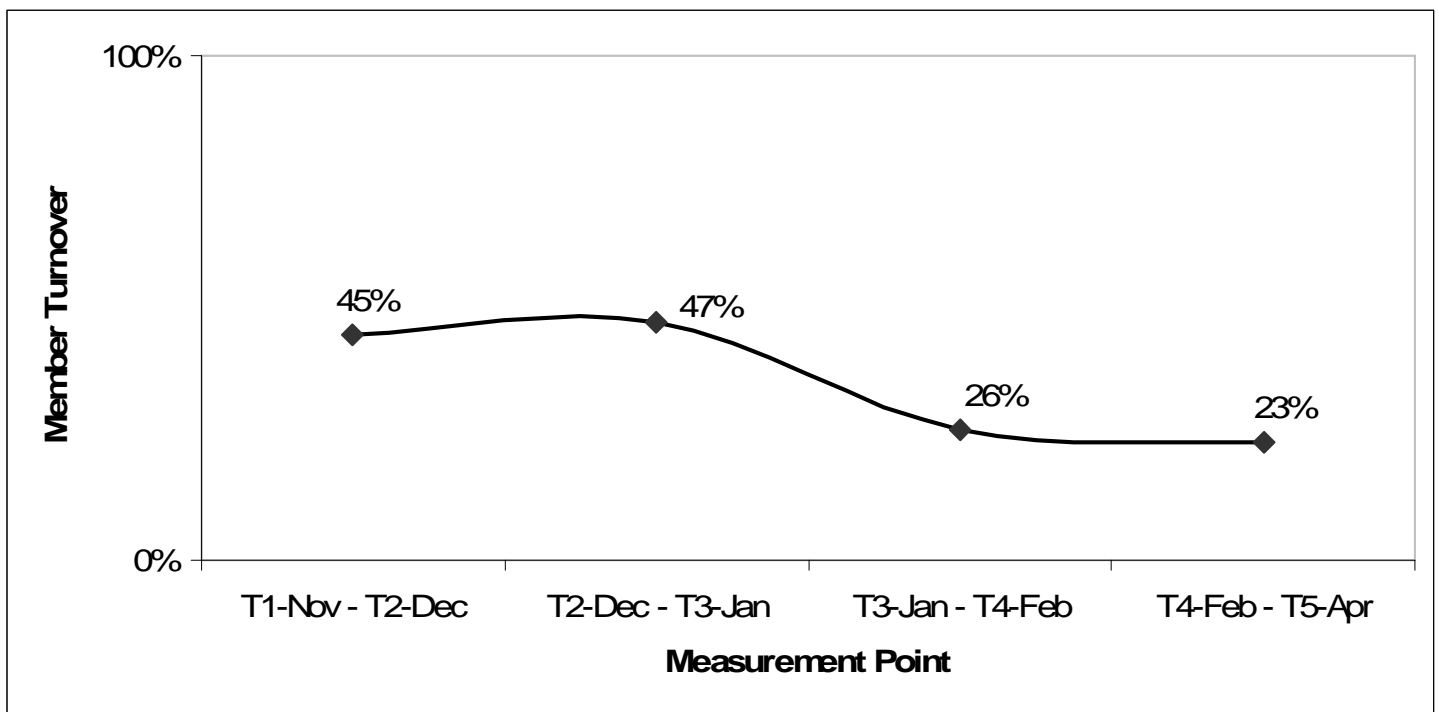


Figure 6.9. Average member turnover by gender

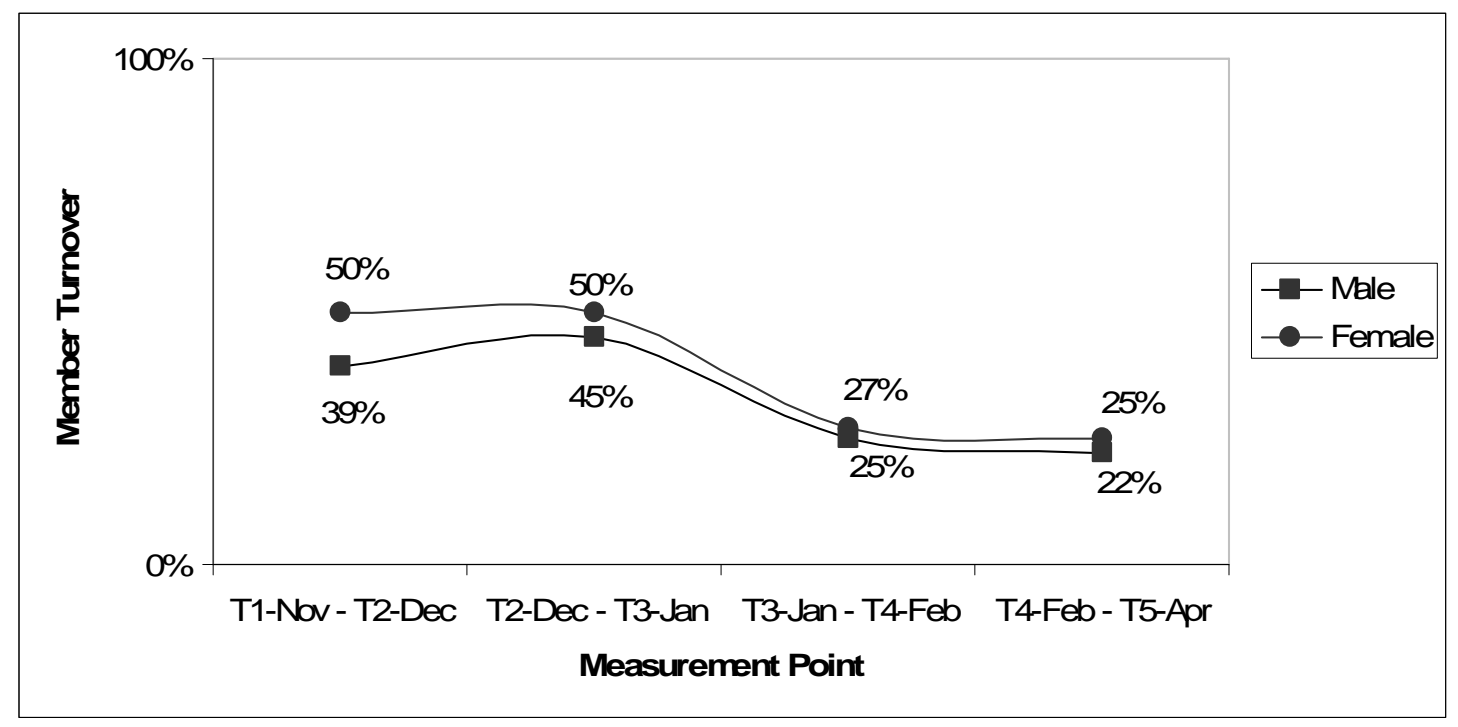

Change in member turnover across the school year. Member turnover ranged from $22 \%$ to $45 \%$ for boys and $25 \%$ to $50 \%$ for girls. A repeated measures ANOVA was used to determine whether there were any significant changes in member turnover across the school year. Time was entered as the within subjects dependent factor with five levels ( $\mathrm{T}_{1}$-Nov, $\mathrm{T}_{2}$-Dec, $\mathrm{T}_{3}$-Jan, $\mathrm{T}_{4}$-Feb, and $\mathrm{T}_{5}$-Apr). Within subject independent variables were the percent member turnover between successive measurement points. Gender was entered as a between-subject independent variable. Mauchly's test indicated that the assumption of sphericity had been violated, $X^{2}(5)=18.85, p<.01$; therefore, degrees of freedom were corrected using Huynh-Feldt estimates of sphericity $(\dot{\varepsilon}=.92)$. There was a significant main effect for time, $\mathrm{F}(2.76,286.59)=21.74, \mathrm{p}<.001$, but no significant main effect for gender, $\mathrm{F}(1,104)=.222, \mathrm{p}>.05$. 
Analyses and Results: Peer Network Emergence 108

Post hoc pair wise comparisons for the within subjects variables using the Bonferroni correction revealed significant differences in member turnover between $\mathrm{T}_{2^{-}}$ Dec $-\mathrm{T}_{3}$-Jan $(M=47 \%)$ and $\mathrm{T}_{3}$-Jan $-\mathrm{T}_{4}-\mathrm{Feb}(M=26 \%), p<.001$. There were no significant differences between $\mathrm{T}_{1}$-Nov $-\mathrm{T}_{2}$-Dec $(M=45 \%)$ and $\mathrm{T}_{2}$-Dec $-\mathrm{T}_{3}$-Jan $(M=$ $47 \%)$, nor were there significant differences between $\mathrm{T}_{3}$-Jan $-\mathrm{T}_{4}-\mathrm{Feb}(M=26 \%)$ and $\mathrm{T}_{4^{-}}$ Feb $-\mathrm{T}_{5}-\operatorname{Apr}(M=23 \%)$.

\section{Change in Peer Network Composition}

Question: How does the composition of the peer network change across the school year? Hypotheses: No specific hypothesis postulated

Of interest for this research question is the psychological composition (group engagement) of the peer network at each measurement point and the change and/or stability in network composition between successive measurement points (e.g., $\mathrm{T}_{1}$ to $\mathrm{T}_{2}$, $\mathrm{T}_{2}$ to $\mathrm{T}_{3}$ and so forth). The network composition for each child at each measurement point was computed as described earlier. Figure 6.10 illustrates the general trend in the average network composition for the entire sample of children across the school year as well as the general trend in network composition by gender. Table 6.4 provides the range, mean, and standard deviation for each measurement point for the sample overall and by gender. 
Figure 6.10. Average peer network composition

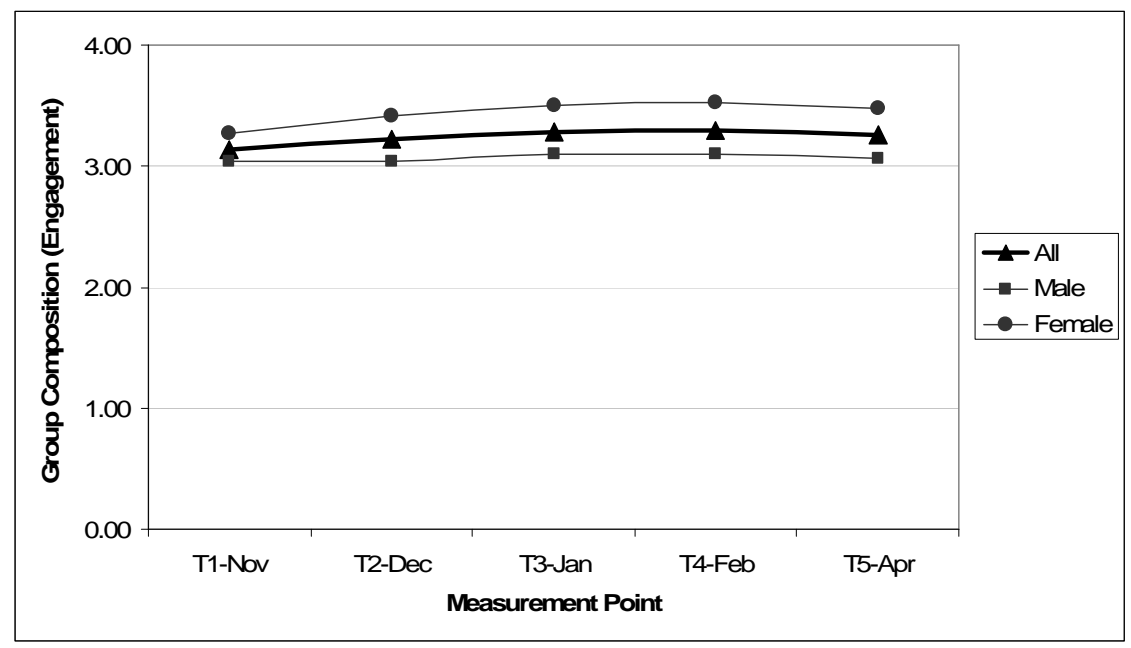

Table 6.4

Peer Network Composition Across the School Year

Measurement Point

\begin{tabular}{rccccc} 
& $\mathbf{T}_{\mathbf{1}}$-Nov & $\mathbf{T}_{\mathbf{2}}$-Dec & $\mathbf{T}_{\mathbf{3}}$-Jan & $\mathbf{T}_{\mathbf{4}}$-Feb & $\mathbf{T}_{\mathbf{5}}$-Apr \\
\hline Total Sample & & & & & \\
Range & $1.77-3.96$ & $2.25-3.88$ & $2.08-3.89$ & $1.93-3.92$ & $1.95-4.00$ \\
Mean & 3.14 & 3.22 & 3.28 & 3.30 & 3.26 \\
SD & 0.41 & 0.39 & 0.39 & 0.42 & 0.41 \\
$\mathrm{~N}$ & 98 & 102 & 102 & 98 & 96
\end{tabular}

Boys

$\begin{array}{rccccc}\text { Range } & 1.77-3.68 & 2.25-3.71 & 2.08-3.72 & 1.93-3.85 & 1.95-3.88 \\ \text { Mean } & 3.04 & 3.04 & 3.10 & 3.10 & 3.06 \\ \text { SD } & 0.37 & 0.38 & 0.38 & 0.40 & 0.38 \\ \mathrm{~N} & 54 & 54 & 55 & 51 & 51\end{array}$

Girls

\begin{tabular}{rccccc} 
Range & $1.82-3.96$ & $2.57-3.88$ & $2.66-3.89$ & $2.78-3.92$ & $2.58-4.00$ \\
Mean & 3.27 & 3.42 & 3.50 & 3.52 & 3.48 \\
SD & 0.41 & 0.33 & 0.28 & 0.31 & 0.33 \\
$\mathrm{~N}$ & 44 & 48 & 47 & 47 & 45 \\
\hline
\end{tabular}

Note: Group composition is the average of the individual engagement scores of the members of each child's peer network. 
Analyses and Results: Peer Network Emergence 110

Change in network composition across the school year. Peer network composition for boys' networks ranged from 1.77 - 3.88 across the school years; girls' peer network composition ranged from 1.82 - 4.00. Trends in children's peer network compositions mirrored the trends of individual engagement across time. On average, children's peer networks showed relatively high composition scores at the beginning of the year (3.14 at $\mathrm{T}_{1}$-Nov) and remained high throughout the school year (3.26 at $\left.\mathrm{T}_{5}-\mathrm{Apr}\right)$. A repeated measures ANOVA was used to determine whether there were any significant changes in member turnover across the school year. Time was entered as the within subjects dependent factor with five levels $\left(\mathrm{T}_{1}-\mathrm{Nov}, \mathrm{T}_{2}\right.$-Dec, $\mathrm{T}_{3}$-Jan, $\mathrm{T}_{4}-\mathrm{Feb}$, and $\mathrm{T}_{5}$-Apr). Within subject independent variables were the network composition scores for each child at each of the respective measurement points. Gender was entered as a between-subject independent variable. Mauchly's test indicated that the assumption of sphericity had been violated, $X^{2}(9)=112.61, p<.001 ;$ therefore, degrees of freedom were corrected using Greenhouse-Geisser estimates of sphericity $(\dot{\varepsilon}=.64)$. There was no significant main effect for time, $F(2.55,221.75)=.856, p>.05$, but there was a significant main affect for gender, $\mathrm{F}(1,87)=.35 .60, \mathrm{p}<.001$, suggesting that girls' network composition scores were higher than boys' network composition scores.

Homophily: An index of group selection. As discussed in Chapter 1, correlations between individual scores and group scores have been used in previous research as indicators of group selection processes. Although the focus of this dissertation was to use alternative methods for examining such processes (see next section), the traditional 
Analyses and Results: Peer Network Emergence 111 approach was applied here merely as a replication of previous research. As in prior studies, peer selection effects are assumed if individual engagement scores are found to be homogeneous with network engagement scores. Correlations were computed between individual scores and peer network scores at each of the five measurement points. The results suggested significant positive correlations at all five measurement points (see Table 6.5). In general, individuals and their network members were slightly homogeneous at the beginning of the year $(r=27, \mathrm{p}<.05)$ and increased in homogeneity at $\mathrm{T}_{2}$-Dec $(r=.40, \mathrm{p}<.001)$. Homogeneity remained relatively stable the remainder of the school year.

\section{Table 6.5}

Homogeneity Among Individuals and Network Members

Measurement Point

\begin{tabular}{rccccc} 
& \multicolumn{1}{c}{$\mathbf{T}_{\mathbf{1}}$-Nov } & $\mathbf{T}_{\mathbf{2}}$-Dec & $\mathbf{T}_{\mathbf{3}}$-Jan & $\mathbf{T}_{\mathbf{4}}$-Feb & $\mathbf{T}_{\mathbf{5}}$-Apr \\
\hline$r$ & $0.27 * *$ & $.40 * * *$ & $.45 * * *$ & $.45 * * *$ & $.48 * * *$ \\
$\mathrm{~N}$ & 98 & 102 & 102 & 98 & 96 \\
& & & & & \\
\hline${ }^{* *} \mathrm{p}<.01,{ }^{* *}<.001$ & & & & &
\end{tabular}


Analyses and Results: Peer Network Emergence

\section{PROXIMAL PROCESSES FROM WHICH THE PEER CONTEXT EMERGES}

For the following analyses, comparisons were made between children's peer network groups and their associative preferences (ideal work groups and ideal play groups). Because not much is known about ideal groups, the focus was first placed on examining differences between the ideal work and ideal play groups (and each was compared to children's peer networks; see research question \#3 below). The outcome of the results from research question \#3 determined the analyses for research question \#4 (details provided in the respective section).

\section{Differences in Structure and Composition Among Network, Ideal Work, and Ideal}

\section{Play Groups}

Research Question: Are there differences in group structure and composition among peer networks, ideal work groups, and ideal play groups?

Hypotheses: No specific hypotheses posited

The structure and composition of children's networks were already examined in research questions 1 and 2. For this research question, the structure (number of members in a given group) and composition (group engagement score) of children's ideal work and ideal play groups were determined and compared to each other as well as to children's peer networks. First, differences in the number of members in children's peer networks, ideal work groups, and ideal play groups were examined. Second, differences in the 
psychological composition of children's peer networks, ideal work groups, and ideal play groups were examined.

Differences in number of children in a group (group size). As described earlier, a child's peer network size was defined as the number of significant interconnections a child had; ideal work and play group size was determined by the number of peers a child nominated for each group. These total counts were tallied for each group type and each measurement point. Figure 6.11 illustrates the general trend in the average peer network, ideal work group, and ideal play group size for the entire sample of children across the school year. Table 6.6 provides the range, mean, and standard deviation for each measurement point.

Figure 6.11. Average Number of Children in Networks, Ideal Work Groups, and Ideal Groups

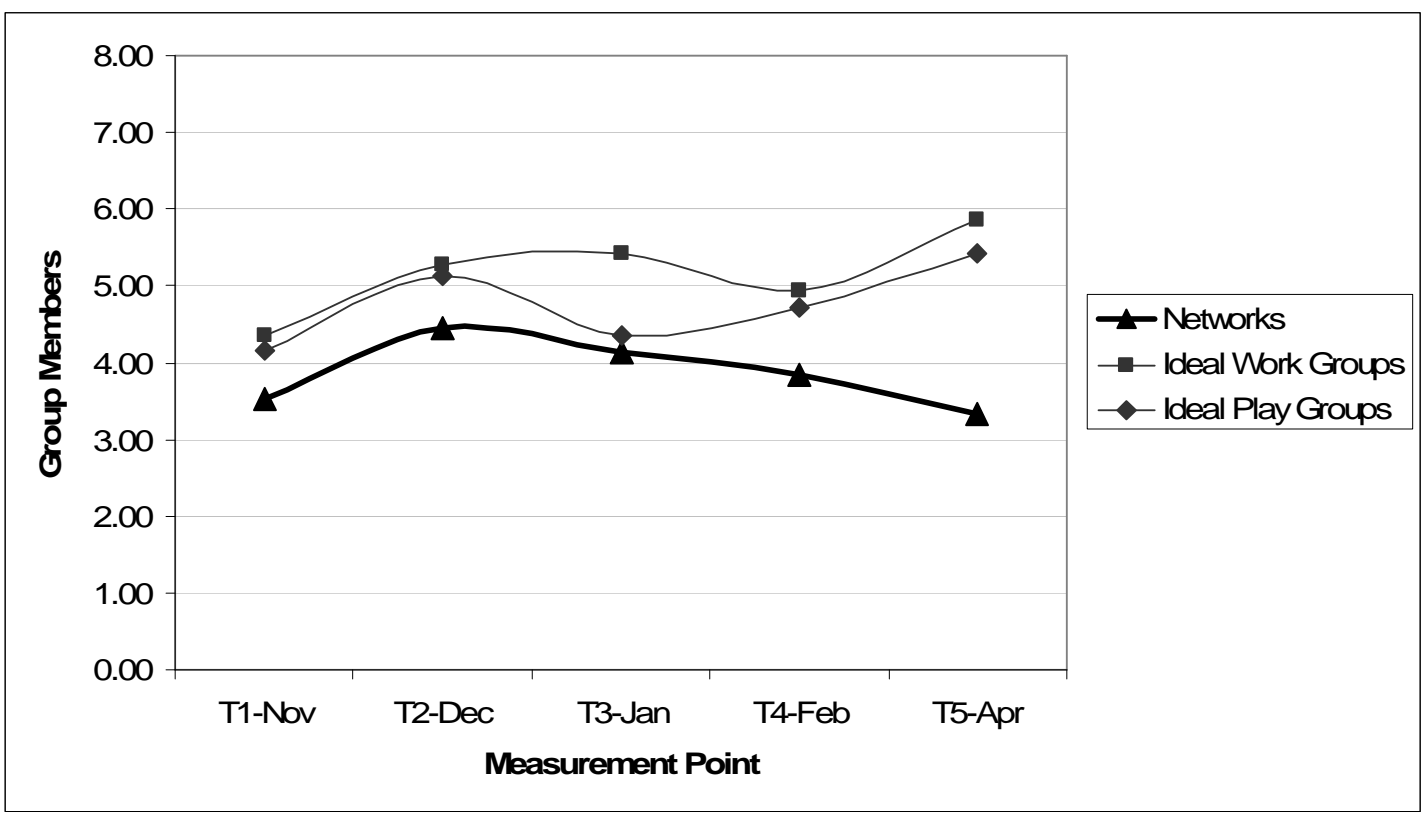


Analyses and Results: Peer Network Emergence 114

Table 6.6

Average Size of Child's Peer Network, Ideal Work Group, and Ideal Play Group

\begin{tabular}{rccccc} 
& \multicolumn{5}{c}{ Measurement Point } \\
\cline { 2 - 6 } & $\mathbf{T}_{\mathbf{1}}$-Nov & $\mathbf{T}_{\mathbf{2}}$-Dec & $\mathbf{T}_{\mathbf{3}}$-Jan & $\mathbf{T}_{\mathbf{4}}$-Feb & $\mathbf{T}_{\mathbf{5}}$-Apr \\
\hline Peer Network & & & & & \\
Range & $0-10$ & $0-15$ & $0-10$ & $0-8$ & $0-8$ \\
Mean & 3.51 & 4.45 & 4.14 & 3.85 & 3.32 \\
SD & 2.16 & 2.71 & 2.18 & 2.16 & 2.17 \\
$\mathrm{~N}$ & 107 & 107 & 106 & 106 & 109 \\
& & & & & \\
Ideal Work Group & & & & & \\
Range & $1-10$ & $0-14$ & $0-16$ & $1-11$ & $0-16$ \\
Mean & 4.36 & 5.27 & 5.43 & 4.93 & 5.87 \\
SD & 2.07 & 2.77 & 3.27 & 2.49 & 3.41 \\
$\mathrm{~N}$ & 91 & 79 & 67 & 83 & 83 \\
& & & & & \\
Ideal Play Group & & & & & \\
Range & $0-13$ & $0-15$ & $0-12$ & $2-12$ & $0-15$ \\
Mean & 4.15 & 5.13 & 4.34 & 4.71 & 5.42 \\
SD & 2.29 & 3.34 & 2.87 & 2.12 & 3.22 \\
$\mathrm{~N}$ & 89 & 79 & 67 & 83 & 83 \\
\hline
\end{tabular}

The range of group members across the school year for each group type was similar. Both peer networks and ideal play groups ranged in size from 0 - 15 members; ideal work groups ranged in size from 0 - 16. At the beginning of the year $\left(\mathrm{T}_{1}\right.$-Nov), children had, on average, a total of 3.51 children in their peer networks, 4.36 children in their ideal work groups, and 4.15 children in their ideal play groups. By the end of the year, ideal work and play groups were larger than peer networks by approximately two group members. While children's peer networks declined in group membership across the year, children's ideal work and play groups increased in size. 
Analyses and Results: Peer Network Emergence 115

Repeated measures ANOVAs were run at each measurement point to determine whether the three groups differed in size. Group type was entered as the within subjects dependent factor with three levels. Within subject independent variables were the total number of members for each group type at the respective measurement point. The results are presented below for each measurement point:

- $\quad T_{1}$-Nov: Mauchly's test indicated that the assumption of sphericity had been violated, $X^{2}(2)=14.07, p=.001$; therefore, degrees of freedom were corrected using Huynh-Feldt estimates of sphericity $(\dot{\varepsilon}=.89)$. The results revealed no significant main effect for group type, $F(1.77,155.95)=3.12, p>.05$; therefore groups did not differ significantly in size at $\mathrm{T}_{1}$-Nov.

- $\quad T_{2}-D e c$ : Mauchly's test indicated that the assumption of sphericity had not been violated, $X^{2}(2)=3.75, p>.05$; therefore, degrees of freedom were not corrected. The results revealed no significant main effect for group type, $F(2$, $156)=.78, p>.05$; therefore groups did not differ significantly at $\mathrm{T}_{2}$-Dec.

- $\quad T_{3}$-Jan: Mauchly's test indicated that the assumption of sphericity had not been violated, $X^{2}(2)=5.79, p>.05$; therefore, degrees of freedom were not corrected. The results revealed a significant main effect for group type, $F(2$, $132)=4.18, p<.05$. Post hoc pair wise comparisons using the Bonferroni correction revealed that ideal work groups were significantly larger than ideal play groups $(p<.01)$ and peer networks $(p<.05)$. There were no significant differences between peer networks and ideal play groups. 
Analyses and Results: Peer Network Emergence 116

- $\quad T_{4}-F e b$ : Mauchly's test indicated that the assumption of sphericity had been violated, $X^{2}(2)=12.38, p=.01$; therefore, degrees of freedom were corrected using Huynh-Feldt estimates of sphericity $(\dot{\varepsilon}=.89)$. The results revealed a significant main effect for group type $F(1.79,146.52)=3.12, p=.001$. Post hoc pair wise comparisons using the Bonferroni correction revealed that ideal work and ideal play groups were both significantly larger than peer networks $(\mathrm{p}<.01$ and $\mathrm{p}<.05$, respectively). There were no significant differences between ideal work and ideal play groups.

- $\quad T_{5}$-Apr: Mauchly's test indicated that the assumption of sphericity had been violated, $X^{2}(2)=10.04, p<.01$; therefore, degrees of freedom were corrected using Huynh-Feldt estimates of sphericity $(\dot{\varepsilon}=.91)$. The results revealed a significant main effect for group type, $F(1.83,149.94)=22.50, p<.001$. Post hoc pair wise comparisons using the Bonferroni correction revealed that ideal work and ideal play groups were both significantly larger than peer networks $(\mathrm{p}<.001$ and $\mathrm{p}<.001$, respectively). There were no significant differences between ideal work and ideal play groups.

Differences in group composition. The group composition for each child's peer network, ideal work group, and ideal play group was computed at each measurement point as described earlier. Figure 6.12 illustrates the general trend in the average group composition across the school year for peer networks, ideal work groups, and ideal play 
groups. Table 6.7 provides the range, mean, and standard deviation for each measurement point for each group type.

Figure 6.12: Average Peer Network, Ideal Work Group, and Ideal Play Group Composition

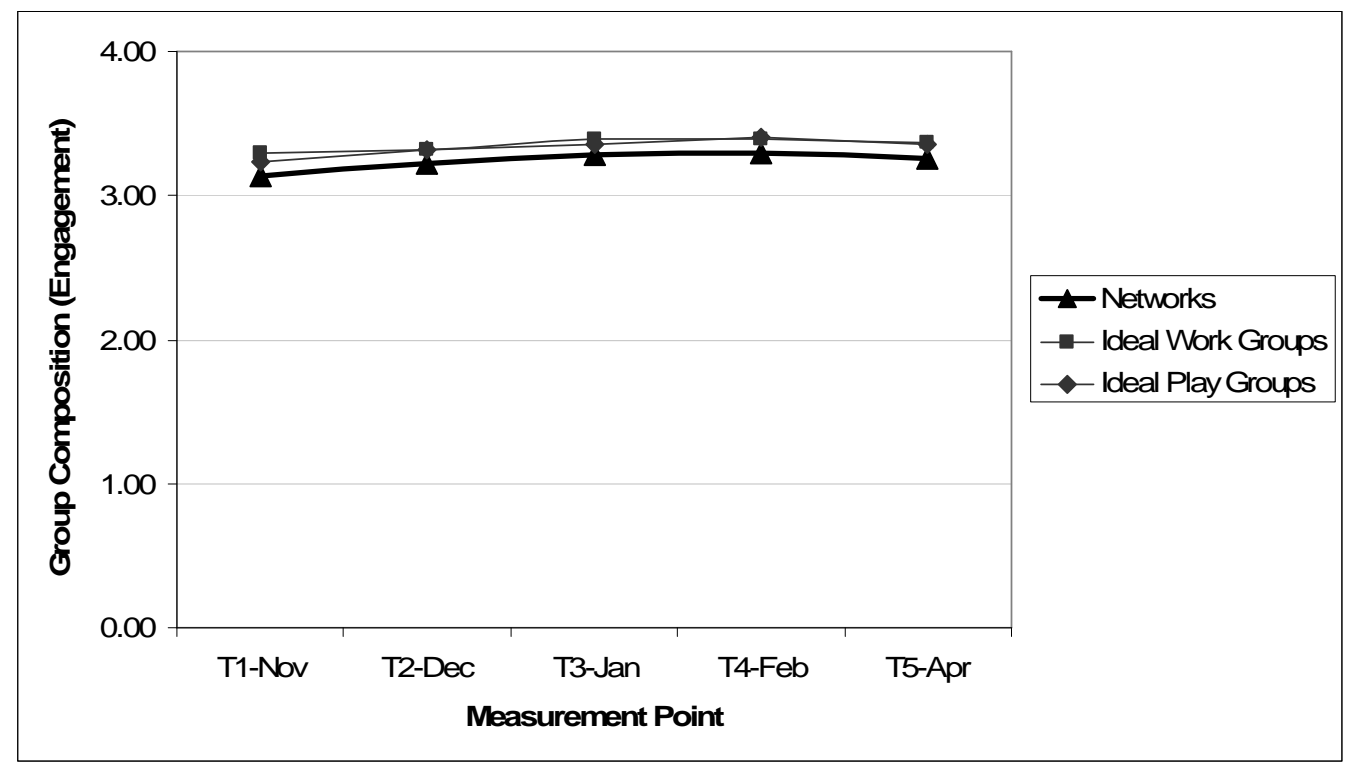


Analyses and Results: Peer Network Emergence 118

Table 6.7

Peer Network, Ideal Work, and Ideal Play Group Composition

\begin{tabular}{|c|c|c|c|c|c|}
\hline & \multicolumn{5}{|c|}{ Measurement Point } \\
\hline & $T_{1}-$ Nov & $\mathbf{T}_{2}$-Dec & $\mathbf{T}_{3^{-} \text {Jan }}$ & $\mathrm{T}_{4}$-Feb & $\mathbf{T}_{5}$-Apr \\
\hline \multicolumn{6}{|l|}{ Networks } \\
\hline Range & $1.77-3.96$ & $2.25-3.88$ & $2.08-3.89$ & $1.93-3.92$ & $1.95-4.00$ \\
\hline Mean & 3.14 & 3.22 & 3.28 & 3.30 & 3.26 \\
\hline SD & 0.41 & 0.39 & 0.39 & 0.42 & 0.41 \\
\hline $\mathrm{N}$ & 98 & 102 & 102 & 98 & 96 \\
\hline \multicolumn{6}{|c|}{ Ideal Work Groups } \\
\hline Range & $1.77-3.95$ & $1.69-3.85$ & $2.41-3.95$ & $2.20-3.91$ & $2.60-3.86$ \\
\hline Mean & 3.30 & 3.32 & 3.39 & 3.39 & 3.37 \\
\hline SD & 0.37 & 0.39 & 0.35 & 0.34 & 0.27 \\
\hline $\mathrm{N}$ & 91 & 77 & 65 & 84 & 80 \\
\hline \multicolumn{6}{|c|}{ Ideal Play Groups } \\
\hline Range & $1.77-3.94$ & $2.17-3.88$ & $2.45-4.00$ & $2.43-3.94$ & $2.33-3.81$ \\
\hline Mean & 3.23 & 3.31 & 3.36 & 3.40 & 3.35 \\
\hline SD & 0.38 & 0.33 & 0.33 & 0.32 & 0.29 \\
\hline $\mathrm{N}$ & 87 & 71 & 59 & 84 & 76 \\
\hline
\end{tabular}

Note: Group composition is the average of the individual engagement scores of the members of each child's peer network.

On average, children's peer networks, ideal work groups, and ideal play groups showed relatively high composition scores at the beginning of the year $(3.14,3.30$, and 3.23 , respectively in $\mathrm{T}_{1}$-Nov) and remained high throughout the school year. Repeated measures ANOVAs were run at each measurement point to determine whether the three groups differed in group composition. Group type was entered as the within subjects dependent factor with three levels. Within subject independent variables were the group composition scores for each group type at the respective measurement point. The results are presented below for each measurement point: 
- $\quad T_{1}$-Nov: Mauchly's test indicated that the assumption of sphericity had been violated, $X^{2}(2)=6.12, p<.05$; therefore, degrees of freedom were corrected using Huynh-Feldt estimates of sphericity $(\dot{\varepsilon}=.95)$. The results revealed a significant main effect for group type, $F(1.91,154.30)=5.02, p<.01$. Post hoc pair wise comparisons using the Bonferroni correction revealed that ideal work groups and ideal play groups had significantly higher composition scores than peer networks ( $\mathrm{p}<.05$ and $\mathrm{p}<.05$, respectively). There were no significant differences between the composition scores of ideal work and ideal play groups.

- $\quad T_{2}$-Dec: Mauchly's test indicated that the assumption of sphericity had been violated, $X^{2}(2)=18.18, p<.001$; therefore, degrees of freedom were corrected using Huynh-Feldt estimates of sphericity $(\dot{\varepsilon}=.82)$. The results revealed no significant main effect for group type, $F(1.63,104.56)=2.95, p>$ .05 ; therefore, groups did not differ significantly at $\mathrm{T}_{2}$-Dec.

- $\quad T_{3}$-Jan: Mauchly's test indicated that the assumption of sphericity had not been violated, $X^{2}(2)=4.27, p>.05$; therefore, degrees of freedom were not corrected. The results revealed no significant main effect for group type, $F(2$, $100)=2.98, p>.05 ;$ therefore groups did not differ significantly at $\mathrm{T}_{3}$-Jan.

- $\quad T_{4}-F e b$ : Mauchly's test indicated that the assumption of sphericity had been violated, $X^{2}(2)=35.49, p<.001 ;$ therefore, degrees of freedom were corrected using Greenhouse-Geisser estimates of sphericity $(\dot{\varepsilon}=.73)$. The 
results revealed a significant main effect for group type, $F(1.46,112.16)=$ $6.36, p>.01$. Post hoc pair wise comparisons using the Bonferroni correction revealed that both ideal work and ideal play groups had significantly larger composition scores than peer networks ( $\mathrm{p}<.05$ and $\mathrm{p}<.05$, respectively). There were no significant differences between ideal work and ideal play groups.

- $\quad T_{5}$-Apr: Mauchly's test indicated that the assumption of sphericity had been violated, $X^{2}(2)=17.33, p<.01$; therefore degrees of freedom were corrected using Huynh-Feldt estimates of sphericity $(\varepsilon=.83)$. The results revealed a significant main effect for group type, $F(1.65,107.40)=4.34, p<.05$. Post hoc pair wise comparisons using the Bonfenroni correction showed that both ideal work and ideal play groups had significantly larger composition scores than peer networks $(\mathrm{p}<.05$ and $\mathrm{p}<.05$, respectively). There were no significant differences between ideal work and ideal play groups. Homophily Among Different Group Types. Correlations were computed between children's individual engagement scores and their (a) peer network composition scores, (b) ideal work group composition scores, and (c) ideal play group composition scores at each of the five measurement points. The results suggested significant positive correlations at all five measurement points for all three groups (see Table 6.8). The homogeneity across the year between individuals and their ideal work and play groups showed a similar pattern to the homogeneity between individuals and 
their peer networks; all three showed increases and then leveling off as the year progressed. However, homogeneity with peer network members increased quicker (by $\mathrm{T}_{2}$-Dec) than the homogeneity with ideal work and ideal play groups (which did not increase until $\mathrm{T}_{3}$-Jan for ideal play groups and $\mathrm{T}_{4}$-Feb for ideal work groups).

Table 6.8

Homogeneity Among Individuals and Groups

Measurement Point

\begin{tabular}{|c|c|c|c|c|c|}
\hline 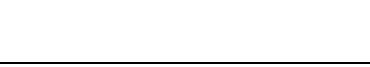 & $\mathrm{T}_{1}-\mathrm{Nov}$ & $\mathbf{T}_{2}$-Dec & $\mathbf{T}_{\mathbf{3}}$-Jan & $\mathrm{T}_{4}$-Feb & $T_{5}-A p r$ \\
\hline \multicolumn{6}{|l|}{ Networks } \\
\hline$r$ & $.27 * *$ & $.40 * * *$ & $.45 * * *$ & $.45 * * *$ & $.48 * * *$ \\
\hline $\mathrm{N}$ & 98 & 102 & 102 & 98 & 96 \\
\hline \multicolumn{6}{|l|}{ Ideal Work Groups } \\
\hline 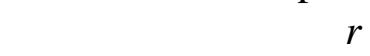 & $.27 *$ & $.31 * *$ & $.34 * *$ & $.44 * * *$ & $.54 * * *$ \\
\hline $\mathrm{N}$ & 91 & 77 & 65 & 84 & 80 \\
\hline
\end{tabular}

Ideal Play Groups

$\begin{array}{cccccc}r & .23 * & .27 * & .45 * * * & .51 * * * & .49 * * * \\ \mathrm{~N} & 87 & 71 & 59 & 81 & 76\end{array}$

${ }^{*} \mathrm{p}<.05 ;{ }^{* \star} \mathrm{p}<.01,{ }^{* \star *}<.001$

\section{Differences in Engagement Between Classmates Whom the Child Would Like to}

Potentially "Select" Versus Potentially "Eliminate"

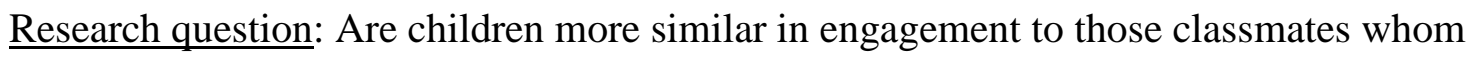
they would like to select than those classmates whom they would like to eliminate? If so, do the differences in homogeneity continue across a school year?

Hypothesis: Children will be similar in engagement to those peers whom they want to select and different in engagement from those whom they want to eliminate. 
The analyses for this research question depended on the outcomes for research question \#3 (which examined the differences between ideal work and ideal play groups). It was proposed that if ideal work groups and ideal play groups seemed to be similar, then the two would be aggregated together. That is, the nominations would be combined and new compositional scores would be computed with the included group members. If ideal work and ideal play groups seemed to be different from one another, then only ideal play groups would be examined. For the dissertation, the focus was on similarity in size and composition (the two constructs of focus). It should be noted, however, that similarity in these two constructs does not imply that the same individuals are nominated for each group type. That is, children may nominate a similar number of children for each group who have similar engagement scores but choose completely different children to do a school project with than those chosen to merely hang out with (see Appendix D for analyses of the overlap in the names of children who were nominated in the two groups). Nonetheless, the premise is held for the dissertation that it is not important to know the differences in the names of the classmates with whom the child would like to do a school project versus those with whom they would like to merely hang out. What matters is whether the groups are similar in composition and size. If they do not differ in size and composition then they are considered to be similar developmental contexts for the child.

As described in the previous section under research question \#2, ideal work and play groups do appear to be similar structure and composition. Therefore, the two groups were aggregated and hereafter referred to as composed ideal peer groups. Prior to 
providing the outcomes of the data analyses on whether children are more similar in engagement to classmates they would like to select than those classmates they would like to eliminate, comparisons among the structure, composition, and homogeneity of composed ideal peer groups to children's peer networks are provided.

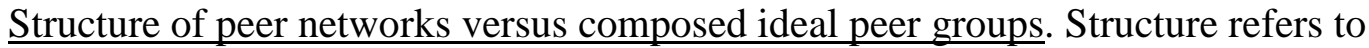
the number of children in a given group. A child's peer network size was defined as the number of significant interconnections a child has and composed ideal peer group size was determined by the aggregate number of peers a child nominated for his/her ideal work and ideal play groups (peers nominated in both groups were counted only once). These total counts were tallied for each group type and each measurement point. Figure 6.13 illustrates the general trend in the average peer network and composed ideal group size for the entire sample of children across the school year. Table 6.9 provides the range, mean, and standard deviation for each measurement point. 
Figure 6.13. Average Size of Peer Networks and Composed Ideal Groups

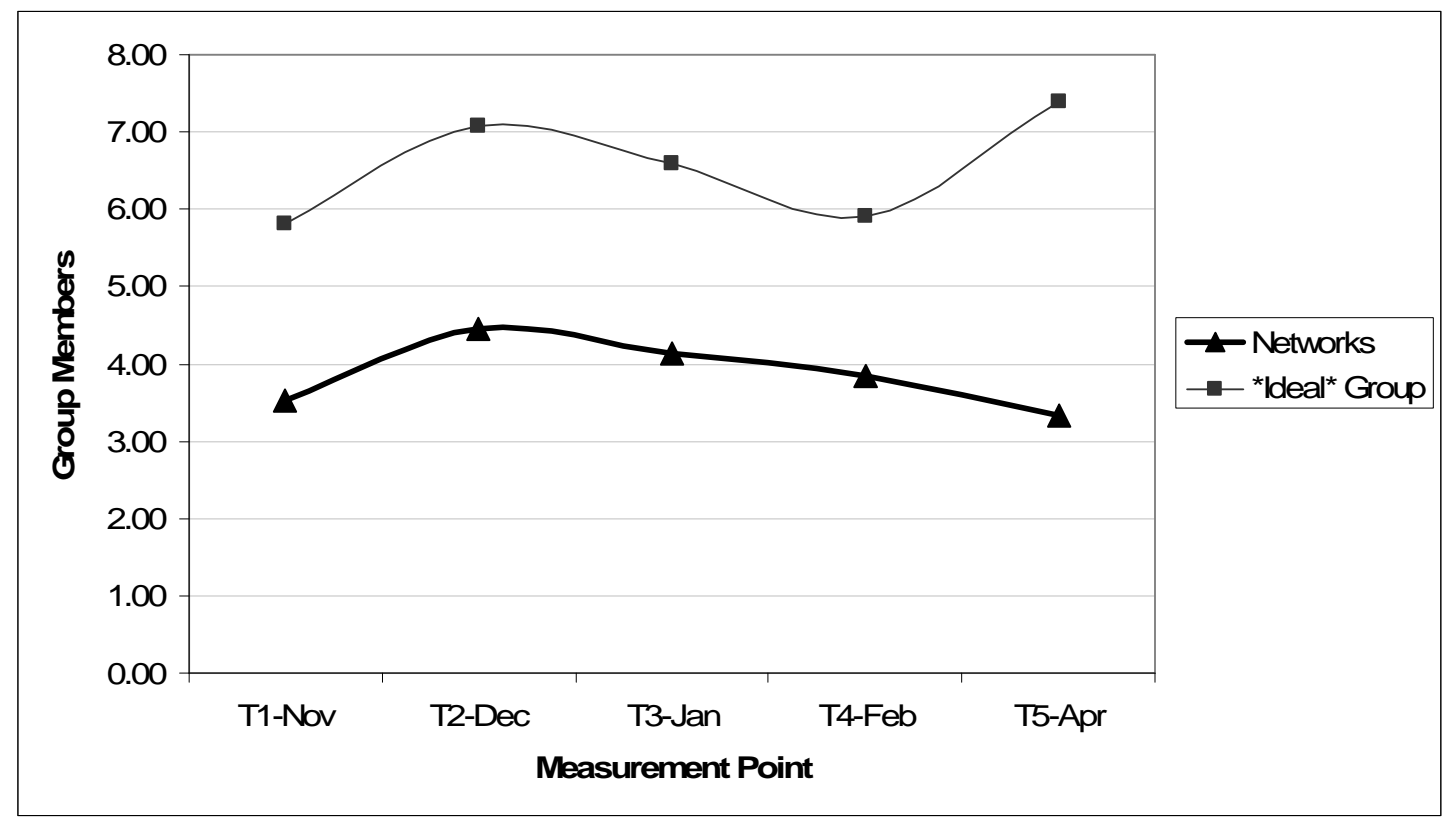

\section{Table 6.9}

Size of Peer Networks and Composed Ideal Groups

Measurement Point

\begin{tabular}{rccccc} 
& $\mathbf{T}_{\mathbf{1}}$-Nov & $\mathbf{T}_{\mathbf{2}}$-Dec & $\mathbf{T}_{\mathbf{3}}$-Jan & $\mathbf{T}_{\mathbf{4}}$-Feb & $\mathbf{T}_{\mathbf{5}}$-Apr \\
\hline Peer Network & & & & & \\
Range & $0-10$ & $0-15$ & $0-10$ & $0-8$ & $0-8$ \\
Mean & 3.51 & 4.45 & 4.14 & 3.85 & 3.32 \\
SD & 2.16 & 2.71 & 2.18 & 2.16 & 2.17 \\
$\mathrm{~N}$ & 107 & 107 & 106 & 106 & 109 \\
Composed & & & & & \\
Ideal Group & & & & & \\
Range & $1-14$ & $1-17$ & $0-17$ & $2-14$ & $1-17$ \\
Mean & 5.80 & 7.08 & 6.60 & 5.92 & 7.40 \\
SD & 2.65 & 3.46 & 3.55 & 2.60 & 3.34 \\
$\mathrm{~N}$ & 91 & 79 & 67 & 83 & 83 \\
\hline
\end{tabular}


On average, children had about 3.51 classmates in their peer networks and 5.80 in their composed ideal groups at the beginning of the year. Both groups increased by about one classmate at $T_{2}$-Dec. This was followed by a decrease for both groups at $T_{3}$-Jan and $\mathrm{T}_{4}$-Feb (with peer networks decreasing more gently than composed ideal groups). While peer networks continued to gently decrease for $\mathrm{T}_{5}$-Apr, ideal groups experienced a sharp increase by a little over one classmate, resulting in a large lead of approximately 4 classmates more than in peer networks. Paired sample $t$-tests were run to determine whether differences existed between the size of peer networks and composed ideal groups. Because multiple comparisons were made, the risk of type I error was higher. To help reduce this risk, only those results where $p<.001$ were interpreted as significant. The results suggested that composed ideal groups were significantly larger than peer networks at all five measurement points, $t(90)=6.45, p<.001\left(\mathrm{~T}_{1}\right.$-Nov $), t(78)=5.06, p$ $<.001\left(\mathrm{~T}_{2}-\mathrm{Dec}\right), t(66)=4.24, p<.001\left(\mathrm{~T}_{3}-\mathrm{Jan}\right), t(82)=5.58, p<.001\left(\mathrm{~T}_{4}-\mathrm{Feb}\right), t(82)=$ 3.22, $p<.001\left(\mathrm{~T}_{5}-\mathrm{Apr}\right)$.

Composition of peer networks versus composed ideal peer groups. The group composition for each child's peer network and composed ideal group was computed at each measurement point as described earlier. Figure 6.14 illustrates the general trend in the average group composition across the school year for peer networks and composed ideal groups. Table 6.10 provides the range, mean, and standard deviation for each measurement point for each group type. 
Figure 6.14. Average Composition of Peer Networks and Composed Ideal Groups

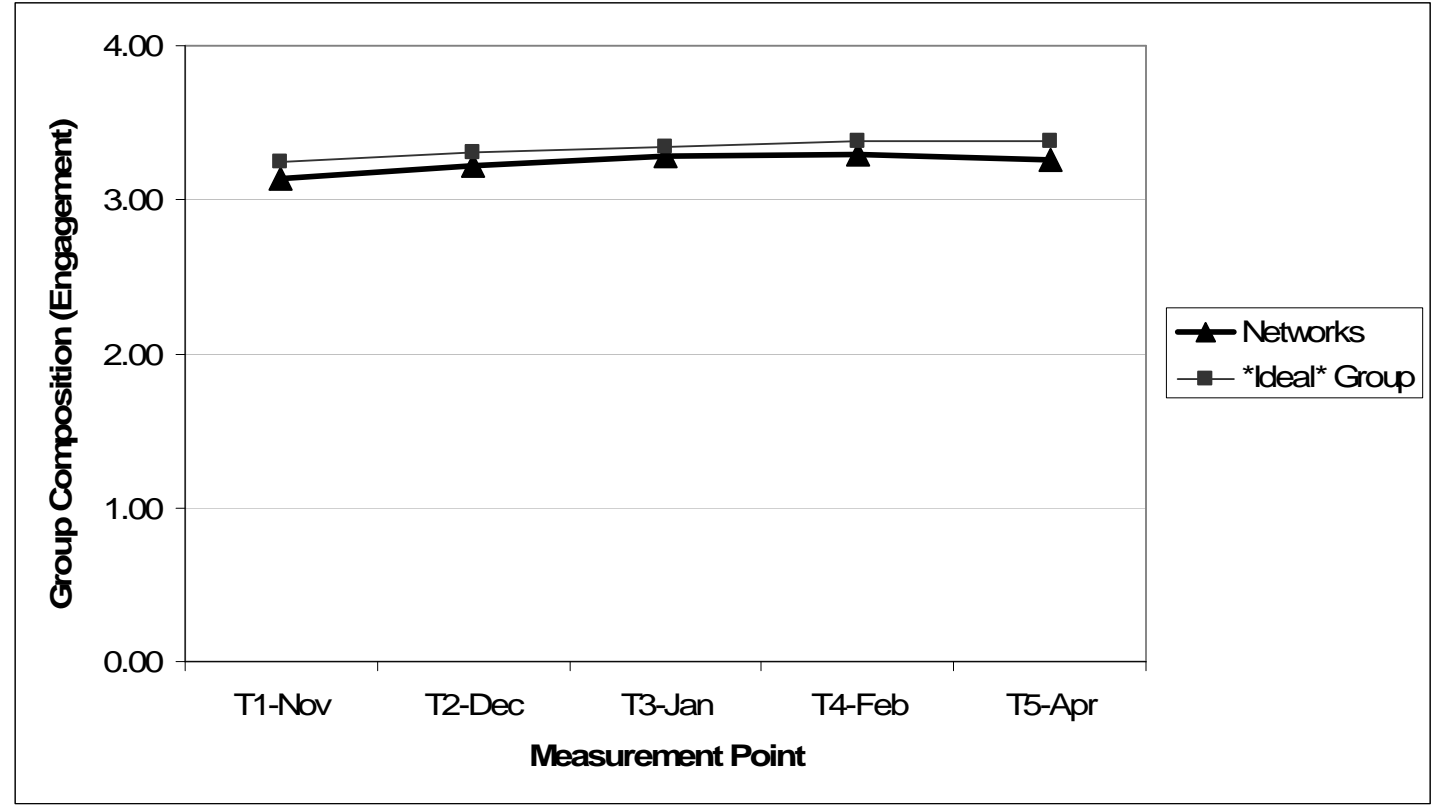

Table 6.10

Peer Network And Composed Ideal Group Composition

\begin{tabular}{rccccc}
\hline & \multicolumn{5}{c}{ Measurement Point } \\
\cline { 2 - 6 } & $\mathbf{T}_{\mathbf{1}}$-Nov & $\mathbf{T}_{\mathbf{2}}$-Dec & $\mathbf{T}_{\mathbf{3}}$-Jan & $\mathbf{T}_{\mathbf{4}}$-Feb & $\mathbf{T}_{\mathbf{5}}$-Apr \\
\hline Networks & & & & & \\
Range & $1.77-3.96$ & $2.25-3.88$ & $2.08-3.89$ & $1.93-3.92$ & $1.95-4.00$ \\
Mean & 3.14 & 3.22 & 3.28 & 3.30 & 3.26 \\
SD & 0.41 & 0.39 & 0.39 & 0.42 & 0.41 \\
$\mathrm{~N}$ & 98 & 102 & 102 & 98 & 96 \\
Ideal Work Groups & & & & & \\
Range & $1.77-3.83$ & $1.69-3.83$ & $2.45-2.95$ & $2.32-3.84$ & $2.76-2.78$ \\
Mean & 3.25 & 3.31 & 3.35 & 3.38 & 3.38 \\
SD & 0.34 & 0.37 & 0.32 & 0.34 & 0.23 \\
$\mathrm{~N}$ & 91 & 79 & 67 & 83 & 83 \\
\hline
\end{tabular}


On average, children's composed ideal groups had relatively high composition scores and maintained these compositions scores across the school year, mirroring the trend of peer networks as well as individual engagement scores. Paired sample t-tests were run to determine whether peer networks and composed ideal groups differed in composition. Because multiple comparisons were made, the risk of type I error was higher. To help reduce this risk, only those results where $p<.001$ were interpreted as significant. The results suggested no significant differences at any of the five measurement points, $\mathrm{T}_{1}$-Nov, $\mathrm{t}(85)=1.38, p>.05, \mathrm{~T}_{2}$-Dec, $\mathrm{t}(73)=1.58, p>.05, \mathrm{~T}_{3}$-Jan, $\mathrm{t}(64)=.84, p>.05, \mathrm{~T}_{3}-\mathrm{Feb}, \mathrm{t}(76)=2.00, p<.05$ and $\mathrm{T}_{5}-\mathrm{Apr}, t(73)=2.63, p<.01$.

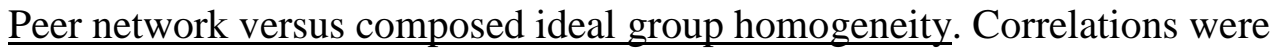
computed between individual engagement scores and the composition scores of composed ideal groups. Similar to network homogeneity, the results suggested significant positive correlations at all five measurement points (see Table 6.11). In general, homogeneity among both groups increased within the first part of the year and remained relatively steady during the latter part of the year. Nonetheless, increases in homogeneity occurred earlier among networks than among composed ideal groups (in $\mathrm{T}_{2}$-Dec compared to $\mathrm{T}_{3}$-Jan). 


\section{Table 6.11}

Peer Network Versus Composed Ideal Group

Homogeneity

\begin{tabular}{|c|c|c|c|c|c|}
\hline & \multicolumn{5}{|c|}{ Measurement Point } \\
\hline & $\mathbf{T}_{1}$-Nov & $\mathbf{T}_{2}$-Dec & $\mathbf{T}_{\mathbf{3}}$-Jan & $\mathrm{T}_{4}$-Feb & $\mathbf{T}_{5}$-Apr \\
\hline \multicolumn{6}{|c|}{ Networks } \\
\hline$r$ & $.27 * *$ & $.40 * * *$ & $.45 * * *$ & $.45 * * *$ & $.48 * * *$ \\
\hline $\mathrm{N}$ & 98 & 102 & 102 & 98 & 96 \\
\hline \multicolumn{6}{|c|}{$\begin{array}{l}\text { Composed Ideal } \\
\text { Groups }\end{array}$} \\
\hline$r$ & $.27 * *$ & $.30 * *$ & $.41 * * *$ & $.49 * * *$ & $.50 * * *$ \\
\hline $\mathrm{N}$ & 91 & 79 & 67 & 83 & 83 \\
\hline
\end{tabular}

$\underline{\text { Homogeneity among potential "selected" classmates versus "eliminated }}$

classmates. As described earlier, comparisons were made between those classmates in a child's peer network and those nominated to be in his/her composed ideal group.

Classmates whom the child nominated for his/her composed ideal group at $\mathrm{T}_{\mathrm{i}}$ but who were not observed to be a part of this child's network at the same measurement point were considered to be those who could potentially be "selected". Classmates whom the child did not nominate for his/her ideal group at $\mathrm{T}_{\mathrm{i}}$ but who were observed as being part of that child's peer network at the same measurement point were considered to be those who could potentially be "eliminated". It was assumed that children would be more similar to those classmates whom they want to potentially "select" than those whom they want to potentially "eliminate". Composition scores of groups of potentially "selected" 
classmates and potentially "eliminated" classmates were computed at each measurement point using the same technique for computing composition scores of peer networks, ideal work groups, and ideal play groups. Correlations were run between individual scores and the composition scores of potentially "selected" classmates at all five measurement points. These are displayed along with the correlations between individual scores and the composition scores of potentially "eliminated" classmates in Table 6.12.

Table 6.12

Homogeneity Among Individuals and Groups of Potentially "Selected" Vs "Eliminated" Classmates

\section{Measurement Point}

\begin{tabular}{rccccc}
\cline { 2 - 6 } & $\mathbf{T}_{\mathbf{1}}$-Nov & $\mathbf{T}_{\mathbf{2}}$-Dec & $\mathbf{T}_{\mathbf{3}}$-Jan & $\mathbf{T}_{\mathbf{4}}$-Feb & $\mathbf{T}_{\mathbf{5}}$-Apr \\
\hline Potentially "Selected" & & & & & \\
Classmates & & & & & \\
$r$ & $.20 *$ & $.27^{*}$ & $.38^{*}$ & $.25^{*}$ & .16 \\
$\mathrm{~N}$ & 81 & 69 & 38 & 76 & 75 \\
& & & & & \\
Potentially & & & & & \\
"Eliminated" & & & & & \\
Classmates & & & & & \\
$r$ & .20 & .27 & .20 & .11 & .07 \\
$\mathrm{~N}$ & 58 & 54 & 55 & 45 & 41 \\
\hline
\end{tabular}

Note: Italics indicate non-significant correlation

${ }^{*} \mathrm{p}<.05 ;{ }^{* *} \mathrm{p}<.01,{ }^{* \star *}<.001$

The results suggested significant positive correlations between individuals and their potentially "selected" classmates at $\mathrm{T}_{1}-\mathrm{Nov}$ through $\mathrm{T}_{4}-\mathrm{Feb}$. At $\mathrm{T}_{5}$-Apr, the correlation was not significant. While the associations were positive between individuals 
Analyses and Results: Peer Network Emergence 130 and potentially "eliminated" classmates at all five measurement points across the school year, they were minimal and not statistically significant.

\section{CHAPTER SUMMARY}

This chapter provided the analyses that were conducted in order to examine the emergence of and changing nature of children's natural peer groups in the classroom (referred to as peer networks). The results were presented in three sections: Initial analyses, change in peer networks across time, and proximal processes from which the peer group emerges. In the first section, analyses focused on computations of individual engagement in the classroom (and the trajectories of these scores across the school year), identification of peer networks, ideal work groups, ideal play groups, groups of classmates to be potentially "selected" and potentially "eliminated", and computation of the psychological characteristics of each group type. On average, children were found to begin the school year highly engaged. A repeated measures ANOVA found no significant changes in engagement across the school year, but significant between group effects were found for gender, suggesting that girls were more engaged than boys.

The results in the second section (change in peer networks across time) addressed the first two of the four research questions for the dissertation: change in network size and change in network composition. Repeated measures ANOVAs were used to determine whether the network structure and/or composition changed significantly across the school year. The results suggested that while girls' networks were significantly higher 
in composition scores than boys' networks, there were no significant differences between boys and girls in network size or in member turnover. With regard to change across time, the results suggested that networks remained the same in composition despite considerable changes in the number and specific members of the network.

The results in the third section (proximal processes from which the peer group emerges), addressed the last two of the four research questions for the dissertation. For research question \#3, differences in the structure and composition of peer networks, ideal work groups, and ideal play groups were examined. Repeated measures ANOVAs were ran separately at each measurement point for each construct with the three types of groups as the within subjects variables. The results revealed no significant differences in the size ideal work and ideal play groups except at $\mathrm{T}_{3}$-Jan, where ideal work groups were found to be significantly larger than ideal play groups. Ideal work groups were also significantly larger than peer networks at $\mathrm{T}_{3}$-Jan, and both ideal work and ideal play groups were larger than peer networks at $\mathrm{T}_{4}-\mathrm{Feb}$ and $\mathrm{T}_{5}$-Apr. With regard to group composition, the results suggested that ideal work and ideal play groups did not differ significantly from one another; they did, however, have significantly higher composition scores than peer networks at all measurement points except $\mathrm{T}_{2}$-Dec.

Because ideal play groups and ideal work groups did not differ in size or composition (aside from the one noted exception), they were combined for the subsequent analyses to form what was referred to as children's composed ideal groups. composed ideal groups were found to be significantly larger in size than peer networks at 
all five measurement points but did not differ significantly from peer networks in composition.

Correlations were computed between children's individual engagement scores and the members of their peer networks and composed ideal groups to determine how similar children were to the members of these groups. The results suggested significant positive correlations at all five measurement points for both groups. In general, homogeneity among both groups increased within the first part of the year and remained relatively stable during the latter part of the year. Nonetheless, increases in homogeneity occurred earlier among networks than among composed ideal groups.

The results of the final analyses addressed research question \#4 and focused on the differences among classmates to be potentially "selected" versus potentially "eliminated". Correlations were computed to determine if children were more similar to those classmates to be potentially "selected" than those classmates to be potentially "eliminated". The results showed significant positive correlations between children and those whom they would like to potentially "select" at $T_{1}-$ Nov through $T_{4}-F e b$. While the associations were positive between children and those whom they would like to potentially "eliminate', the correlations were not significant. 


\section{CHAPTER 7}

\section{DISCUSSION OF RESULTS, LIMITATIONS OF THE STUDY, AND SUGGESTIONS FOR FUTURE RESEARCH}

Organized into four sections, this chapter provides the final chapter of the dissertation. The first section contains a brief summary of the dissertation's focus, methods, and analytic approach. In the second section, implications of the results (presented in chapter 6) are discussed. The third section provides a discussion of the significance of the study. Limitations and suggestions for future research are presented in the fourth section. A summary of all four sections is provided at the end.

\section{SUMMARY OF THE DISSERTATION'S FOCUS, METHODS, AND ANALYTIC APPROACH}

This study examined peer group processes in the classroom that can potentially explain why the motivationally "rich" get "richer" whereas the motivationally "poor" get "poorer". In contrast to prior research on group processes which focuses on socialization influences from group to individual, this study examined contributions from the individual to his/her group. While it is acknowledged that groups can be influential for shaping children's behaviors in the classroom (c.f., Sage \& Kindermann, 1999; 2000), the viewpoint of this dissertation is that children actively choose group members based on their own self-system state and therefore create their own peer environments in which they develop (c.f., Scarr \& McCartney, 1983). 
Viewed as open complex systems, children's natural peer groups and the underlying processes by which they are created were examined using longitudinal data collected across five measurement points during the 2000-2001 school year. Children's classroom engagement was assessed using Wellborn's (1991) self-and teacher- reports of classroom engagement, peer networks were identified using Cairns' and colleagues' (1985) SCM procedure, and children's associative preferences (ideal groups) were obtained via self-reports of who children would like to hang out with and/or do a school project with. A multiple systems perspective was used to examine influences from the individual to his/her peer network. First, the focus was on the changing nature of a child's peer network context. Attention was given specifically to the change in structure and composition of children's networks. It was assumed that these attributes emerge as a result of the characteristics of each network member and the interactions or proximal processes between them. Next the focus shifted to the specific interaction patterns (or proximal processes) from which the peer network emerges; namely, potential "selection" and "elimination" processes.

Because this is among the first studies to date to examine change in children's groups (as well as children's associative preferences in the classroom) in intervals as small as one to two months apart, explicit expectations were not provided. Rather, the outcomes were mostly exploratory and descriptive in nature. However, the findings are assumed to provide the foundation necessary for higher order hypotheses regarding how children contribute to change in their peer contexts. Because such higher order 
hypotheses cannot be generated without first having a rich description of the data, the focus of this dissertation was to provide descriptions of patterns of change across time as well as illustrate how a systems framework can be applied for studying peer group processes in the classroom.

\section{IMPLICATIONS OF THE RESULTS}

\section{Individual Engagement in the Classroom}

Congruent with previous research examining change in individual engagement across a single school year, children were, on average, found to be highly engaged at the beginning of the year and remained highly engaged throughout the school year (with girls showing significantly higher engagement levels than boys; see Kindermann, 1993, 2007; Sage \& Kindermann, 1999). It should be noted that while engagement levels were found to be high in a single school year and remained high, research examining trends in motivational change across multiple school years suggests a continuous decline between kindergarten and high school completion or drop-out (Eccles \& Wigfield, 2002; Wigfield, et al., 2006). Hence it could be that motivational loss is more likely to occur between school years rather than within a school year. Research examining changes in school motivation across multiple years suggests that the most striking losses occur during transitions between years, particularly those from elementary to middle school and middle school to high school. This decrease in engagement is even more evident for boys 
and students who are economically disadvantaged and/or of minority status (see Eccles, Wigfield, \& Schiefel, 1998 and Wigfield, et al., 2006 for reviews).

\section{Change in Peer Networks Across Time}

Children's peer networks ranged in size from 0-15 across the school year, with an average size ranging from 3.32-4.45. This size is slightly smaller than the average group size found among self-selected groups (or "cliques", Ennett \& Bauman, 1994; Urberg, Degimencioglu, \& Pilgram, 1997), but similar to the size found in studies examining peer networks in a classroom (Kindermann, 1993, 2007; Sage \& Kindermann, 1999). In this study there were no differences in the size of boys' and girls' peer networks. This contradicts the conventional view that girls tend to prefer smaller, more exclusive, groups than boys (c.f., Benenson, 1990; Beneson, Apostoleris, and Parness, 1997; Berndt, 1982). It also does not align with Chan and Poulin's (2007) findings that girls' friendship networks were larger than boys' friendship networks. These contrasting findings may be due in part to the different methods used to define the group. The social cognitive procedure was used in this study to identify groups of kids known to hang out with one another, whereas Benenson and colleagues used sociometric techniques and Berndt, Chan, and Poulin used friendship nominations.

Previous research on the same sample suggested that children experienced a 56\% member turnover from T1-Nov to T4-Apr (Sage, Hiller, Weaver, Newton-Curtis, \& Kindermann, 2002). The results from the current study suggested that the majority of this change appears to have occurred within the first few months of the school year (45\% 
group turnover between $\mathrm{T}_{1}$-Nov and $\mathrm{T}_{2}$-Dec; $47 \%$ between $\mathrm{T}_{2}$-Dec and $\mathrm{T}_{3}$-Jan). In contrast, only about $20-25 \%$ member turnover occurred during the middle and latter months of the school year. During these latter months $17 \%$ of the total member turnover was due to members lost whereas only $6 \%$ of the turnover was due to members gained.

The finding that member turnover slows to approximately $20-25 \%$ during the latter part of the school year mirrors the findings in Chan and Poulin's (2007) study of the stability of adolescent friendship groups. The authors found high stability (about $66 \%$ of friends were maintained) during the second half of the school year; they did not find any variation among the five measurements points in their study. As stated by the authors, the converse of stability is instability. Instability of a group is similar to what is referred to as member turnover in the dissertation. In Chan and Poulin's study, about $34 \%$ of friends "turned over" during the latter half of the school year. This lower turnover during the latter part of the year among friendship and peer networks may make it more difficult for new students who come in the middle of the year to form peer relations. Studies show that mobile students are more likely to experience difficulties with peer relationships than non mobile students (c.f., South \& Haynie, 2004). Perhaps it is even more difficult for new students who come during the middle of the year (in contrast to new students who come at the beginning of the year) to enter existing peer network groups due to the decrease in member turnover during the latter part of the school year.

Patterns across the school year suggested that the size of children's networks increased significantly between $T_{1}-N o v$ and $T_{2}$-Dec, remained the same between $T_{2}$-Dec 
Discussion: Peer Network Emergence 138

and $\mathrm{T}_{4}$-Feb, and then decreased significantly between $\mathrm{T}_{4}-\mathrm{Feb}$ and $\mathrm{T}_{5}$-Apr. At the time of the significant increase in network size $\left(\mathrm{T}_{1}-\mathrm{Nov}\right.$ to $\left.\mathrm{T}_{2}-\mathrm{Dec}\right)$, children were also experiencing relatively large member turnover (45\%), suggesting that a good portion of the increase may be due to additions (members gained) to the group. While member turnover was lower (23\%) when significant decreases in network size occurred (between $\mathrm{T}_{4}$-Feb and $\mathrm{T}_{5}$-Apr), the turnover was mostly due to members lost as opposed to members gained (17\% members lost versus 6\% members gained). The finding that member turnover occurred at the same time as significant increases in network size is consistent with Chan and Poulin's (2007) and Neckerman's (1997) research that showed negative associations between group size and member stability.

Patterns of change in network composition mirrored those of individual engagement; on average, networks had relatively high engagement composition scores at the beginning of the year and these remained high throughout the school year (with girls' networks having significantly higher composition scores than boys' networks). These findings confirm prior research suggesting that peer network composition remains relatively stable across the school year. This stability in peer network composition despite considerable changes in membership can imply that new members are added (selected) and old members are eliminated in a way that the psychological characteristics of the network are preserved (see Kindermann, 1993, 2007; Sage \& Kindermann, 1999; Hillier, et al., 2003). 
Correlations between children and their network members (homophily) revealed that children were somewhat similar to their network members at the beginning of the year $\left(\mathrm{T}_{1}\right.$-Nov), confirming previous research and suggesting that initial network affiliation is based (at least somewhat) on children's own engagement level in the classroom (c.f., Kindermann, 1993, 2007; Sage \& Kindermann, 1999). Between November and January children experienced a great amount of member turnover in their networks and while the average composition of the network remained the same, the homogeneity among members increased. This increased homogeneity held steady the remainder of the year despite a slowing down of the member turnover between January and April.

Using selection processes as an explanation of homogeneity (c.f., Kandal, 1978), it can be inferred that children begin the school year initially affiliating with children who are somewhat similar in engagement to themselves. Within the first two months of school, knowledge about their classmates' engagement levels may become more transparent (due to more frequent interaction with and/or observations of others in the classroom) and large shifts in network affiliations occur so that children eliminate those who are less like themselves with regard to engagement and select new members who are more similar to themselves in engagement, leading to greater homogeneity.

As noted earlier in chapter 2, homogeneity can also be a result of concurrent socialization (Kandal, 1978). In prior research, socialization effects were assumed if individual children's engagement at $\mathrm{T}_{\mathrm{n}}$ could be predicted from the child's group 
engagement at $\mathrm{T}_{\mathrm{n}-1}$ (controlling for the child's own engagement at $\mathrm{Tn}$ ). Post hoc analyses were therefore conducted to determine whether the homogeneity found could also be explained by socialization influences (see Appendix E for details of these analyses). The results suggested that when member turnover was high, children's engagement at $T_{n}$ could not be significantly predicted from their network composition at $\mathrm{T}_{\mathrm{n}-1}$. However, when member turnover was low, children's engagement at $T_{n}$ could be significantly predicted from their network composition at $\mathrm{T}_{\mathrm{n}-1}$. Therefore, it could be inferred that the significant changes in network structure during the first half of the school year was likely due to selection and elimination processes. This exchange involves a child selecting new members who are more similar in engagement to him/herself and eliminating those members who are less similar. In turn, socialization effects from those members within the newly selected group (along with continual selection and elimination efforts) maintain this homogeneity during the latter part of the school year. These changes in children's peer networks coincide with Arrow's (1997) concept of robust equilibrium. That is, the peer system moved quickly toward a stable state and then maintained itself at that state.

\section{Proximal Processes By Which The Peer Group Emerges}

Despite having relatively similar ranges in number of group members, networks were on average significantly smaller in size than composed ideal groups at all five measurement points. In general, composed ideal groups contained approximately two more members than networks at each measurement point and more closely mirrored the size of self- 
selected groups or “cliques” (c.f., Ennett \& Bauman, 1994; Urberg, Degimencioglu, \& Pilgram, 1997). Nonetheless, despite being different in size, networks and composed ideal groups were not significantly different in their psychological profiles (composition) at any of the five measurement points.

With regard to similarity among affiliates, the data suggested that at the beginning of the school year children were somewhat similar to network members and the peers they nominated for their composed ideal groups. This homogeneity appeared to increase during the first part of the year and then remained relatively steady during the latter part of the year. Nonetheless, increases in homogeneity occurred earlier among network groups than it did among composed ideal groups. By the end of the year, children were slightly more similar to those children with whom they would like to hang out and/or do a school project with than their network groups, providing indication of selective optimization (c.f., Baltes \& Baltes, 1990) in children's composed ideal peer environment. Selective optimization implies that individuals seek out those environments that enhance their own development (see also "Niche Picking”, Scarr \& McCartney, 1983).

Examination of the homogeneity among groups of peers with whom children would like to potentially "select" versus "eliminate" suggested that children were more similar to those whom they would like to potentially "select" than those whom they would like to potentially "eliminate". While additional examination of whether children do indeed eventually select or eliminate the children as assumed is needed, the results do 
tend to support the notion that children likely create a peer group context (based on their self-system state) that in turn becomes an important source of influence.

\section{Attention to the "Relevant" Environment}

The results of this dissertation provided evidence that peer groups are complex selforganizing systems that emerge as a result of mutual liking and/or similarity (c.f., Hinde, 1978). As discussed in Chapter 3, peer groups are also viewed as open systems; that is, peer groups do not exist in isolation but are embedded within multiple layers of surrounding environment. The boundaries between these layers are permeable so that information passes within and between them. In order to fully understand the peer group system, at least three system levels need to be attended to: individual members, the group as a system, and the various layers of the surrounding environment (Arrow, McGrath, \& Berdahl, 2000). The discussion thus far has focused on the individual members and the group as a system. For this part of the discussion, attention is turned toward the various layers in which the peer group system is situated. Because these various layers are infinite, Lendaris (1986) suggests extrapolating from these layers the relevant components which are defined as the relevant environment. As shown in Figure 3.7: Perceptual stance \#6 and \#7 (see Chapter 3), the classroom context and teacher influences are defined as the higher order elements or relevant environment for the system of focus in this dissertation.

One thing to be mindful of when interpreting the results of the dissertation, particularly those results regarding the homogeneity among individuals and groups, is the 
effect of the teachers themselves. Earlier in the dissertation, the homogeneity found among individuals and groups was attributed to the result of group emergence based on mutual liking and/or similarity among individuals and their group members. However, it is possible that the teachers played a critical role in the formation of these groups. Along with nationwide trends to organize classroom activities as more group-oriented, the teachers paid more attention to organizing work groups than teachers in previous studies (e.g., Kinderman, 1993).

While the increase and then eventual stable homogeneity across the year in children's peer networks was attributed to selection effects along with concurrent peer socialization, it is possible that group homogeneity was due to socialization forces from the teacher. As Skinner and Belmont's (1993) study showed, teachers have been found to interact differently with students who enter a classroom motivationally "rich" than with students who enter the classroom motivationally "poor" and this differential interaction has effects on how students change across time (see Rosenthal \& Jacobsen, 1968, for a discussion of the Pygmalion Effect). Differential teacher treatment may extend to entire groups of students who are motivationally similar (Brophy, 1985). Teachers may treat students alike whom they perceive to be similar, and the students may change in a similar way as a result. 


\section{SIGNIFICANCE OF THE STUDY}

This dissertation provided many contributions to the study of children's natural peer groups as contexts for academic development. While it is acknowledged by peer group researchers that three underlying group processes contribute to intra-individual change in academic development (socialization, selection, and elimination), most research focuses on processes of socialization. Lacking in the literature is an emphasis on group selection and elimination processes. Those researchers who have attended to such processes have resorted primarily to traditional methods to indicate selection processes (i.e., homophily) and have done so only in light of their efforts to uncover socialization processes. This dissertation is one of the few studies that emphasized potential "selection" and "elimination" efforts in the classroom by which the peer context emerges.

A second contribution is that this study employed systems strategies. Groups are viewed as complex open systems. Therefore, in order to effectively study them, attention was given to three systems levels: individual members, the group as a system, and the various layers of the embedded contexts (c.f., Arrow et al., 2005). In addition, a hierarchical systems framework was presented whereby seven different perceptual levels can be attended to so that processes of selection, elimination, and socialization can be delineated and explained in relation to other influences that contribute to children's academic development ${ }^{8}$. Although the dissertation focused on only two of the seven

\footnotetext{
${ }^{8}$ This framework was based on Lendaris' (1986) notions of levels and multiple perspectives and Bronfenbrenner \& Morris' (1998) Bioecological Model of Development.
} 
perspectives, the framework provides a guideline for generating future studies emphasizing the multiple influences on children's academic development.

Yet another significant contribution was the findings of change in natural groups across a single school year in small intervals of one to two months. While there is an abundant amount of research that examines change in groups from Fall to Spring in a single school year, there is currently only one other study besides this dissertation that examines group change across multiple measurement points: Chan and Poulin's (1997) study of the stability of young adolescent friendship groups. Descriptions of these microtime changes have provided a better understanding of the continuity and discontinuity of group change across the school year. The results suggested that a good portion of group change occurs during the first part of the school year, indicating the need for studies that focus on microtime changes within children's groups during the first few months of the school year.

\section{LIMITATIONS AND SUGGESTIONS FOR FUTURE RESEARCH}

Although this dissertation contributed to the peer group literature, it nonetheless faced several challenges. These limitations are discussed in the following five sections. Included in each section are suggestions for future research that could minimize the limitation. 


\section{Generalizability of the Study}

The first limitation has to do with the generalizability of the study. Data were collected in a suburban school district in a relatively affluent area. While homogeny among demographic variables can be advantageous because confounding variables are less likely to be introduced (and this is helpful for studies introducing new methods for examination), homogenous samples impede the ability to make generalizations based on the findings. Replication of these findings in a school district with a more diverse sample of children would be useful.

\section{Missing Data}

A second limitation is the missing data on self-report measures of engagement and/or associative preferences. As noted in Chapter 4, overall participation rate was relatively high (84\%); however, there were times that data were missing for an entire measure due to a child being absent or choosing to opt out. The self-report measures were administered during regular classroom sessions to the class as a whole. During each administration of the measures, children were reminded of their rights as participants, including that they did not have to complete the survey if they did not want to. Occasionally children would simply choose not to do the survey and would write at the top of their survey "I don't want to do this". Opting out of the self-report measures seemed to be a popular choice in one classroom in particular where two initially nonparticipating children were vocal about their desire not to participate in the study. By the second measurement point, there were a couple other students who chose to selectively 
opt out of one or more of the measures and by the end of the year, this group of children choosing to opt out grew from a small group of about four children to a larger group of about eight children in one class who chose not to complete the self-report survey of engagement and associative preferences. Missing values on individual engagement scores were estimated as discussed in Chapter 6. However, missing data on the associative preferences measure decreased the sample size of the analyses for research questions \#3 and \#4. An interesting question for future research would be to examine whether the trend in "opting out" occurred among children who naturally chose to hang out with one another.

\section{Teacher Versus Self-Report of Engagement}

For the dissertation, teacher report of engagement was obtained at the beginning and at the end of the school year (similar to my other work) and self-report of engagement was obtained at $\mathrm{T}_{2}$-Dec through $\mathrm{T}_{5}$-Apr. Trends in individual and group engagement were examined using the teacher report of student engagement for $\mathrm{T}_{1}-\mathrm{Nov}$ and the student report of engagement at $\mathrm{T}_{2}$-Dec through $\mathrm{T}_{5}$-Apr. Because of issues with self-report bias (c.f., insert reference here) it would have been ideal to have obtained the teacher report of engagement at all five measurement points. However, this would have put a considerable amount of undue burden on the teacher to complete a 28 question survey for each child in the classroom, five times during the school year. The next best option would have been to use self-reported engagement at all five measurement points but unfortunately the selfreport measure was not administered during the first measurement point. 
It is possible that the use of teacher report for the first measurement point and self-report for the remaining measurement points affected the results. For example, one could assert that the relatively low homogeneity $(r=.27)$ among individuals and networks members at $T_{1}-\mathrm{Nov}$ (followed by a sharp increase in homogeneity to .40 at $T_{2^{-}}$ Dec, then .48 by $\mathrm{T}_{5}$-Apr) was an artifact of the teacher report being used during the first measurement point and the self-report being used the remaining measurement points. That is, perhaps the teachers did not yet know the engagement levels of the individual children well at the beginning of the year. However, this is not believed to be the case for the dissertation. First, previous research examining the concurrence between teacher and self-reports of engagement show positive correlations both in the Fall and Spring (Skinner and Belmont, 1993). Second, the trends in individual engagement levels across the school year presented in the dissertation showed no deviation between the first measurement point and the subsequent measurement points, suggesting that the teacher reported behavior at $\mathrm{T}_{1}$-Nov closely resembled the student report of engagement at $\mathrm{T}_{2^{-}}$ Dec. Hence it seems more plausible to infer that the lower homogeneity among individuals and their network members is due to the individuals themselves not yet knowing their classmates and therefore initially selecting peers who are only somewhat similar to themselves in motivation. Through processes of selection, elimination, and socialization, a child's peer network context evolves across the school year so that it more closely mirrors the motivational level of the child (and as a result homogeneity among individuals and group members increases). 
Another issue with these reports is the possible ceiling effects that can occur due to the item scale. Children were assessed as engaged versus disaffected on a scale of 1-4 for each item in the survey ( 4 being high). Ceiling effects can result in limited variability and therefore increase the likelihood of type I error and correlations involving the variable can be attenuated (c.f., Patrick, Skinner, \& Connell, 1993; see Wang, Zhang, McArle, and Salthouse, 2008 for a discussion of ceiling effects in longitudinal data analyses). Such effects are present if the percentage of respondents who scored the highest score exceed $15 \%$ (c.f., Larsson, Johannesson, Andersson, \& Atroshi, 2009). In the dissertation, individual engagement scores used the full range of the scale and mean scores were found to be on average relatively high (between 3 and 3.5), mirroring the scores of other studies using the same measure. Examination at each measurement point revealed that less than $15 \%$ of the respondents scored a $4(7 \%, 3 \%, 13 \%, 0 \%$, and $8 \%$, respectively). Therefore, ceiling effects were not apparent.

\section{Interview Versus Questionnaire Administration}

The Peer Affiliations Measure which assessed children's peer networks and associative preferences (i.e., ideal work and play groups) was administered via interview during the first and last measurement points. A parallel questionnaire format was used during the second through fourth measurement points due to time constraints. The procedure for both types of administration required the informants to respond from free-recall (no lists or pictures). Students were encouraged to name an unlimited number of nominees. The interview format allowed for an infinite number of nominations more readily than the 
questionnaire format because in the latter, students were bound by a pre-determined number of blank lines with which to indicate their nominations. That is, space was provided on the questionnaire form for up to 12 network groups (with 10 members in each group) and up to 12 classmates for ideal work, ideal play, and friendship groups. Students were told that they did not have to fill all the spaces if they did not want. They were also told that if they needed more space for additional groups or members that additional sheets would be provided to them upon request. Most students did not utilize all the spaces provided; only a small handful of students asked for additional sheets. Although care was taken to limit the likelihood that the results may be confounded by the differences in the administration of the measures across the five measurement points, there is always the possibility that students responded differently when assessed via interview than when they were assessed via questionnaire.

\section{Permeability of the Group}

Peer groups were described as complex open systems (see Chapter 3). They are complex in that they occur naturally and they adapt and change. They are open in that they are embedded within multiple surrounding environments defined by "fuzzy" permeable boundaries. While groups were examined with regard to how they change across time and such changes were interpreted in relation to the surrounding (relevant) environment, the ease with which members can enter or leave the group (known as permeability; c.f., Arrow, et al., 2000) was not examined. For the dissertation, examination focused merely on whether members were retained, gained, or lost. However, the likelihood of members 
being retained, gained, or lost can be affected by the permeability of the group. Four group characteristics have been found to affect the ease with which members move in and out of groups: group size, interpersonal distance, status, and activity (c.f., Knowles, 1971; Milgram, Bickman, Berkowitz, 1969; Milgram and Toch, 1969; Mullen, Copper, Cox, Fraser, Hu, Meisler, Smith, Symon, 2001; South, \& Hayne, 2004). In these studies, larger groups were perceived as being less permeable by outsiders; however, this effect was found to be strongly moderated by interpersonal distance, status, and the specific activity of the group.

Whether the results of the dissertation were affected by children's perceived permeability of groups is difficult to ascertain. To answer that question, it would be necessary to measure group permeability in some way. For example, during the social cognitive procedure administered as part of the Beaverton 2000/2001 study, children were asked (after they nominated a group of children known to affiliate with one another) how difficult it would be to get into that group. Their answers could provide some indication of perceived permeability of the network groups and would be an interesting avenue for future research examining selection and elimination processes.

\section{Patterns of Group Composition Change Across the School Year}

A third limitation is with regard to the examination of the change in group composition across the school year. The analyses in the dissertation focused only on descriptions of group change at each measurement point. To do this, the average group composition was examined across the school year and no within individual differences were found. It 
would be interesting to examine whether between individual differences exist in group composition scores and to focus future analyses on the patterns of change in group composition as a function of the individual him/herself. A launch and change-to-change model could be used to predict how individuals contribute to change in their peer group contexts (for detailed description of these models see Zimmer-Gembeck, 1998; also see Connell \& Skinner, 1990, Kindermann \& Skinner, 1992).

In a Launch Model, individual differences in the initial level of the antecedent variable are assumed to predict differences in the rate of change in the outcome variable. With regard to academic development, initial engagement of each individual child could be assumed to predict (or "launch") the pattern of change in his/her group trajectory. It could therefore be expected that those children with high levels of engagement at the beginning of the year would "launch" their group toward a positive trajectory. In contrast, those with low levels of engagement at the beginning of the year would "launch" their group toward a negative trajectory (see Figure 7.1). 
Figure 7.1. Example of launch

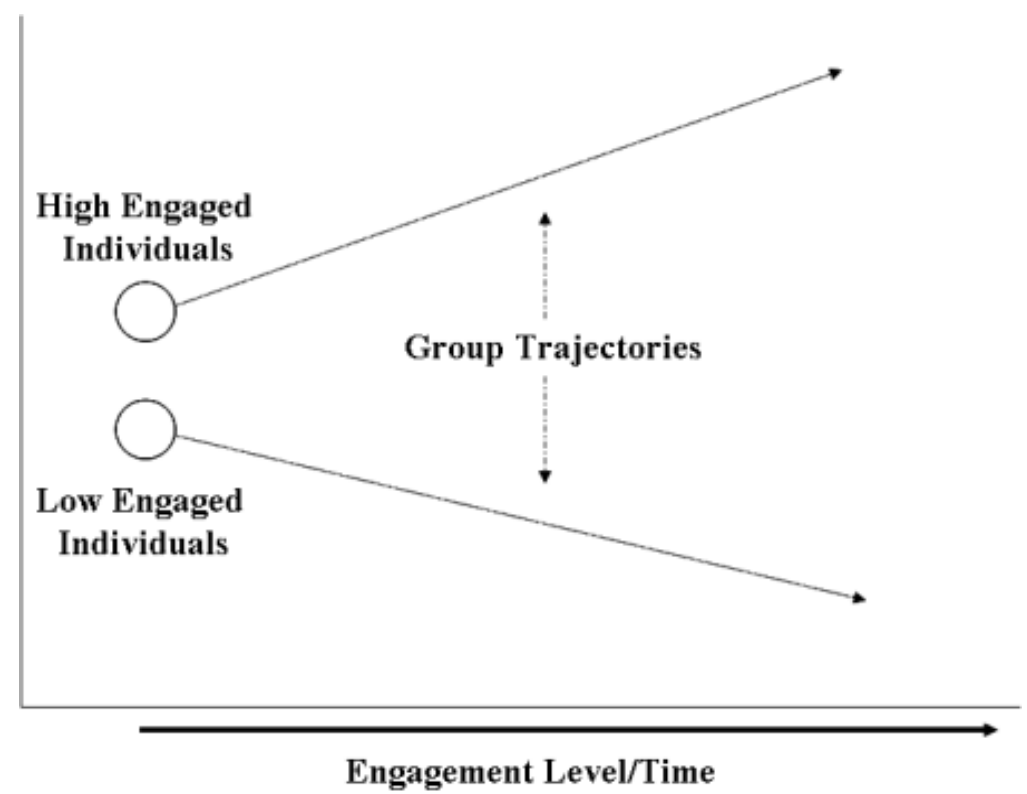

Figure 7.1. Individual's initial engagement at $\mathrm{T}_{1}$ will launch the trajectory of their peer group's engagement across the school year

In a Change-to-Change Model the trajectories of both the antecedent and target variable are examined simultaneously, with one predicting the other. In specific, individual differences in the pattern or rate of change of the antecedent variable (individual engagement) are assumed to predict individual differences in the pattern or rate of change in the target variable (group engagement). For the dissertation topic it could be expected that children who have positive patterns of change (trajectories) in individual classroom engagement across the school year would have peer group contexts that also change positively. In contrast, children who have negative patterns of change in individual classroom engagement across the school year would have peer groups contexts that also change negatively (see Figure 7.2). 
Figure 7.2. Example of change-to-change model

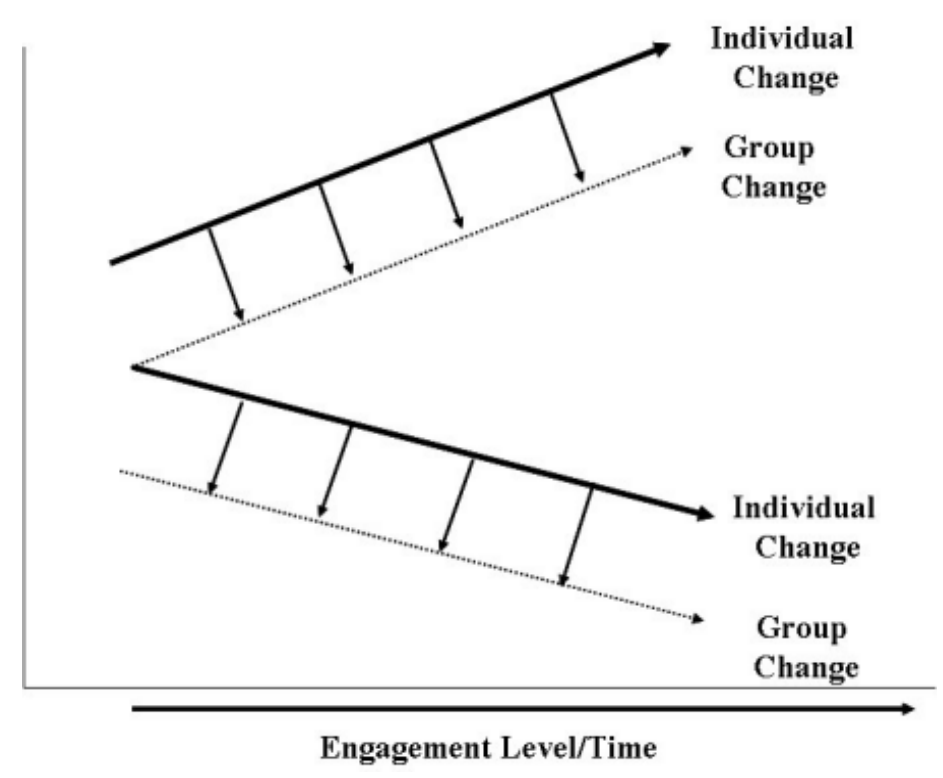

Figure 7.2. As children's individual engagement increases, their peer group engagement also increases. As children's individual engagement decrease, their peer group engagement also decreases.

These models were applied to the same data set of this dissertation to examine patterns of change in groups as a result of intra-individual change (Sage, 2002). Of particular interest were selection processes indicating upward (optimization, Baltes \& Baltes, 1990) or downward mobility. Indicators of (initial) selection suggested that children select others who are similar to themselves in school motivation. Children's own (initial) engagement subsequently "launched" the trajectory of their peer group engagement across the year. That is, (initially) highly motivated children showed upward group trajectories and (initially) low motivated children showed downward group trajectories. Finally, change in children's own trajectories across the school year produced changes in the trajectories of their peer groups. That is, upward changes in children's peer group trajectories were 
predicted by the upward changes in children's own trajectories (and vice versa). It should be noted that this study was exploratory in nature and among the first attempts by SONET to utilize growth curve analyses for the study of peer group selection in the classroom. Therefore, these results should be considered with caution and used only as an example of how these models can be applied to examine patterns of group change in a classroom as a result of intra-individual change in engagement.

\section{Examination of Selection and Eliminations Processes}

A fourth limitation of the dissertation is with regard to the examination of the proximal processes by which the peer group emerges. To examine these processes, children's composed ideal groups were compared with their networks at each measurement point. If a classmate was nominated to be part of the child's composed ideal group but not observed to be part of that child's network, it was assumed that the child would like to potentially "select" that child. If a classmate was observed to be part of the child's network but was not nominated to be part of that child's composed ideal group, it was assumed that the child would like to potentially "eliminate" that child. It should be noted, however, that the size of the child's network at the respective measurement point increases or decreases the selection pool of other classmates. That is, children with larger networks have less non-member classmates to potentially "select" than children with smaller networks. Conversely, the "elimination" pool is higher for children with larger networks than children with smaller networks. For the dissertation, peer networks ranged in size from zero to fifteen across the school year. Therefore, the child with fifteen 
network members had fifteen less classmates in his potential "selection" pool than the child with zero network members. In subsequent research, it is suggested to use methods to control for these selection and elimination pool differences.

Also, while children's self-reports of composed ideal groups (or associative preferences) can indicate the potential for "selection" and "elimination" processes, the study did not demonstrate whether selection or elimination actually took place. One would need to compare the ideal groups to children's actual peer networks at subsequent measurement points to determine whether children did indeed select and/or eliminate children as indicated in their associative preferences.

An alternative avenue would be to tap into mechanisms that could be observed in children's interactions with his/her group and non-group members. Examples of selection processes could be: going to or doing activities the non-group member does, imitating the non-group member's behavior or clothing style, and asking to play with the non-group member on recess (or eat lunch with him/her). Examples of elimination processes could be: not including a group member in 'group' activities (e.g., a birthday party), gossiping about a group member behind his/her back, and making fun of the group member in front of others.

One could assume that selection of new members would begin with relatively benign microtime interactions where a child merely imitates the individual(s) he/she would like to hang out with. If not accepted into this new group, the child would then proceed to more overt actions such as going to or doing activities with the desired group 
members. If the desired group members display evidence of elimination processes to this child, he/she may take more drastic actions to become a member, or give up and seek a new group to join. Once he/she is accepted and joins a new group, the selection process ceases, processes of maintenance begin and socialization occurs whereby group members become more similar.

\section{Do Associative Preferences Affect Individual Engagement in the Classroom?}

A fifth and final limitation is that the dissertation did not examine the effects of children's associative preferences on intra-individual change in engagement across the school year. Future research could assess children's engaged versus disaffected behavior in the classroom as a function of three constructs: the child's classroom engagement, his/her peer group motivational profile, and his/her associative preference (upward or downward mobility). The nonlinear relationships among these constructs can be conceptualized based on a catastrophe model (see Figure 7.3). 
Figure 7.3. Example of a cusp catastrophe model of student engagement

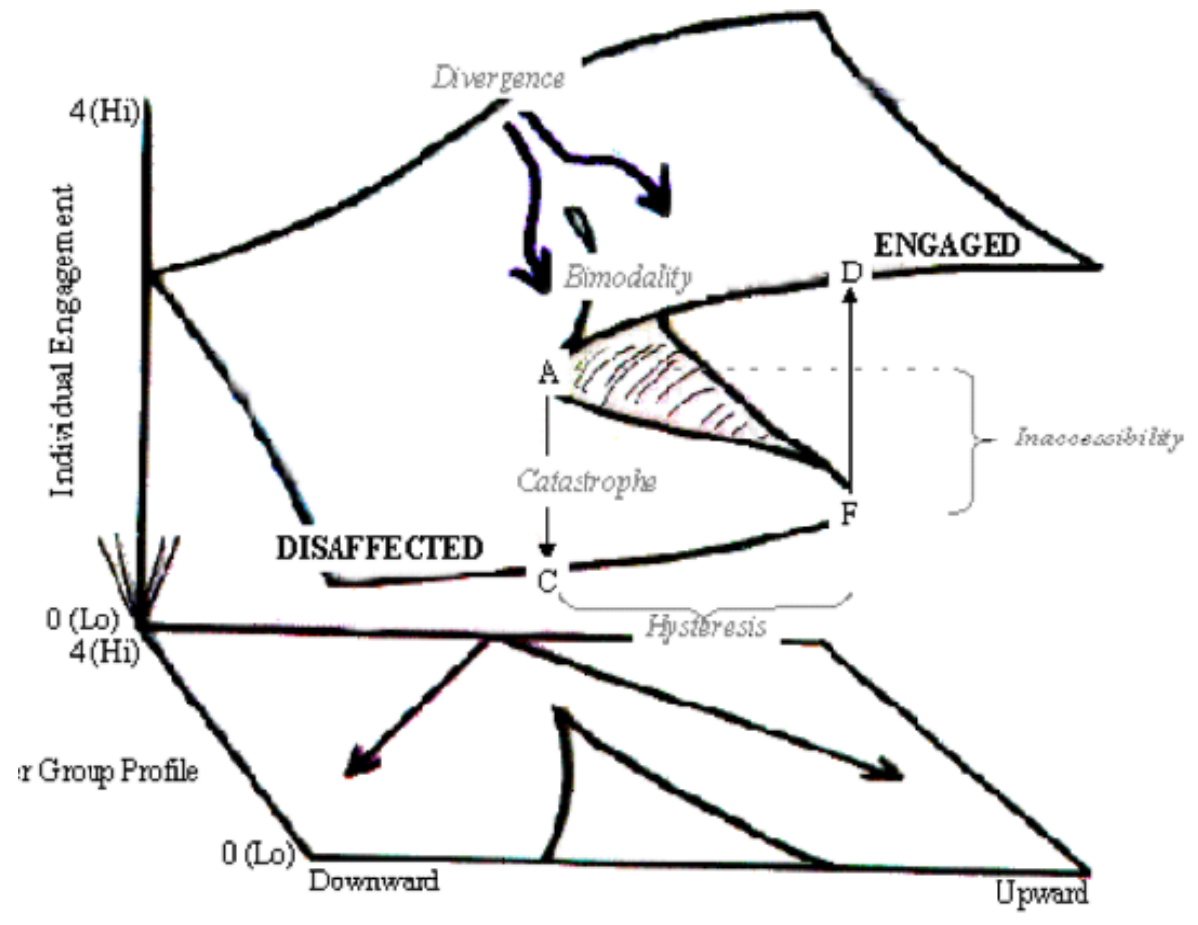

In order for a phenomenon to be simulated using a cusp catastrophe model, five qualities are necessary. "If any of (the five qualities) is apparent in a process, the other four should be looked for, and if more than one can be found, then the process should be considered a candidate for description as a cusp catastrophe" (Zeeman 1976). The five qualities that this model of student engagement is proposed to have in common with the generic cusp model are:

1. Bimodality - There can be only two types of achievement behavior in the classroom over part of the model's range. In this model, these two types are "Engaged" versus "Disaffected". Studies that measure classroom engagement using a continuous variable can recode the variable into two categories. In 
previous research, I have used a median split (defined separately for boys and girls) to define engaged versus disaffected children in the classroom (Sage \& Kindermann, 1999, 2001).

2. Sudden Transitions - Sudden changes are observed from one mode of behavior to another. In this model, an individual can suddenly change from being engaged to disaffected and vice versa.

3. Hysteresis - As illustrated by the dotted vertical lines in Figure 7.3, the transition from line segment DF to line segment AC does not take place at the same point as the transition from line segment $\mathrm{AC}$ to line segment DF. Noting the axes of the model, this translates to the lag between the three constructs.

4. Inaccessibility - A neutral zone of behavior is not possible to reach over part of the model's range. Perhaps the most difficult of the five qualities to demonstrate, this region is characterized by the upper fold in the model.

5. Divergence - A small change in the initial state of the system can result in a large difference in the final state.

Based on the qualities of the cusp catastrophe model described above, the following expectations can be generated regarding intra-individual change in engagement:

- For children with high levels of engagement and high group composition, a slight decrease in associative preferences (from moderately upward to 
downward) will result in a catastrophic decrease in engaged behavior (i.e., change to disaffection)

- $\quad$ For children with high levels of engagement and high group composition, a slight increase in associative preferences (from moderately downward to upward) will result in a catastrophic increase in behavior (i.e., engagement)

- $\quad$ For children with low levels of engagement and low group composition, a slight increase in associative preferences (to upward) will result in only moderate increases in engaged behavior

\section{CHAPTER SUMMARY}

This chapter provided the final comments regarding the use of a multiple systems perspective to examine change and emergence of children's peer networks in the classroom. The chapter began with a brief summary of the dissertation (i.e., its focus, methods, and analytic approach). The second section provided a discussion of the implications of the results. Key implications were that a child is likely to create his/her own group context (based on his/her self-system state), that will in turn be an important source of influence. This peer system appears to orient toward robust equilibrium; that is it moves quickly during the first half of the school year toward a stable state and then maintains itself at that state for the remainder of the year.

The third section of this chapter focused on the significance of the study, namely the focus on potential selection and elimination efforts in the classroom, employment of 
systems strategies, and examination of change and emergence of the peer group across the school year using multiple measurement points in small intervals of 1-2 months. Despite its potential significance, the dissertation does have its limitations. These were discussed in the fourth and final section of this chapter. Five limitations were discussed and suggestions for future research that would overcome these limitations were made. 


\section{REFERENCES}

Altermatt, E. R., \& Pomerantz, E. M. (2003). The development of competence-related and motivational beliefs: An investigation of similarity and influence among friends. Journal of Educational Psychology, 95, 111-123.

Arrow, H. (1997). Stability, bistability, and instability in group influence patterns. Journal of Personality and Social Psychology, 72, 75-85.

Arrow, H. McGrath, J. E., \& Berdahl, J. L. (2000). Small groups as complex systems: Formation, coordination, development, and adaptation. Thousand Oaks, CA: Sage.

Asher, S. R. (1983). Social competence and peer status: Recent advances and future directions. Child Development, 54, 1427-1434.

Asher, S. R., \& Coie, J. D. (Eds.). (1990). Peer rejection in childhood. New York: Cambridge University Press.

Asher. S. R., \& Wheeler, V. A. (1985). Children's loneliness: A comparison of rejected and neglected peer status. Journal of Consulting and Clinical Psychology, 53, 500-505.

Bagwell, C. L., Newcomb, A. F., Bukowski, W. M. (1998). Preadolescent friendship and peer rejection as predictors of adult adjustment. Child Development, 69, 140-153.

Bakeman, R., \& Quera, V. (1995). Analyzing interaction: Sequential analysis with SDIS and GSEQ. New York: Cambridge University Press. 
Baltes, P. B., \& Baltes, M. M. (1990). Psychological perspectives on successful aging: The model of selective optimization with compensation. In P. B. Baltes and M. M. Baltes (Eds.), Successful Aging: Perspectives from the Behavioral Science (pp. 1-34). New York: Cambridge University Press.

Bauman, K. E. \& Ennett, S. T. (1996). On the importance of peer influence for adolescent drug use: Commonly neglected considerations. Addiction, 91, 185-198.

Bauman, K. E. \& Fisher, L. A. (1986). On the measurement of friend behavior in research on friend influence and selection: Findings from longitudinal studies of adolescent smoking and drinking. Journal of Youth and Adolescence, 15, 345353.

Benenson, J. F. (1990). Gender differences in social networks. Journal of Early Adolscence, 10, 472-495.

Benenson, J. F., Apostoleris, N. H., \& Parnass, J. (1997). Age and sex differences in dyadic and group interaction. Developmental Psychology, 33, 538-543.

Berndt, T. J. (1982). The features and effects of friendship in early adolescence. $\underline{\text { Child }}$ Development, 53, 1447-1460.

Berndt, T. J. (1992). Friendship and friends' influence in adolescence. Current Directions in Psychological Science, 1, 156-159.

Berndt, T. J. (2002). Friendship quality and social development. Current directions in psychological science, 11(1), 7-10. 
Berndt, T. J., Hawkins, J. A., \& Jiao, Z. (1999). Influences of friends and friendships on adjustment to junior high school. Merrill-Palmer Quarterly, 45, 13-41.

Berndt, T. J, \& Keefe, K. (1995). Friends' influence on adolescents' adjustment to school. Child Development, 66, 1312-1329.

Berndt, T. J., Laychak, A. E., \& Park, K. (1990). Friends' influence on adolescents' academic achievement motivation: An experimental study. Journal of Educational Psychology, 82(4), 664-670.

Berndt, T. J., \& Murphy, L. M. (2002). Influences from friends and friendships: Myths, truths, and research recommendations. Advances in Child Development and Behavior, 30, 275-310.

Bertalanffy, L.V. (1950). An outline of General Systems Theory. British Journal of the Philosophy of Science, 1, 139-164.

Billy, J. O. G. \& Udry, J. R. (1985). The influence of male and female best friends on adolescent sexual behavior. Adolescence, 20, 21-32.

Birch, S. H., \& Ladd, G.W. (1996). Interpersonal relationships in the school environment and children's early school adjustment: The role of teachers and peers. In J. Jovonen \& K. R. Wentzel (Eds), Social motivation: Understanding children's school adjustment (pp. 199-225). New York: Cambridge University Press.

Larsson, B. Johannesson, A. Andersson, I. H., \& Atroshi, I (2009). The locomotor capabilities index; validity and reliability of Swedish version in adults with lower limb amputation. Health and Quality of Life Outcomes, 7(44). 
Bronfenbrenner, U. (1979). The ecology of human development. Cambridge, MA: Harvard University Press.

Bronfenbrenner, U., \& Morris, P. A. (1998). The ecology of developmental processes. In W. Damon (Series Ed.) \& R. M. Lerner (Vol. Ed.), Handbook of child psychology: Vol. 1. Theoretical models of human development (5th ed., pp. 9931028). New York: Wiley.

Brophy, J. (1986). Teacher influences on student achievement. American Psychologist, 41, 1069-1077.

Brown, B. B. (1990). Peer groups and peer culture. In S. S. Feldman \& G. R. Elliot (Eds.), At the threshold: The developing adolescent (pp. 171-196). Cambridge, MA: Harvard University Press.

Brown, B. B. (1999). Measuring the peer environment of American adolescents. In S. L. Friedman, \& T. D. Wachs (Eds.), Measuring the environment across the life span: Emerging methods and concepts (pp. 59-90). Washington, DC: American Psychological Association.

Buhs, E. S., Ladd, G. W., \& Herald, S. L. (2006). Peer exclusion and victimization: Processes that mediate the relation between peer group rejection and children's classroom engagement and achievement? Journal of Educational Psychology, $\underline{98(1)}, 1-13$.

Buhrmester, D. (1990). Intimacy, friendship, interpersonal competence, and adjustment during preadolescence and adolescence. Child Development 61, 1101-1111. 
Cairns, R. B., \& Cairns, B. D. (1994). Lifelines and risks: Pathways of youth in our time. New York: Cambridge University Press.

Cairns, R. B., Gariépy, J. -L., \& Kindermann, T. A. (1990). Identifying social clusters in natural settings. Unpublished manuscript: Chapel Hill, NC: University of North Carolina and Chapel Hill.

Cairns, R. B., Leung, M., Buchanan, L., \& Cairns, B. D. (1995). Friendships and social networks in childhood and adolescence: Fluidity, reliability, and interrelations. Child Development, 66, 1330-1345.

Cairns, R. B., Leung, M., \& Cairns, B. (1995). Social networks over time and space in adolescence. In L. Crockett \& A. Crouter (Eds.), Pathways through adolescence: Individual development in relation to social contexts (pp. 35-56). Mahwah, NJ: Erlbaum

Cairns, R. B., Perrin, J. E., \& Cairns, B. D. (1985). Social structure and social cognition in early adolescence: Affiliative patterns. Journal of Early Adolescence, 5, 339-355.

Cairns, R. B., Xie, H., \& Leung, M. C. (1996). The popularity of friendship and the neglect of social networks: Toward a new balance. In W.M. Bukowski \& A. H. N. Cillessen (Eds.), Sociometry then and now: Recent developments in the study of peer children's peer groups (pp. 25-53). San Francisco: Jossey Bass.

Chan, A. \& Poulin, F. (2007). Monthly changes in the composition of friendship networks in early adolescence. Merrill-Palmer Quarterly, 53(4), 578-602. 
Cohen, J. M. (1977). Sources of peer group homogeneity. Sociology of Education, 50, $227-241$.

Coie, J. D., Dodge, K. A., \& Coppotelli, H. (1982). Dimensions and types of social status. Child Development, 59, 815-829.

Connell, J. P. \& Skinner, E. A. (1990, April). Predicting trajectories of academic engagement: A growth curve analysis of children's motivation in school. In P. wood (Chair), Methodological advances in the study of change processes in education. Symposium presented at the meeting of the American Educational Research Association. Boston, MA.

Connell, J. P., \& Wellborn, J. G. (1991). Competence, autonomy, and relatedness: A motivational analysis of self-system processes. In M. R. Gunnar \& L. A. Sroufe (Eds.), Minnesota Symposium on Child Psychology, Vol. 23 (pp. 43-77). Hillsdale, NJ: Erlbaum.

Complex System. (2009, May 16). In Wikipedia, the free encyclopedia. Retrieved May 27, 2009, from http://en.wikipedia.org/wiki/Complex_System

Csikszentmihalyi M. \& Larson, R. (1974). Being adolescent. New York: Basic Books.

Deci, E. L., \& Ryan, R. M. (1985). Intrinsic motivation and self-determination in human behavior. New York: Plenum.

Deci, E. L, Vallerand, R. J., Pelletier, L. G., \& Ryan, R. M. (1991). Motivation and education: The self-determination perspective. Educational Psychologist, 26, 325346. 
Dishion, T. J., Patterson, G. R., Stoolmiller, M., \& Skinner, M. L. (1991). Family, school, and behavioral antecedents to early adolescent involvement with antisocial peers. Developmental Psychology, 27, 172-180.

Dishion, T. J., Spracklen, K. M., Andrews, D. W., \& Patterson, G. R. (1996). Deviancy training in male adolescent friendships. Behavior Therapy, 27, 373-390.

Donohew, R., Hoyle, R., Clayton, R., Skinner, W., Colon, S., \& Rice, R. (1999). Sensation seeking and drug use by adolescents and their friends: Models for marijuana and alcohol. Journal of Studies in Alcohol, 60, 622-631

Dornbusch, S., Ritter, P. L., Liederman, P., Roberts, D., and Fraleigh, M. (1987). The relationship between parenting style to adolescent school performance. Child Development, 58, 1244-1257.

Eccles, J. S., \& Wigfield, A. (2002). Motivational beliefs, values, and goals. Annual Review of Psychology, 53, 109-132.

Eccles, J. S., Wigfield, A., \& Schiefele, U. (1998). Motivation to succeed. In W. Damon (Series Ed.) \& N. Eisenberg (Vol. Ed.), Handbook of child psychology: Vol. 3.

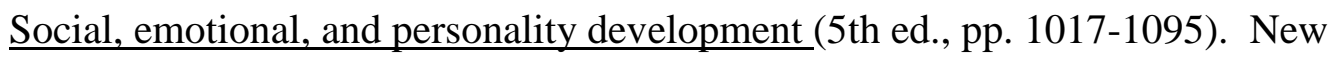
York: Wiley.

Ecckerman, C. O., \& Stein, M. R. (1990). How imitation begets imitation and toddler's generation of games. Developmental Psychopathology, 26, 370-378.

Eckerman, C. O., Whatley, J. L., \& Kutz, S. (1975). Growth of social play with peers during the second year of life. Developmental Psychology, 11, 42-49. 
Elliot, D.S, \& Vos, H.L. (1974). Delinquency and dropout. Lexington MA: Lexington Books.

Emergence System. (2009, May 20). In Wikipedia, the free encyclopedia. Retrieved May 27, 2009, from http://en.wikipedia.org/wiki/Emergence

Ennett, S. T., \& Bauman, K. E. (1994). The contribution of influence and selection to adolescent peer group homogeneity: The case of adolescent cigarette smoking. Journal of Personality and Social Psychology, 67, 653-663.

Estell, D. B., Farmer, T.W., Cairns, R. B., \& Cairns, B. D. (2002). Social relations and academic achievement in inner-city early elementary classrooms. International Journal of Behavioral Development, 26(6), 518-528.

Epstein, J. L. (1983). The influence of friends on achievement and affective outcomes. In J. L. Epstein \& N. Karweit (Eds.), Friends in school: Patterns of selection and influence in secondary schools (pp. 177-200). New York: Academic Press.

Freud, A., \& Dann, S. (1967). An experiment in group upbringing. In Brackbill, Y., \& Thompson, G. G. (Eds.), Behavior in infancy and early childhood (pp. 494-514). New York: Free Press. (Originally published in 1951).

Gest, S. D, Farmer, T. W., Cairns, B. D., \& Xie, H.-L. (2003). Identifying children's peer social networks in school classrooms: Links between peer reports and observed interactions. Social Development, 12, 513-529. 
Green, K. D., Forehand, R., Beck, S. J., \& Vock, B. (1980). An assessment of the relationship among measures of children's social competence and children's academic achievement. Child development, 51, 1149-1156.

Gottlieb, G., Wahlsten, D., \& Lickliter, R. (1998). Developmental psychobiological systems view. In W. Damon (Editor-in-Chief) \& R. M. Lerner (Vol Ed.), Handbook of child psychology: Vol 1. Theoretical models of human development ( $5^{\text {th }}$ ed., pp. 233-274). New York: Wiley.

Gottman, J., Gonso, J., \& Rasmussen, B. (1975). Social interaction, social competence, and friendship in children. Child Development, 46, 709-718.

Hallinan, M. T. (1981). Recent advances in sociometry. In S.M. Asher \& G.M. Gottman (Eds.), The development of children's friendships (pp. 91-115). New York: Cambridge University Press.

Harlow, H. F., \& Harlow, M. K. (1962). Social deprivation in monkeys. Scientific American, 207, 136-146.

Harris, J. R. (1995). Where is the child's environment? A group socialization theory of development. Psychological Review, 102, 458-489.

Harris, J. R. (1998). The nurture assumption. Why children turn out the way they do. New York: Free Press.

Hartup, W. W. (1983). Peer groups. In P.H. Mussen (Gen Ed.), $\underline{\text { Handbook of child }}$ psychology (Vol. 4, pp. 103-196). New York: Wiley. 
Hartup, W. W. (1993) Adolescents and their friends. In B. Laursen (Ed.). Close friendships in adolescence (pp. 3-22). San Francisco: Jossey-Bass.

Hartup W. W. (1996). The company they keep. Friendships and their developmental significance. Child Development, 67, 1-13.

Hartup, W. W., \& Laursen, B. (1999). Relationships as developmental contexts: Retrospective themes and contemporary issues. In W. A. Collins \& B. Laursen (Eds.), The Minnesota Symposia on Child Psychology, Vol. 30. Relationships as developmental contexts (pp. 13-36). Mahwah, NJ: Erlbaum.

Hayni, D. L. \& Osgood, D. W. (2005). Reconsidering peers and delinquency: How do

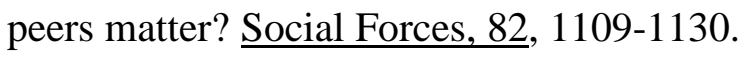

Henrich, C. C., Kuperminc, G. P., Sack, A., Blatt, S. J., \& Leadbeater, B. J. (2000). Characteristics and homogeneity of early adolescent friendship groups: A comparison of male and female clique and nonclique members. Applied Developmental Science, 4(1), 15-26.

Hillier, S. K., Weaver, S., Newton-Curtis, L., \& Sage, N. A. (2003, April). Peer group processes and intra-individual change in classroom engagement. Poster session presented at the biennial meeting of the Society for Research in Child Development, Tampa, FL.

Hinde, R. A. (1987), Individuals, relationships, and culture. Cambridge: Cambridge University Press. 
Hinde, R. A. (1995). A suggested structure for a science of relationships. Personal Relationships, 2, 1-15.

Hymel, S., Comfort, C., Schonert-Reichl, K., \& McDougall, P. (1996). Academic failure and school drop-out: The influence of peers. In J. Jovonen \& K.R. Wentzel (Eds.), Social Motivation: Understanding children's school adjustment (pp. 313-345). New York: Cambridge University Press.

Ide, J. K., Parkerson, J., Haertel, G. D., \& Walberg, H. J. (1981). Peer group influences on educational outcomes: A quantitative synthesis. Journal of Educational Psychology, 73, 472-484.

Jaccard, J., Blanton, H., \& Dodge, T. (2005). Peer influences on risk behavior: An analysis of the effects of a close friend. Developmental Psychology, 41, 135-147.

Kandel, D. B. (1978). Homophily, selection, and socialization in adolescent friendships. American Journal of Sociology, 84, 427-436.

Kandel, D. B. (1996). The parental and peer contexts of adolescent deviance: An algebra of interpersonal influences. Journal of Drug Issues, 26, 289-315.

Katz \& Kahn, (1978). The social psychology of organizations. New York: Wiley

Kindermann, T. A. (1993). Natural peer groups as contexts for individual development: The case of children's motivation in school. Developmental Psychology, 29, 970977. 
Kindermann, T. A. (2003). Development of children's social relationships. In J.

Valsiner \& K. Connolly (Eds.), Handbook of developmental psychology (pp. 407430). Thousand Oaks, CA: Sage.

Kindermann, T. A. (1996). Strategies for the study of individual development within naturally existing peer groups. Social Development, 5, 158-173.

Kindermann, T. A. (2007). Effects of naturally existing peer groups on changes in academic engagement in a cohort of sixth graders. Child Development, 78(4), 1186-1203.

Kindermann, T. A. \& Gest, S. D. (2008). Assessment of the peer group: Identifying naturally occurring social networks and capturing their effects. In K.H. Rubin, W. Bukowski, \& B.B. Laursen (Eds). Handbook of peer interactions, relationships, and groups (pp. 100-120). New York: Guilford.

Kindermann T. A., Kwee R., \& Sage, N. A. (2002). NETWORKS (version 4.0) [Computer program]. Portland State University, The SOcial NETworks Research Group.

Kindermann, T. A., McCollam, T. L., \& Gibson, E. (1996). Peer group influences on children's developing school motivation. In K. Wentzel \& J. Juvonen (Eds.), Social motivation: Understanding children's school adjustment (pp. 279-312). Newbury Park, CA: Sage.

Kindermann, T. A. \& Newton-Curtis, L. (2003, April). Family member's engagement during academic activities at home and children's school motivation in the 
classroom. Poster presentation at the biennial meeting of the Society for Research in Child Development, Tampa, Florida.

Kindermann, T. A. \& Skinner, E. A. (1992). Modeling environmental development: Individual and contextual trajectories. In J.B. Asendorph \& J. Valsiner (Eds.), Framing stability and change: An investigation into methodological issues. Newbury Park, CA: Sage.

Knowles, E. S. (1971, April). Boundaries and group interaction: The effect of size and status. Paper presented at the meeting of the Eastern Psychological Association. New York, New York.

Kozlowski, S. W. J., \& Klien, K. J. (2000). A multilevel approach to theory and research in organization: Contextual, temporal, and emergent processes. In S.W.J. Kelin \& K.J. Kozlowski, (Eds.), Multilevel theory, research, and methods in organization: Foundations, extensions, and new directions (pp. 3-90). San Francisco: JosseyBass.

Ladd, G. W. (1990). Having friends, keeping friends, making friends, and being liked by peer in the classroom: Predictors of children's early school adjustment? Child Development, 61, 1081-1100.

Ladd, G. W. \& Kochenderfer, B. J. (1996). Linkages between friendship and adjustment during early school transitions. In. W. M. Bukowski, A. F. Newcomb, \& W. W. Hartup (Eds.), The company they keep: Friendship in childhood and adolescence (pp. 322-345). Cambridge: Cambridge University Press. 
Ladd, G. W., Kochenderfer, B. J., \& Coleman, C. C. (1996). Friendship quality as a predictor of young children's early school adjustment. Child Development, 67, 1103-1118.

Larson, R., \& Richards, M. H. (1991). Daily companionships in late childhood and early adolescence: Changing developmental contexts. Child Development, 62, 284300.

Ladd, G. W., \& Troop-Gordon, W. (2003). The role of chronic peer difficulties in the development of children's psychological adjustment problems. Child Development, 74(5), 1344-1367.

Lazarsfeld, P. F. \& Merton, R. K. (1954). Friendship as a social process. In M. Berger, T Able, and C.H. Page (Eds.). Freedom and control in modern society (pp 18-66). Princeton NJ: Von Nostrand.

Lendaris, G. G. (1986). On systemsness and the problem solver: Tutorial comments. IEEE transactions on Systems, Man, and Cybernetics, 16, 603-610.

Leung, M-C. (1996). Social networks and self enhancement in Chinese children: A comparison of self reports and peer reports of group memberships. $\underline{\text { Social }}$ Development, 5, 146-157.

Lewis, M., Young, G., Brooks, J., \& Michaelson, L. (1975). The beginning of friendship. In M. Lewis \& L.A. Rosenblum (Eds.), Friendship and peer relations (pp. 27-66). New York: Wiley. 
Magnussen, D. \& Statin, H. (1998). Person-context interaction theories. In W. Damon

(Ed). Handbook of child psychology: Theoretical models of human development. (Vol 1, pp. 685-740). New York: Wiley.

Maunders, D. (1994). Awakening from the dream: The experience of childhood in Protestant orphan homes in Australia, Canada, and the United States. $\underline{\text { Child \& }}$ Youth Care Forum, 23, 393-412.

McCollam, T. L., Kindermann, T. A., \& Metzler, B. (1995, April). Peer group networks in a cohort of 6th grade children: A composite social-cognitive map. Poster session presentated at the biennial meeting of the Society for Research in Child Development, Indianapolis, IN.

Meldrich, E. A., Rosen, J., Rubin, B., \& Buckley, S. (1982). The serious business of growing up. Berkeley: University of California Press.

Merton, R. K. (1968). The Matthew effect in science. Science, 159, 56-63.

Milgram, S., Bickman, L., \& Berkowitz, L. (1969). Note on the drawing power of crowds of different size. Journal of Personality and Social Psychology, 13, 79-82.

Milgram, S., \& Toch, H. (1969). Collective behavior: Crowds and social movements. In G. Lindzey and E. Aronson (Eds.), Handbook of social psychology, Vol. 4. ( $2^{\text {nd }}$ Ed., pp. 507-610). Reading, Mass.: Addison Wesley.

Moreno, J. L. (1934). Who shall survive? A new approach to the problem of human interrelations. Washington, DC: Nervous and Mental Disease Publishing. 
Morison, P., \& Masten, A. S. (1991). Peer reputation in middle childhood as a predictor of adaptation in adolescence: A seven-year follow-up. Child Development, 62, 991-1007.

Mullen, B., Copper, C., Cox, P., Fraser, C., Hu, L.-T., Meisler, A., Smith, C. Symons, C. (2001). Boundaries around group interaction: A meta-analytic integration of the effects of group size. The Journal of Social Psychology, 131(2), 271-283.

Neckerman, H. J. (1996). The stability of social groups in childhood and adolescence: The role of the classroom social environment. Social Development, 5 131-145.

Newcomb, A. F., Bukowski, W. M., \& Pattee, L. (1993). Children's peer relations. A meta-analytic review of popular, rejected, neglected, controversial, and average sociometric status. Psychological Bulletin, 113, 99-128.

Newton-Curtis, L (2006). Parent engagement with children's at-home academic endeavors: Reciprocal relationships with school motivation and academic performance. Unpublished masters thesis. Portland State University, Portland, Oregon.

Newton-Curtis, L. \& Kindermann, T. A. (2002, August). Parents' engagement in children's out of school academic activities. Poster session presented the meeting of the International Society for the Study of Behavioral Development, Ottawa, Canada. 
Open System (Systems Theory). (2009, April 24). In Wikipedia, the free encyclopedia. Retrieved May 27, 2009, from http://en.wikipedia.org/wiki/Open_system_(systems_theory)

Parker, J. G., \& Asher, S. R. (1987). Peer relations and later person adjustment: Are lowaccepted children at risk? Psychological Bulletin, 102(3), 357-389.

Patrick, B. C., Skinner, E. A., \& Connell, J. P. (1993). What motivates children's behavior and emotion? The joint effects of perceived control and autonomy in the academic domain. Journal of Personality and Social Psychology, 65 (4), 781-791.

Piaget, J. (1952). The origins of intelligence in children. New York: International Universities Press.

Rosenthal, R. \& Jacobsen, L. (1968). Pygmalion in the classroom. New York: Holt.

Rubin, K. H., Bukowski, W. \& Parker, J. G. (1998). Peer interactions, relationships, and groups. In W. Damon (Series Ed.) \& N. Eisenberg (Vol. Ed.), $\underline{\text { Handbook of child }}$ psychology: Vol. 3. Social, emotional, and personality development (5th ed., pp. 619-700). New York: Wiley.

Rubin, K. H., Bukwoski, W. \& Parker, J. G., (2006). Peer interactions, relationships, and groups. In W. Damon (Series Ed.). \& N. Eisenberg (Vol. Ed.), Handbook of child psychology: Vol 3. Social, emotional, and personality development $\left(6^{\text {th }}\right.$ ed., pp. 571-645). New York: Wiley. 
Ryan, A. M. (2000). Peer groups as contexts for the socialization of adolescents' motivation, engagement, and achievement in school. Educational Psychologist, $\underline{31}(2), 101-111$.

Ryan, A. M. (2001). The peer group as a context for the development of young adolescents' motivation and achievement. Child Development, 72, 1135-1150.

Sage, N. A. (1997). Peer context influences on school motivation: A naturalistic observation of peer and teacher contingencies following on- and off-task behavior in a fifth grade classroom. Unpublished masters thesis. Portland State University, Portland, Oregon.

Sage, N. A. (2002, August). Growth curve patterns of selective optimization in children's peer affiliations in school. Poster session presented at the meeting of the International Society for the Study of Behavioral Development. Ottawa, Canada.

Sage, N. A., \& Kindermann, T. A. (1999). Peer networks, behavior contingencies, and children's engagement in the classroom. Merrill-Palmer-Quarterly, 45, 143-171.

Sage, N. A. \& Kindermann, T. A. (2000). Influences socio-structurelles engroupe de pairs sur la motivation scolaire des jeunes enfants (Peer group influences on children's school motivation: An observational study of social learning mechanisms in the classroom). Revue Canadienne des Scineces de l'Education. 
Sage, N. A., \& Kindermann, T. A. (2001, April). Mechanisms of influence and intraindividual change in children's school motivation: The importance of peer networks and friends. Poster session presented at the biennial meeting of the Society for Research in Child Development, Minneapolis, MN.

Sage, N. A., Hiller, S. K., Weaver, S., Newton-Curtis, L., \& Kindermann, T. A. (2002, August). Peer group selection and socialization processes in children's school motivation: A replication and extension. Poster session presented at the meeting of the International Society for the Study of Behavioral Development. Ottawa, Canada

Scarr, S. \& McCartney, K. (1983). How people make their own environments: A theory of geneotype $\rightarrow$ environment effects. Child Development, 54, 424-435.

Schunk, D. H., \& Zimmerman, B. J. (1996). Modeling and self-efficacy influences on children's development and self-regulation. In J. Juvonen \& K. R. Wentzel (Eds.), Social motivation: Understanding children's school adjustment. New York: Cambridge University Press.

Sherif, M., Harvey, O. J., White, B. J., Hood, W. P., \& Sherif, C. W. (1961). Intergroup conflict and cooperation: The robbers cave experiment. Norman: University of Oklahoma Book Exchange.

Skinner, E. A., \& Belmont, J. B. (1993). Motivation in the classroom: Reciprocal effects of teacher behavior and student engagement across the school year. Journal of Educational Psychology, 85, 571-581. 
Skinner, E. A., Johnson, S. J., \& Snyder, T. (2005). Six dimensions of parenting: A motivational model. Parenting: Science and Practice, 2, 175 - 235.

Skinner, E. A., Kindermann, T. A., Connell, J. P., \& Wellborn, J. G. (in press). Engagement and disaffection as organizational constructs in the dynamics of motivational development. In K. R. Wentzel \& A. Wigfield (Eds.), Handbook of motivation in school. Mahwah, NJ: Erlbaum.

Skinner, E. A., \&Wellborn, J. G. (1994). Coping during childhood and adolescence: Amotivational perspective. In D. Featherman, R. Lerner, \& M. Perlmutter (Eds.), Life-span developmentand behavior (Vol. 12, pp. 91-133). Hillsdale, NJ: Lawrence Erlbaum Associates, Inc.

Skinner, E. A., \& Wellborn, J. G. (1997). Children's coping in the academic domain. In S. A. Wolchik \& I. N. Sandler (Eds.), Handbook of children's coping with common stressors: Linking theory and intervention (pp. 387-422). New York: Plenum.

Skinner, E. A., Zimmer-Gembeck, M. J., \& Connell, J. P. (1998), Individual differences and the development of perceived control. Monographs of the Society for Research in Child Development, 63(1-2, Serial No 254).

South, S. J. \& Hayne, D. L. (2004). Friendship networks of mobile adolescents. Social Forces, 83(1), 315-350. 
Steinberg, L., Dornbusch, S. M., \& Brown, B. B. (1992). Ethnic differences in adolescent achievement: An ecological perspective. American Psychologist, 47(6), 723-729.

Stipek, D. (2002). Motivation to learn. Integrating theory and practice. Boston: Allyn \& Bacon.

Urberg, K. A., Degirmencioglu, S. M., \& Pilgrim, C. (1997). Close friend and group influence on adolescent cigarette smoking and alcohol use. Developmental Psychology, 33, 834-844.

Vandell, D. L., Wilson, K. S., \& Buchanan, N.R.. (1980). Peer interaction during the first year of life. An examination of its structure, content, and sensitivity to toys. $\underline{\text { Child }}$ Development, 51, 481-488.

Wang, L., Zhang, Z., McArdle, J. J., \& Salthouse, T. A. (2008). Investigating ceiling effects in longitudinal data analysis. Multivariate Behavioral Research, 43, 476496.

Wellborn, J. G. (1991). Engaged versus disaffected action: Conceptualization and measurement of motivation in the academic domain. Unpublished doctoral dissertation, Graduate School of Human Development and Education, University of Rochester, Rochester, NY.

Wellborn, J. G. \& Connell, J. P. (1991). Teacher report of engagement questionnaire: A teacher-report measure of student motivation in the classroom. Unpublished manuscript. University of Rochester. 
Wigfield, A., Eccles, J. S., Schiefele, U., Roeser, R. \& Davis-Kean, P. (2006). Development of achievement motivation. In W. Damon (Series Ed.) \& N. Eisenberg (Volume Ed.), Handbook of child psychology: Vol. 3. Social, emotional, and personality development $\left(6^{\text {th }}\right.$ ed., pp. 933-1002). New York: John Wiley.

Williamson, G. L., Appelbaum, M., \& Epanchin, A. (1991). Longitudinal analyses of academic achievement. Journal of Educational Measurement, 28, 61-76.

Wilcox, S., \& Udry, R. (1986). Autism and accuracy in adolescent perceptions of friends' sexual attitudes and behavior. Journal of Applied Social Psychology, 16, 361374.

Wentzel, K. R. (1999). Social influences on school adjustment: Commentary. Educational Psychologist, 54, 59-69.

Wentzel, K. R. \& Asher, S. R. (1995). The academic lives of neglected, rejected, popular, and controversial children. Child Development, 66, 754-663.

Wentzel, K. R. \& Caldwell, K. (1997). Friendships, peer acceptance and group membership: Relations to academic achievement in middle school. Child Development, 68, 1198-1209.

Wentzel, K. R., McNamara-Barry, C., \& Caldwell, K. A. (2004). Friendships in middle school: A longitudinal study. Journal of Early Adolescence, 23, 5-28.

Zeeman, E. C. (1976). Catastrophe theory. Scientific American, pp. 65-83. 
Zimmer-Gembeck, M. J. (1998). Using hierarchical linear modeling and SAS Proc mixed to investigate launch, ambient-level, and change-to-change relations. Appendix B in E.A. Skinner, M.J. Zimmer-Gembeck, \& J.P. Connell (Eds.), Individual differences and the development of perceived control. Monographs of the Society for Research in Child Development, 63(1-2, Serial No 254). 
APPENDIX A:

SELF AND TEACHER REPORTS OF STUDENT ENGAGEMENT

Student Number Code:

Class Code:

Student Questionnaire

Beaverton 2000-2001 [INSERT MONTH HERE] 


\section{PRACTICE QUESTIONS}
A. I am in 4th grade
Very true
B. I am in 5th grade
Very true
C. I like dogs
Very true
Sort of true
Not very true
Not true at all
Sort of true
Not very true
Not true at all
Sort of true
Not very true 


\section{PART 1: FEELINGS WHEN AT SCHOOL}

Directions: This part asks you to think about when how you feel when you are at school.

1. I try very hard to do well in school.
Very true
Sort of true
Not very true
Not true at all

2. When I'm in class, I participate in class discussions.

Very true $\quad$ Sort of true Not very true $\quad$ Not true at all

3. I pay attention in class.

Very true $\quad$ Sort of true Not very true $\quad$ Not true at all

4. W hen I'm in class, I concentrate on doing my work.

Very true $\quad$ Sort of true Not very true $\quad$ Not true at all

5. When I'm in class, I work as hard as I can.

Very true $\quad$ Sort of true Not very true $\quad$ Not true at all

6. I don't try very hard in school.

Very true $\quad$ Sort of true $\quad$ Not very true $\quad$ Not true at all

7. When I'm in class, I usually think about other things.

$\begin{array}{lll}\text { Very true } & \text { Sort of true } \quad \text { Not very true } & \text { Not true at all }\end{array}$

8. When I'm in class, I just act like I'm working.

Very true $\quad$ Sort of true Not very true $\quad$ Not true at all

9. I only pay attention to things that interest me when I'm in class.

Very true $\quad$ Sort of true Not very true Not true at all

10. W hen I'm in class, I feel nervous.

Very true $\quad$ Sort of true Not very true $\quad$ Not true at all

11. W hen I'm in class, I feel angry.

Very true $\quad$ Sort of true Not very true $\quad$ Not true at all

12. When I'm in class, I feel discouraged.

Very true $\quad$ Sort of true Not very true $\quad$ Not true at all

13. W hen I'm in class, I feel happy.

Very true $\quad$ Sort of true Not very true $\quad$ Not true at all 
Teacher-Report of Student Engagement Questionnaire

Student: Teacher:

This questionnaire is part of a study to understand student behavior in the classroom. Your candid observations and opinions will help us understand more about how what students do in the classroom is connected to learning.

When you are done, please remove this top page from the questionnaire

Thank you for your help.

The SOcial NETworks Research (SONET) Group at Portland State University 
Student Number Code: Class Code:

Teacher-Report of Student Engagement Questionnaire Beaverton 2000-2001 [INSERT DATE HERE] 
Appendix A: Peer Network Emergence

$\begin{array}{llll}\text { Very } & \text { Somewhat } & \text { Not Very } & \text { Not At All } \\ \text { Characteristic } & \text { Characteristic } & \text { Characteristic } & \text { Characteristic } \\ \text { Of This } & \text { Of This } & \text { Of This } & \text { Of This } \\ \text { Student } & \text { Student } & \text { Student } & \text { Student }\end{array}$

1. In my class, this student fights me at every turn.

2. This student prefers classroom activities that are difficult.

3. This student doesn't change his/her approach to solving problems, even when it isn't working.

4. In my class, this student pays attention.

5. This student depends on me to make all decisions regarding his/her schoolwork.

6. In my class, this student appears angry.

7. This student doesn't try very hard.

8. This student likes to figure out things for him/herself.

9. In my class, this student pays attention only to topics or activities that interest him/her.

11. When this student is faced with a difficult problem or question in my class, s/he seems to enjoy the challenge.

12. In my class, this student appears anxious 


$\begin{array}{llll}\text { Very } & \text { Somewhat } & \text { Not Very } & \text { Not At All } \\ \text { Characteristic } & \text { Characteristic } & \text { Characteristic } & \text { Characteristic } \\ \text { Of This } & \text { Of This } & \text { Of This } & \text { Of This } \\ \text { Student } & \text { Student } & \text { Student } & \text { Student }\end{array}$

13. This student likes to do things for him/herself.

14. This student works only as hard as necessary to get by.

15. This student isn't very creative when it comes to schoolwork.

16. This student concentrates on doing his/her work in my class.

17. When it comes to doing classroom assignments, this student doesn't think for him/ herself.

18. This student does the best $\mathrm{s} / \mathrm{he}$ can in school.

19. In my class, this student appears depressed.

20. This student often plays around with ideas that are on the questions.

21. This student prefers doing schoolwork that is easy for him/her.

22. In my class, this student appears happy.

23. This student only pays attention to subjects that interest him/her.

24. This student comes up with unique ways to do school assignments. 
Appendix A: Peer Network Emergence

$\begin{array}{llll}\text { Very } & \text { Somewhat } & \text { Not Very } & \text { Not At All } \\ \text { Characteristic } & \text { Characteristic } & \text { Characteristic } & \text { Characteristic } \\ \text { Of This } & \text { Of This } & \text { Of This } & \text { Of This } \\ \text { Student } & \text { Student } & \text { Student } & \text { Student } \\ & & & \end{array}$

25. This student prefers assignments

which s/he already knows how

to do.

4

3

2

1

26. This student does more than is required of him/her.

4

3

2

1

27. This student doesn't like to

figure out anything for

him/herself.

4

3

2

1

28. This student works hard in my class.

4

3

2

1 
Appendix B: Peer Network Emergence

\section{APPENDIX B:}

\section{PEER AFFILIATIONS INTERVIEW INSTRUCTIONS (To Be Kept Apart From Data Sheet)}

\section{WRITE IN THE DATE AND YOUR FIRST AND LAST INITIALS ON THE OVERVIEW OF PEER AFFILIATIONS}

\section{INTRODUCTION}

[Pick student up from classroom at time suggested by the teacher. Make sure that parental permission is obtained for the student. While going from the classroom to your interviewsite, some discussion might be helpful with the student about how things are going in school and/or with the research project so far]

"Hi, my name is I'm from Portland State University. As you know, we are doing a project that looks at what goes on in fourth and fifth grade classrooms, how students feel about school, and what kids do together in the classroom.

So far, we have started looking at what goes on in the classroom. These are the observations we have been doing so far. Today, we will be talking about what kids do together and also a little about your friends.

Although your parents have signed a form saying that is O.K. to talk with you, you can choose not to participate if you don't want to. If you remember, we told everyone in the classroom that we are doing this for our research at Portland State University. Therefore, only myself and the other researchers will be allowed to see the information we are collecting. We will never give the information we collect from you to your teachers, parents, or anyone else.

We do however, understand if you don't want to participate. However, we hope that you are interested and would be willing to be a part of our study. No matter what you decide, there will be no effect on your grades in school, how your teachers feel about you, or even how we feel about you.

If you do decide to be a part of our study, you can always decide later not to. You can even tell us that you don't want to answer some of the questions we ask or not to be observed if you 
don't feel like it.

Before we do the interview, I need to have you sign a form where you indicate whether or not you are willing to be a part of our study

\section{[SHOW CHILD THE STUDENT CONSENT FORM]}

This form is just like the one we sent to your parents. What is says is that you understand that you are being asked to be apart of a research project that includes observations of what goes on in the classroom, interviews about what kids do together and about your friends, and questionnaires about how you feel about school. You need to mark a box saying either "yes" you agree to participate or "no" you don't want to participate and then sign your name

[GIVE CHILD THE FORM TO SIGN AND ASK IF HE/SHE HAS ANY QUESTIONS ABOUT THE STUDY]

\section{If the child indicated that he/she does NOT want to participate....}

Because you chose not to be a part of our study, I cannot interview you. We also will NOT be observing you or having you fill out any of our questionnaires. However, you can always choose later to be a part of our study. Just let one of us know if you change your mind.

\section{[TAKE CHILD BACK TO THE CLASSROOM]}

\section{If the child indicated that he/she DOES want to participate...}

We will now begin the interview about what kids do together. Remember, everything you say to me today will be kept top secret and I won't let anyone see what you said. Nevertheless, I think you only want to talk about things that you feel comfortable with saying, and, as we said in class, we are only interested in things that you think the other students in your class would also feel comfortable with if you talked about it. Also, you don't have to answer any of the questions I will be asking you if you don't want to and we can stop for any reason”. 


\section{INTERVIEW QUESTIONS}

PART 1 "There are four parts of the interview. The first part asks about groups of kids who hang out together at school. Since we are doing the research project in the $4^{\text {th }}$ and $5^{\text {th }}$ grade pod and not the whole school, I need you to think about groups of kids in only your pod. What we've noticed is that some kids in your pod hang out together all the time, or they may be working together on class projects, or just do a lot together.

Thinking about the students in your pod, I'd like for you to think about the groups of students who hang out together. The way I think about it, even two students together can be called a group."

1. (Group 1): "Let's start with any group. Who hangs out together?" (Fill in nominations on data sheet number 1 , in the order the individuals are nominated; e.g., 1, 2, 3, etc) “"

* Note: the children generate these groups from free-recall

1a. (G-1: LEADER) "Who is a LEADER in this group?" (Circle this person on data sheet page 1)

1b. (G-1: NAME) "Does this group have a name when you talk about them? What would you call this group? Please give only a name that the people in this group would feel comfortable with if they knew what you said. Can you come up with a name?"

(Note name and number on data sheet page 2)

1c. (G-1: SPECIALTY) "Can you tell me a bit more about the group?"

- "What is it that makes these people a group?"

- "How can you tell that they are in a group?"

- "Why do they hang out together"

(IF NO ANSWER:) "Is it something they do or is it something they have $\underline{\text { in }}$ common with each other? What is it?"

1d. (G-1: OPENNESS) "If someone in the pod was interested in joining this group, would it be easy for them, not so easy, or very hard (if not impossible)? Why?"

PROCEED WITH OTHER GROUPS UNTIL CHILD CANNOT NOMINATE ANY MORE GROUPS 
2. (ALONE) "Are there any students in your pod that don't hang out with a group? (If so:) Who? Who pretty much stays by themselves?"

(Indicate with an " $L$ " on data sheet page 1)

3. (NOMINEE) (If informant has not named him/herself:) "What about you? Do you hang out with a group, or do you stay more by yourself?"

(If alone, indicate with an " $L$ " on data sheet page 1)

(If he/she hangs out with a group:) "Which group or groups do you hang out with?"

* Precede with steps $1 a-d$

PART 2 "The second part of the interview asks you about who you would choose to do a school project with"

4. (IDEAL WORK GROUP) "Think of all of the kids IN YOUR POD. If you could choose ANY of these kids to work with on a project for school, who would they be (this can include those kids with whom you already do a project with and/or those who whom you've done one with before, or even those you would like to do a project with, but haven't yet)? Be sure to mention only those kids that you would LIKE to do a project with"

(List names in the order they are nominated on data sheet page 3; left column)

PART 3 "The third part of the interview is similar to the second part. However, instead of asking who you would choose to do a school project with, I am now interested in who you would choose to hang out with"

5. (IDEAL "PLAY" GROUP) "Still thinking about all the kids IN YOUR POD, who would you choose to hang out with (e.g., on recess or at lunch)? This may or may not be some (or all) of the same kids you would choose to do a project with. This may be the same kids you hang out with already or even those who you would LIKE to hang out with"

(List names in the order they are nominated on data sheet page 3; right column) 


\section{PART 4}

"The last part of the interview asks about your friends both at school and outside of school"

6. (FRIENDS) “Thinking about ALL of your friends, who are your closest friends?

(List names in the order they are nominated on data sheet page 4; left column)

6a (F-LOCATION) (For each nominated friend): Is (name of child) a friend...

- in the same pod?

- in school, but not in your pod? - outside of school?

* Place a check next to the appropriate box; check only 1)

6b. (F-Rating) (For each nominated friend): "Would you say that (name of child) is 1. a very good friend, 2. a good friend, or 3, Sort-of a good friend?"

* Place check next to the appropriate box; check only 1

6c. (F-“1st BEST")"Who among your list of friends is your most BEST friend?"

(Put B1 next to the child's name)

- (If "best friend" is not a child in the participant's pod):

"Who is your most best friend IN YOUR POD"? (Put a Bl* next to the child's name)

"This is all I need to ask you today. Thanks you for letting me talk with you and let me assure you again that everything we have talked about will be kept confidential and not discussed with anyone in school or at home.

Before we go back to your class, are there any other things you would like to say about any of the questions I have asked?" 
THE PEER AFFILIATIONS INTERVIEW DATA SHEET

[INSERT DATE HERE]

Student Number Code: Class Code:

\section{GROUPS (Data Sheet 1)}

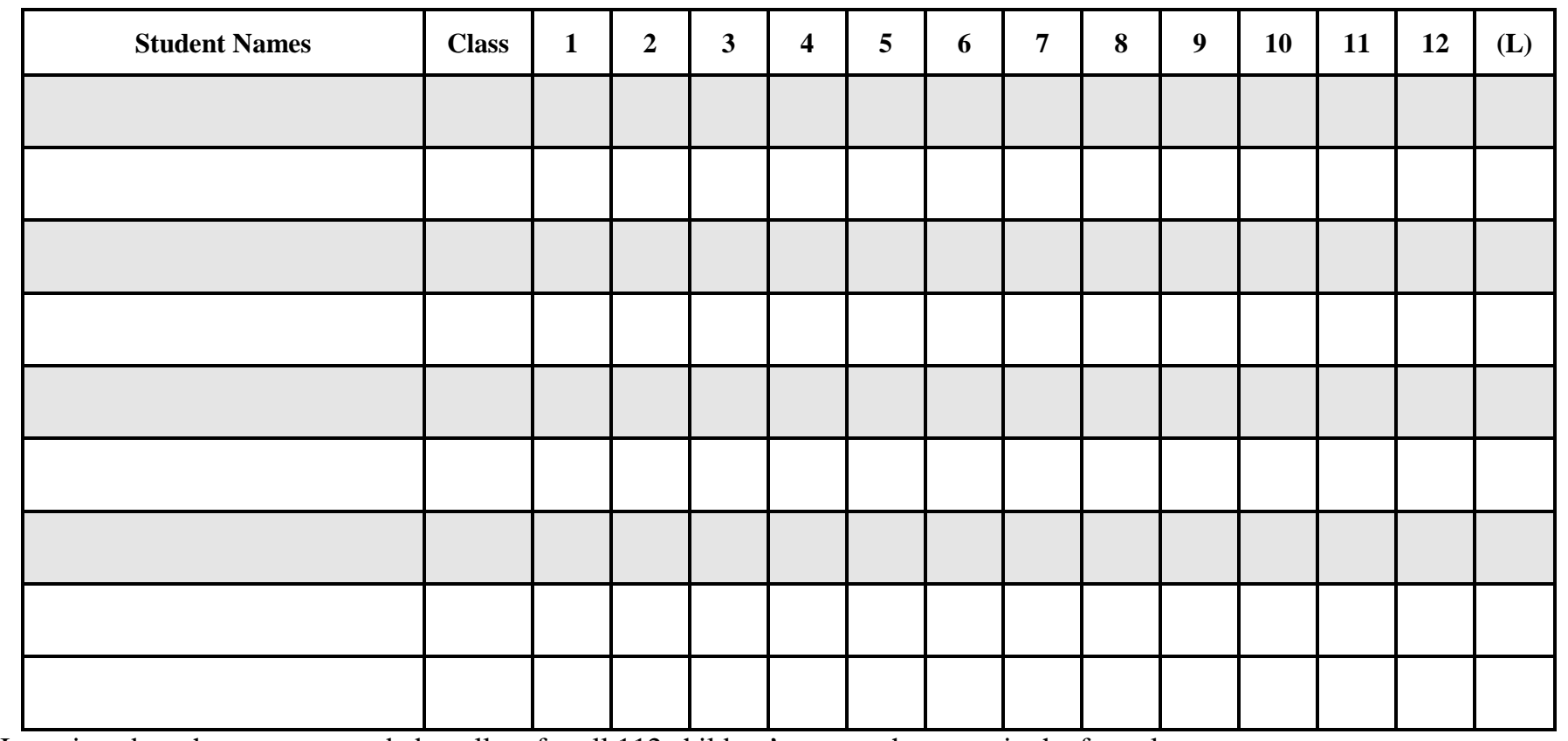




\section{GROUP DESCRIPTORS (Data Sheet 2)}

\begin{tabular}{|l|l|l|l|}
\hline GROUP & NAME & SPECIALTY & OPENNESS \\
\hline $\mathbf{1}$ & & & \\
\hline $\mathbf{3}$ & & & \\
\hline $\mathbf{4}$ & & & \\
\hline $\mathbf{5}$ & & & \\
\hline $\mathbf{6}$ & & & \\
\hline $\mathbf{7}$ & & & \\
\hline $\mathbf{8}$ & & & \\
\hline
\end{tabular}


SELF-REPORT GROUPS (Data Sheet 3)

\begin{tabular}{|l|l|}
\hline SCHOOL PROJECT GROUP & HANG OUT WITH GROUP \\
\hline 1. & 1. \\
\hline 2. & 2. \\
\hline 3. & 3. \\
\hline 4. & 4. \\
\hline 5. & 5. \\
\hline 6. & 6. \\
\hline 7. & 7. \\
\hline 8. & 8. \\
\hline 9. & 9. \\
\hline 10. & 10. \\
\hline
\end{tabular}

Note: Self-Reported Groups data sheet was expanded if more than 10 names were provided 


\section{SELF-REPORT FRIENDS (Data Sheet 4)}

\begin{tabular}{|c|c|c|}
\hline FRIENDS' NAMES & LOCATION & $R A T I N G$ \\
\hline 1. & $\square$ Friend in pod $\square$ Friend in school $\square$ Friend outside of school & $\square$ very good friend $\square$ good friend $\square$ sort of good friend \\
\hline 3. & $\square$ Friend in pod $\square$ Friend in school $\square$ Friend outside of school & $\square$ very good friend $\square$ good friend $\square$ sort of good friend \\
\hline 4. & $\square$ Friend in pod $\square$ Friend in school $\square$ Friend outside of school & $\square$ very good friend $\square$ good friend $\square$ sort of good friend \\
\hline 5. & $\square$ Friend in pod $\square$ Friend in school $\square$ Friend outside of school & $\square$ very good friend $\square$ good friend $\square$ sort of good friend \\
\hline 6. & $\square$ Friend in pod $\square$ Friend in school $\square$ Friend outside of school & $\square$ very good friend $\square$ good friend $\square$ sort of good friend \\
\hline 7. & $\square$ Friend in pod $\square$ Friend in school $\square$ Friend outside of school & $\square$ very good friend $\square$ good friend $\square$ sort of good friend \\
\hline 8. & $\square$ Friend in pod $\square$ Friend in school $\square$ Friend outside of school & $\square$ very good friend $\square$ good friend $\square$ sort of good friend \\
\hline 10. & $\square$ Friend in pod $\square$ Friend in school $\square$ Friend outside of school & $\square$ very good friend $\square$ good friend $\square$ sort of good friend \\
\hline
\end{tabular}

Note: Self-Reported Friends data sheet was expanded if more than 10 names were provided 


\section{PEER AFFILIATIONS QUESTIONNAIRE}

Student: Teacher:

To the student:

This questionnaire has 4 parts. We have asked you these questions before, but we are interested in finding out if there are any changes since then.

$\underline{\text { Part } 1}$, asks about what groups of kids in your pod and what they do together

$\underline{\text { Part 2 }}$, asks you about who, from the kids in your pod, you would choose to do a school project with

$\underline{\text { Part } 3}$, ask you about who, from the kids in your pod, you would choose to hang out with

$\underline{\text { Part } 4}$, ask you about your friends

Please be sure to read and follow the directions for each part. This will help us a lot if you do. If you do not follow the directions, it will make it harder for us to do our project. If you have any questions, just raise your hand and one of us will help you out.

Do NOT put your name anywhere on this questionnaire. We have put your code number at the top of the next page so only the researchers doing this project can identify who you are. We are only asking you about things that you and your other classmates should feel comfortable telling us. However, if you don't feel comfortable answering a question, you can leave it blank. For those questions you do answer, your responses will be kept top secret.

\section{When you have completed the questionnaire, take off this top sheet}

Thank you very much for doing this questionnaire, 
Student Number Code: Class Code:

\section{PEER AFFILIATIONS QUESTIONNAIRE Beaverton 2000-2001 [INSERT MONTH HERE]}




\section{PART 1 \\ WHAT KIDS DO TOGETHER IN THE 4TH/5TH GRADE POD}

Directions:

This part asks you to think about the kids in your pod. Some hang out together all the time. They may be working together or just do a lot together.

The next three pages provide spaces for you to write the names of groups of kids who do things or hang out together in the 4 th/5th grade pod. The way we think about it, even two people can be in a group together.

We have provided enough spaces for 12 groups. If you don't know about this many groups, that is fine. If you know about more than this many groups, then we can give you more answer sheets if needed.

If possible, please PRINT the students' first and last names. If you don't know, briefly describe the student so we can write in his/her first and last name after you are done. Be sure to print so we can read your responses.

\section{Don't forget to include yourself!}




\section{GROUPS OF CHILDREN WHO DO THINGS OR HANG OUT IN THE 4TH/5TH GRADE POD}

\begin{tabular}{|l|l|l|l|}
\hline GROUP 1 & GROUP 2 & GROUP 3 & GROUP 4 \\
\hline & & & \\
\hline & & & \\
\hline & & & \\
\hline & & & \\
\hline & & & \\
\hline & & & \\
\hline & & & \\
\hline & & & \\
\hline & & & \\
\hline $\begin{array}{l}\text { Is there a name for this } \\
\text { grout name here if there is) }\end{array}$ & $\begin{array}{l}\text { Is there a name for this group? } \\
\text { (Put name here if there is) } \\
\text { name) }\end{array}$ & $\begin{array}{l}\text { Is there a name for this group? } \\
\text { (Put name here if there is) }\end{array}$ & $\begin{array}{l}\text { Is there a name for this group? } \\
\text { (Put name here if there is) }\end{array}$ \\
\hline
\end{tabular}

Note: Data sheet was expanded to allow for up to 12 groups. If children wanted to nominate more than 12 , they could get additional data sheets

ARE THERE ANY KIDS WHO DON'T HANG OUT IN A GROUP AND PREFER TO BE ALONE? If so, write their names here 


\section{PART 2}

\section{WHO YOU WOULD CHOOSE TO DO A SCHOOL PROJECT WITH?}

\section{Directions:}

For this part, you are to think about all of the kids in your pod and write the names of EVERYONE you would choose do a school project with.

This can include...

- Those who you already do projects with

- Those who you haven't done a project with, but would like to

Print the first and last names of these kids in the section below. If you don't know someone's name, describe him/her so we can write down his/her name after you are done. You can use as many or as few of the spaces on the right that you like. If you need more space, raise your hand and we will give you another sheet.

\section{PRINT THE FIRST AND LAST NAMES HERE}




\section{PART 3 \\ WHO YOU WOULD CHOOSE TO HANG OUT WITH?}

\section{Directions:}

For this part, you are to think about all of the kids in your pod and write the names of EVERYONE you would choose to hang out with. For example, who would you hang out with at recess, lunch, music.

This can include...

- Those who you already hang out with

- Those who don't hang out with, but would like to

Print the first and last names of these kids in the section below. If you don't know someone's name, describe him/her so we can write down his/her name after you are done. You can use as many or as few of the spaces on the right that you like. If you need more space, raise your hand and we will give you another sheet.

\section{PRINT THE FIRST AND LAST NAMES HERE}

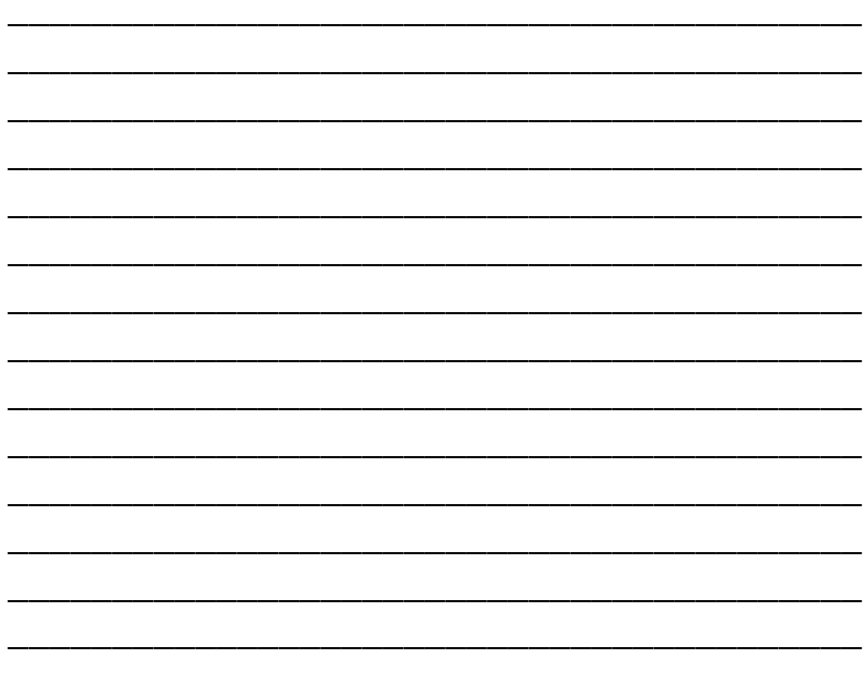




\section{PART 4 \\ WHO ARE YOUR FRIENDS?}

\section{Directions:}

For this part you are to think about your friends.

You may have some friends in the pod some in school, but who are not in your pod, and others who do not go to your school. Thinking about ALL of them, who are your closest friends?

\begin{tabular}{|l|l|l|}
\hline $\begin{array}{l}\text { FRIENDS' NAMES } \\
\text { (Please PRINT their first and last names) }\end{array}$ & $\begin{array}{l}\text { WHERE ARE YOU ARE FRIENDS AT? } \\
\text { (Choose the one's that are true) }\end{array}$ & $\begin{array}{l}\text { HOW GOOD OF FRIEND IS THIS KID? } \\
\text { (Choose only ONE) }\end{array}$ \\
\hline 1. & $\square$ Friend in pod $\square$ Friend in school $\square$ Friend outside of school \\
$\square$ very good friend $\square$ good friend $\square$ sort of good friend \\
\hline 2. & $\square$ Friend in pod $\square$ Friend in school $\square$ Friend outside of school & $\square$ very good friend $\square$ good friend $\square$ sort of good friend \\
\hline 3. & $\square$ Friend in pod $\square$ Friend in school $\square$ Friend outside of school & $\square$ very good friend $\square$ good friend $\square$ sort of good friend \\
\hline 4. & $\square$ Friend in pod $\square$ Friend in school $\square$ Friend outside of school & $\square$ very good friend $\square$ good friend $\square$ sort of good friend \\
\hline
\end{tabular}

Note: Data sheet used to collect that data had 10 spaces for friendship nominations; if the child wanted more space additional data sheets were providedWHO IS YOUR BEST

FRIEND IN YOUR $\underline{\text { POD? }}$ WHO IS YOUR BEST FRIEND IN YOUR CLASS? 
Appendix C: Peer Network Emergence 209

\section{APPENDIX C: METHODS FOR CALCULATING MEMBER TURNOVER}

Member turnover was calculated to better examine the dynamic aspect of the structure of children's peer networks. To compute member turnover, the identities of the classmates in each child's network at $\mathrm{T}_{\mathrm{n}}$ were compared to the identities of the classmates at each child's network at $\mathrm{T}_{\mathrm{n}+1}$. Total counts were obtained for members maintained (stable members), members lost, members gained, and member turnover (sum of members lost and gained). The results were presented in percentages and specific focus was placed on the percent of member turnover between each successive measurement point. A variety of different denominators could have been used to compute percentages:

- $\quad$ Total number of different network members between the two successive measurement points $\left[\left(\mathrm{T}_{\mathrm{n}}+\mathrm{T}_{\mathrm{n}+1}\right) /\right.$ members maintained $]$

- $\quad$ Total number of network members at the beginning measurement point $\left[\mathrm{T}_{\mathrm{n}}\right]$

- $\quad$ Total number of network members at the successive measurement point $\left[\mathrm{T}_{\mathrm{n}+1}\right]$

- $\quad$ The average number of network members at each of the two measurement points $\left[\left(T_{n}+T_{n+1}\right) / 2\right]$

Table C.1 shows the percentage of stable members, members gained, members lost, and total member turnover at each successive measurement point using these four different denominators. 
Appendix C: Peer Network Emergence 210

Table C.1

Percent of Members Maintained, Lost, Gained, and Total Member

Turnover Using Four Different Denominators

Denominator

\begin{tabular}{|c|c|c|c|c|}
\hline & \multicolumn{4}{|c|}{ Denominator } \\
\hline & $\begin{array}{c}(\mathrm{Tn}+\mathrm{Tn}+1)- \\
\text { Members } \\
\text { Maintained } *\end{array}$ & $\mathrm{Tn}$ & $\mathrm{Tn}+1$ & $(\operatorname{Tn}+\mathrm{Tn})+1 / 2$ \\
\hline \multicolumn{5}{|l|}{$T_{1}$-Nov \& $T_{2}$-Dec } \\
\hline Stable & $55 \%$ & $81 \%$ & $64 \%$ & $71 \%$ \\
\hline Lost & $13 \%$ & $19 \%$ & $15 \%$ & $17 \%$ \\
\hline Gained & $31 \%$ & $46 \%$ & $36 \%$ & $40 \%$ \\
\hline Turnover & $45 \%$ & $65 \%$ & $51 \%$ & $57 \%$ \\
\hline \multicolumn{5}{|l|}{$\mathbf{T}_{2}$-Dec \& $\mathbf{T}_{3}$-Jan } \\
\hline Stable & $53 \%$ & $66 \%$ & $72 \%$ & $69 \%$ \\
\hline Lost & $27 \%$ & $33 \%$ & $36 \%$ & $35 \%$ \\
\hline Gained & $21 \%$ & $26 \%$ & $28 \%$ & $27 \%$ \\
\hline Turnover & $47 \%$ & $59 \%$ & $64 \%$ & $62 \%$ \\
\hline \multicolumn{5}{|l|}{$\mathrm{T}_{3}$-Jan \& $\mathrm{T}_{4}$-Feb } \\
\hline Stable & $74 \%$ & $82 \%$ & $89 \%$ & $85 \%$ \\
\hline Lost & $16 \%$ & $18 \%$ & $20 \%$ & $19 \%$ \\
\hline Gained & $10 \%$ & $11 \%$ & $11 \%$ & $11 \%$ \\
\hline Turnover & $26 \%$ & $29 \%$ & $31 \%$ & $30 \%$ \\
\hline \multicolumn{5}{|l|}{$T_{4}$-Feb \& $T_{5}$-Apr } \\
\hline Stable & $77 \%$ & $82 \%$ & $93 \%$ & $87 \%$ \\
\hline Lost & $17 \%$ & $18 \%$ & $21 \%$ & $20 \%$ \\
\hline Gained & $6 \%$ & $7 \%$ & $8 \%$ & $7 \%$ \\
\hline Turnover & $23 \%$ & $25 \%$ & $28 \%$ & $27 \%$ \\
\hline
\end{tabular}

* the denominator used in this dissertation 
Appendix C: Peer Network Emergence 211

Which method to apply likely depends on the specific research question. For the dissertation, the denominator used was the total number of different network members between the two successive measurement points. It was argued that this denominator was the most plausible for the questions posed in this dissertation as it captures the child's social context between measurement points (i.e., it takes into account all possible socialization agents - i.e., social partners who were either continuously or temporarily associated with the child - during that time). 
Appendix D: Peer Network Emergence 212

\section{APPENDIX D: POST HOC ANLYSIS - OVERLAP BETWEEN IDEAL WORK AND IDEAL PLAY GROUPS}

Examination of group structure and composition suggested no significant differences between ideal work and ideal play groups (see Chapter 6). Therefore the two group types were combined to form what was referred to as composed ideal groups (groups of classmates with whom children nominated to do a school project and/or merely hang out). However, this should not imply that the actual classmates nominated for each group type were the same. That is, it is possible that children nominated a similar number of classmates for each group type who have similar engagement scores but prefer to do school projects with an entirely different set of classmates than those with whom they would like to merely hang out.

Post hoc analyses were conducted to determine the degree of overlap of the classmates nominated for ideal work versus ideal play groups. The names of the classmates nominated for ideal work groups were compared with the names of the classmates nominated for ideal play groups at each measurement point. Those classmates nominated for both group types were considered to be overlapping. The total number of overlapping classmates was divided by the total number of different classmates nominated between the two group types to obtain the percentage of overlap. Figure D.1 shows the percentage of overlap across the school year. 
Appendix D: Peer Network Emergence 213

Figure D.1. Percentage of Overlap Between Ideal Work Groups and Ideal Play Groups

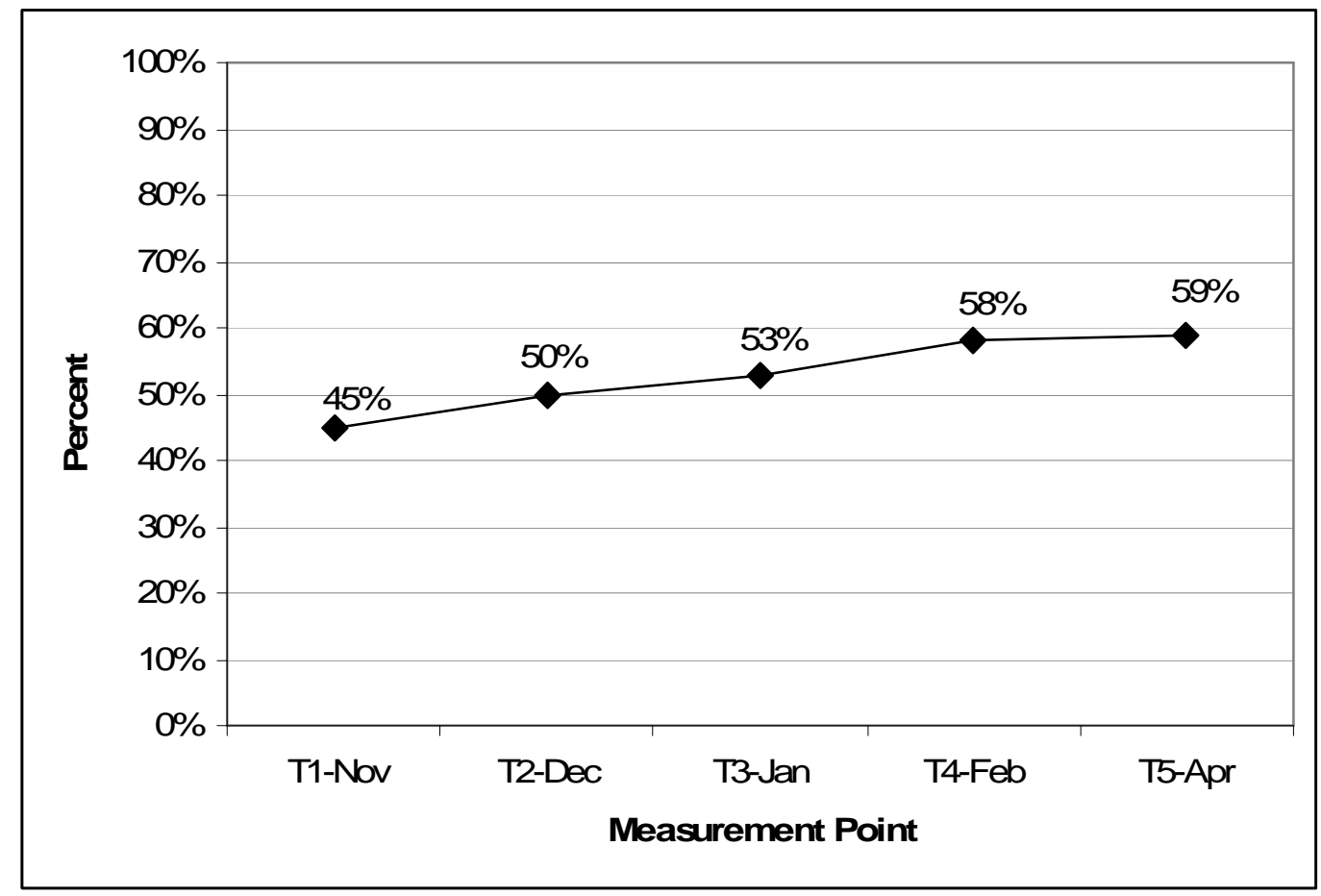

The results suggested that at the beginning of the school year, $45 \%$ of classmates nominated for ideal work groups were the same as classmates nominated for ideal play groups. This overlap increased gently across the school year to $59 \%$ overlap by the end of the year. Apparently children become less discerning regarding their preference for who they would like to do school projects with versus those they would like to hang out with. The degree of overlap between children's ideal work and ideal play groups is an interesting question and one that (if pursued) can be fruitful to the study of peer group relationships, particularly for unveiling processes of selection and elimination.

It is the premise for the dissertation that regardless of whether the names of classmates with whom the child would like to do a school project versus those with 
Appendix D: Peer Network Emergence 214

whom he/she would like to merely hang out may be different, if the groups are similar in composition and size, then they are considered similar developmental contexts for the child. Therefore, ideal work and play groups were combined for the dissertation because they were similar in size and composition. 
Appendix E: Peer Network Emergence 215

\section{APPENDIX E: POST HOC ANLYSIS - SOCIALIZATION EFECTS}

\section{Examining Group Socialization Effects}

As described in Chapter 6, children were found to be similar in engagement to their network members at all five measurement points. This homogeneity increased during the first part of the school year at the same time that member turnover was high, which indicates selection and elimination effects occurring in the classroom that coincide with children's own engagement. Member turnover decreased during the latter few months of the school year and at the same time, the homogeneity among individuals and their groups held steady, indicating that socialization effects may be occurring concurrently with selection and elimination. To determine whether this inference held true, post hoc analyses were conducted that specifically examined socialization influences from groups to individuals. As described in Chapter 1, one method for examining such influences is to examine individual change in development between Time 1 and Time 2 as a result of group characteristics at Time 1 (c.f., Berndt, Hawkins, \& Jiao, 1999; Hillier, Weaver, Newton-Curtis, \& Sage, 2003; Kindermann, 2007; Ryan, 2001).

Post hoc analyses using this method were conducted to determine whether socialization effects could explain the homogeneity found among individuals and their peer networks. Regression analyses were run with children's engagement at $T_{n}$ as dependent variables. Independent variables were entered in two steps; step 1 was children's own engagement at $\mathrm{T}_{\mathrm{n}-1}$ and step 2 was children's network composition scores at $T_{n-1}$. If $R^{2}$ change is found to be significant for children's network composition, then 
Appendix E: Peer Network Emergence 216

socialization influences are presumed (c.f., Hillier, Weaver, Newton-Curtis, \& Sage, 2003). The results were not significant for predicting $T_{2}-$ Dec from $T_{1}$-Nov nor for predicting $\mathrm{T}_{3}$-Jan from $\mathrm{T}_{2}$-Dec: $\mathrm{R}^{2}$ change $=.01, \mathrm{~b}=.12, \mathrm{p}>.05$ and $\mathrm{R}^{2}$ change $=.01, \mathrm{~b}$ $=.08, \mathrm{p}>.05$. However, the results were significant for predicting $\mathrm{T}_{4}-\mathrm{Feb}$ from $\mathrm{T}_{3}-\mathrm{Jan}$ and for predicting $\mathrm{T}_{5}$-Apr from $\mathrm{T}_{4}-\mathrm{Feb}: \mathrm{R}^{2}$ change $=.01, \mathrm{~b}=.10, \mathrm{p}<.05$ and $\mathrm{R}^{2}$ change $=.01, \mathrm{~b}=.10, \mathrm{p}<.05$. 